


\section{About IDS}

The Institute of Development Studies is one of the world's leading organisations for research, teaching and communications on international development. Founded in 1966, the Institute enjoys an international reputation based on the quality of its work and the rigour with which it applies academic skills to real world challenges. Its purpose is to understand and explain the world, and to try to change it - to influence as well as to inform.

IDS hosts five dynamic research programmes, five popular postgraduate courses, and a family of worldclass web-based knowledge services. These three spheres are integrated in a unique combination - as a development knowledge hub, IDS is connected into and is a convenor of networks throughout the world.

The Institute is home to approximately 80 researchers, 50 knowledge services staff, 50 support staff and about 150 students at any one time. But the IDS community extends far beyond, encompassing an extensive network of partners, former staff and students across the development community worldwide.

(DS Institute of Development Studies

For further information on IDS publications and for a free catalogue, contact:

IDS Communication Unit

Institute of Development Studies

at the University of Sussex

Brighton BN1 9RE, UK

Tel: $+44(0) 1273915637$

Fax: +44 (0) 1273621202

E-mail: bookshop@ids.ac.uk

Web: www.ids.ac.uk/ids/bookshop

IDS is a charitable company, limited by guarantee and registered in England (No. 877338) 
IDS RESEARCH REPORT 61

\section{State-Business Relations and Investment in Egypt}

Abla Abdel-Latif and Hubert Schmitz

October 2009 
State-Business Relations and Investment in Egypt

Abla Abdel-Latif and Hubert Schmitz

IDS Research Report 61

First published by the Institute of Development Studies in October 2009

(C) Institute of Development Studies 2009

Cover photo: Mark Henley

Photo caption: Cairo, Egypt: Businessmen in discussion on a downtown street.

ISSN: 2040-0217 ISBN: 9781858647975

A catalogue record for this publication is available from the British Library.

All rights reserved. Reproduction, copy, transmission, or translation of any part of this publication may be made only under the following conditions:

- with the prior permission of the publisher; or

- with a licence from the Copyright Licensing Agency Ltd., 90 Tottenham Court Road, London W1P 9HE, UK, or from another national licensing agency; or

- under the terms set out below.

This publication is copyright, but may be reproduced by any method without fee for teaching or non-profit purposes, but not for resale. Formal permission is required for all such uses, but normally will be granted immediately. For copying in any other circumstances, or for re-use in other publications, or for translation or adaptation, prior written permission must be obtained from the publisher and a fee may be payable.

Available from:

Communication Unit

Institute of Development Studies

at the University of Sussex

Brighton BN1 9RE, UK

Tel: +44 (0) 1273915637

Fax: +44 (0) 1273621202

E-mail: bookshop@ids.ac.uk

Web: www.ids.ac.uk/ids/bookshop

Typeset by Warwick Printing, Leamington Spa, UK. Printed by Nexus, Brighton, UK.

IDS is a charitable company limited by guarantee and registered in England (No. 877338) 


\title{
State-Business Relations and Investment in Egypt
}

\author{
Abla Abdel-Latif and Hubert Schmitz
}

\section{Summary}

This study shows that informal relationships between key policymakers and investors have played an important role in raising levels of investment and fostering economic growth. Comparative observations show that common social roots and common professional background facilitate the emergence of an effective public-private growth alliance but the only necessary conditions are common interest and common understanding of the problems to be solved.

The comparative research on two old and two new sectors shows in detail how informal relationships have emerged and how they have made an impact but it warns against overstating their investment-enhancing role. Effective relationships between policymakers and investors - abbreviated to CIPI - are not the direct cause of increases in investment but can play a critical role in unleashing the profit potential of specific sectors. Research on the food industry shows how CIPI helped to overcome supply constraints and political obstacles in decision-making. Research on the communications industry shows how CIPI helped Egypt to overcome initial barriers to entry and establish a new industry virtually from scratch. While the gains were sometimes appropriated by a few actors, the research shows that exclusive relationships can have inclusive effects, depending on how the private sector is organised.

Quantitative examination of whether CIPI had an enduring investment-enhancing effect was inconclusive. There is no doubt however that the CIPI was an effective transitional arrangement. It helped investors to overcome barriers to economic growth, it helped policymakers to overcome deficiencies in their own government agencies and it helped both sides to work together in establishing new sectorspecific rules and improving the general regulatory framework. The general lesson from this research is that such transitional arrangements deserve more attention, both to gain a better understanding of the political economy of investment and growth and to make research more relevant for policy. 
Keywords: state-business relations; investment; economic growth; investment climate; transitional arrangements; Egypt.

JEL classification: P16, 010.

Abla Abdel-Latif is Professor of Economics at the American University of Cairo and Fellow of the Economic Research Forum in Cairo: alatif@aucegypt.edu

Hubert Schmitz is Professorial Fellow of the Institute of Development Studies, University of Sussex, and Convenor of the Research Programme 'Public Action and Private Investment': h.schmitz@ids.ac.uk 


\section{Contents}

Summary 3

Keywords, author notes 4

Navigating the research report $\quad 8$

$\begin{array}{ll}\text { Acknowledgements } & 11\end{array}$

$\begin{array}{ll}\text { Acronyms } & 11\end{array}$

Part I Objectives, analytical framework and national context

1 Introduction 13

2 Rules-based governance and industrial investment in Egypt 1970-2007 17

3 Conceptual framework 20

4 Hypotheses and methodology 24

Part II Findings from old sectors

5 Sectoral context: food and furniture 29

6 Emergence of CIPI in old sectors 30

7 Impact of CIPI in old sectors 40

\section{Part III Findings from new sectors}

8 Sectoral context: communication and information technology 53

9 Emergence of CIPI in new sectors 55

10 Impact of CIPI in new sectors 63

Part IV Conclusions

11 Commonalities and differences 76

12 Implications for policy and future research 80

$\begin{array}{lr}\text { Appendix } & \mathbf{8 6}\end{array}$

References $\quad 103$ 


\section{Figures}

Figure 2.1 Public and private industrial investment: annual growth rates, 1973-1996 (\%)

Figure 2.2 Annual growth rate of real industrial investment, 1998/99_ 2005/06 (\%)

Figure 2.3 Annual real investment in some of the manufacturing industries, 1995-2008* (in million Egyptian pounds)

Figure 3.1 The CIPI path

Figure 6.1 Informal linkages between members from the business community and government members specific to food industries

Figure 6.2 Cabinet community members appointing other members from the business community in key public and semi-public institutions

Figure 6.3 The Investment Circle - the network of quick decision-making

Figure 7.1 Annual real investment in food industries, 1995-2008* (in million Egyptian pounds)

Figure 7.2 Trend of Egyptian food industries exports, 2002-2008

Figure 7.3 Annual real investment in food industries, 1995-2008* (in million Egyptian pounds)

Figure 9.1 Pathways of key policymakers in CIT

Figure 9.2 Relationships between key policymakers and business leaders in CIT

Figure 9.3 The network of key public decision-makers in CIT

Figure 10.1 Annual real investment in communications, 1997-2008* (in million Egyptian pounds)

Figure 10.2 Annual real investment in IT sector, 1997-2008* (in million Egyptian pounds)

Figure 12.1 Organisation of the private sector and its effects

Figure A1 Telecommunication licences in Egypt

\section{Tables}

Table 4.1 Interviews in old and new sectors

Table 7.1 Exclusive relationships and their exclusive/inclusive effects

Table 9.1 CIT Working Groups of 1999-2000

Table 10.1 Some key performance indicators of the CIT industry, 1999-2007

Table A1 Policy changes of relevance to investment 1974-1997

Table A2 Recent policies and strategies for improving the investment and business climates in Egypt, 1997-2006

Table A3 Hypothesised CIPI phases

Table A4 Actions triggered by CIPI - proxy governance benefits to the food sector 
Table A7 Structure of the IT sector 96

Table A8 Phases of development of the IT sector 98

Table A9 The institutional framework directly relevant to CIT 99

Table A10 Critique of law \#10 for $2003 \quad 100$

Table A11 Main objectives of the two official plans for development of the CIT industry and the Egyptian Information Society Initiative (EISI) 102 


\section{Navigating the research report}

This report presents the results of research conducted in Egypt on a topic about which many economists and policymakers have strong views: how can private investment be increased in an institutional and political environment that is not conducive to such investment? There are already standard policy 'solutions' to this problem: 'Improve the investment climate!' is the dominant policy advice. This can mean many things but usually concentrates on the institutional dimensions of investment climate reform. The standard advice in such reform is that governance through informal relationships should be replaced with governance through formal rules. Effective regulatory reform, including legal reform, is seen as the key. We are not suggesting that this is wrong; we believe this is a good long-term ambition. We are however suggesting that this approach is unlikely to trigger the desired wave of investment. It is more difficult and takes longer than is usually assumed. This is where we are coming from. We are looking for ways forward which are quicker and more realistic. In this report we present insights drawn from the recent Egyptian experience. The report shows the limitations of an approach which is hands-off and rules-based in explaining and fostering investment and the importance of an approach which is hands-on and relationship-based for overcoming barriers and promoting investment.

We looked at Egypt because we were aware that, in some sectors, there had been large increases in private investment in recent years and because we had indications that these increases were associated with close cooperation between a relatively small number of people in government and in the industry concerned. We wanted to find out how and why these relationships had developed, and whether and how they led to change in the ways in which government and business interacted, and to a substantial increase in investment. While our research is imperfect in several senses, we believe that we have produced evidence that should lead policymakers to widen their notion of what constitutes a good investment climate: in some circumstances, close (particularistic) relations between small groups of people in government and business can catalyse private investment and produce benefits that are not exclusive to this group.

Conducting research on these relationships was difficult because they are often informal and because we had no template. This research report shows not just what we found but also how we obtained the findings and where we have doubts. What follows is a brief guide to the report.

The report has four Parts, each of them subdivided into Sections. Part I sets out the WHAT, WHY and HOW?

WHAT are we trying to find out? The research questions are: how can one explain the substantial investment and growth in particular sectors and localities of countries that are thought to have poor investment climate at the national level? Did close relationships between government and business play a role in bringing about this investment? How and why did these relationships emerge? What were the key features that made them effective? The Introduction (Section 1) shows briefly how the recent literature leads us to these questions. The questions are then operationalised in two sets of hypotheses, one concerned with the 
emergence of the state-business relationships and one concerned with their impact on investment. These hypotheses are set out in Section 4. Essential for the specification of the hypotheses is the conceptual framework presented in Section 3.

WHY the research is important is explained in Section 1 - with reference to recent international literature - and then further in Section 2 - with reference to Egypt.

HOW was the research carried out? The contextual Section 2 shows that investment in Egypt over the last ten years varied substantially between sectors and over time. These variations open up the space for new research, which is based on inter-sectoral and inter-temporal comparisons. Section 4 explains the choice of sectors and how the required information was collected. While the investment data comes from secondary sources, the information concerning relationships is based entirely on primary sources, in particular 61 interviews with policymakers and business leaders.

Part II presents the findings on two old sectors: food and furniture; and Part III presents the findings on two new sectors: communication and information technology. Both Parts are organised around the same sets of hypotheses which are examined one by one. They mirror each other. It is however important to present the findings of the old and new sectors separately to make space for the initial comparison between the two old sectors and between the two new sectors. Each pair has one sector that did very well (food and communications) and one sector that did less well (furniture and information technology). While not constituting full-blown comparisons, contrasts between them are an essential part of the analysis. Government-business relationships differed and this seems to have had an effect on regulations and policies and ultimately on investment. The flow in these detailed empirical sections is as follows.

Part II: The first hypothesis states that state-business relationships become effective only when there is a common interest in the sector's growth and common understanding of its problems. We use the term CIPI to refer to relationships which fulfil this condition of common interest and understanding. The interviews show that CIPI exists for the food sector but less so for the furniture sector. The effects of CIPI are examined in detail by focusing on a number of hypotheses. One of the most important ones is the hypothesis that CIPI plays a critical role in attracting investment to specific sectors. The report shows the difficulty of examining this effect because the respondents were concerned that a positive response could be interpreted as evidence of corruption. In-depth discussions were necessary to unravel how CIPI helped reduce uncertainties and solve chronic problems in the food sector. This had a positive documented influence on investment. The examination of a further hypothesis shows that the way the private sector is organised influences whether the effects are inclusive or exclusive. Then there are further hypotheses about whether the investment increases are just short-lived surges or give rise to a new dynamic.

Part III: The same hypotheses are then examined for the new sectors: communication and information technology. In a nutshell, the findings are clearer in the new sectors because the relationships between government and business leaders are closer. The common interest is strong and the common understanding 
of the problems is helped by the fact that members on both sides have the same professional background. The report shows that this alliance played a critical role in generating the investment and establishing a new communications and information technology industry. Particularly interesting is that the initial round of investment occurred before new rules for regulating the sectors were introduced. The investors played a major role in designing the new legislation by participating in a public-private working group set up for this purpose. By examining specific hypotheses and contrasting the communications and information technology industries, the report produces new insights on how constructive state-business relations have emerged, how they change over time and how they affect investment decisions. All this is done in some detail but we have tried to make complex case material accessible. Nevertheless Parts II and III (and the related Appendix) are demanding on the reader because introducing the key players, the (changing) institutional infrastructure and sectoral specificities is unavoidable for providing evidence, bringing out contingences, or showing that answers to our questions have different layers.

The hurried or impatient reader might prefer go straight to Part IV which pulls together the findings from the old and new sectors and brings out commonalities and differences. The most important overall finding is that informal relationships between key policymakers and investors have played an important role in raising levels of investment and fostering economic growth. But the report warns against overstating this role. CIPI is not the sole or direct cause of an increase in investment but it helps to unleash the profit potential and unblock the way forward in the short and medium term. It has been an effective transitional arrangement. Part IV then draws together the findings and reflections on how CIPI helped to overcome barriers, what determines whether the willingness to take action translates into ability to take action, under what conditions exclusive relationships have inclusive effects, how the organisational capacity of the private sector influences the outcomes, whether the investment increases are short-lived or take the sector beyond the tipping point, whether and how informal relationships can be institutionalised, and why the global financial crisis and economic downturn reinforce the need to examine state-business relationships. 


\section{Acknowledgements}

We thank the members of the Egyptian business and policymaking communities who contributed to this research either by providing valuable data and (often confidential) information and/or facilitating access to other key players. Without their support and trust it would have been impossible to address the often sensitive issues examined in this research. Special thanks are owed to Tarek Tawfik, Hossam Saleh, Alaa Agamawy and Mohamed Kassem. We are grateful for helpful comments provided by our colleagues in the Research Programme 'Public Action and Private Investment', participants of the Annual Meeting of the Centre for the Future State (Brighton, 24-26 June 2008), and participants of the Conference of the Middle East Economic Association (Nice, 18-20 March 2009). Particular thanks go to Mick Moore, Neil McCulloch, Padmini Swaminathan and Sue Unsworth for their detailed suggestions and comments on previous drafts. Dina Abdel-Fattah, Maha Hamza and Charlotte Huggett provided valuable research and editorial assistance for which we are very grateful. We acknowledge with gratitude the financial support from the Agence Française de Développement (Paris) and the Department for International Development (London). The responsibility for the views expressed, as well as for errors or omissions, lies with us alone.

This report is published by the Centre for the Future State, which is funded by the Department for International Development (DFID) UK, and based at the Institute of Development Studies (IDS). The Centre enables researchers from IDS and their partners in Africa, Asia and Latin America to work together and carry out research on what makes states more effective, accountable and responsive.

For further information please visit: www.ids.ac.uk/futurestate/
Acronyms

CIT
CIPI
DFID
ECES
EITESAL
ERP
FDI
FEI
GAFI
IDSC
IMC
ITIDA
$\mathrm{MCIT}$
NTRA
PAPI
communication and information technology
common interest between policymakers and investors
Department for International Development
Egyptian Center for Economic Studies
Egyptian Information Telecommunications Electronics Software Alliance
Enterprise resource planning
Foreign Direct Investment
Federation of Egyptian Industries
General Authority for Investment
Information and Decision Support Center
Industrial Modernization Center
Information Technology Industry Development Agency
Ministry of Communications and Information Technology
National Telecommunication Regulatory Authority
Public action and private investment 
IDS RESEARCH REPORT 61 


\section{Part I Objectives, analytical framework and national context}

\section{Introduction}

Generating private investment for more and better growth is one of the key challenges for a better future. It is especially difficult in the political and institutional environments typical of developing countries. What can their governments do to achieve substantial increases in productive private investment? This is the question that drives the research programme 'Public Action and Private Investment' (PAPI) of the Centre for the Future State. The study presented here is a component of the PAPI programme.

The policy relevance of the question addressed by this programme is clear. It is now generally accepted that substantial reduction in poverty requires accelerating economic growth and that such growth requires increasing investment. Low levels of private sector productive investment appear to be a major obstacle to economic growth in the poor countries. Even though this issue has received much attention in the academic debate in the last 40 years, solutions for developing countries remain difficult to derive.

In the recent policy debate, these issues are discussed in terms of improving the investment climate. For example, the 2005 World Development Report 'A Better Investment Climate for Everyone' identifies a range of obstacles and ideas for moving forward. Many other policy documents have appeared concerned with improving the climate for business. At their core is the suggestion that improving the institutional framework is essential for raising investment and growth. A lot of effort has gone into developing indicators to measure the burden of regulations. The best known is the 'Doing Business' indicator (of the World Bank-IFC) which is used to provide benchmarks, compare countries and urge governments to reform regulations. With such quantification, it seems, attention to investment climate issues has increased further. International conferences and workshops around the world are trying to take stock and derive lessons.

The protagonists of regulatory reform claim that the key to investment and growth lies in clear property rights and low levels of regulation and that this can be shown empirically using business indicators. The criticisms fall roughly into two groups. First, there are those that concentrate on the measurement. They criticise the choice of indicators, the reliability of the data, and the uses to which it has been put (for example, Commander and Tinn 2007; IEG 2008). Or they argue that measurement is more effective if carried out at the sub-national level - the district or province (for example, $\mathrm{VNCl} 2007$ ).

The second group concentrates not on measurement but on dynamics and context, questioning the assumption that reforming regulations is the key to raising investment and generating growth. These critics are not against reforming regulations but against making it the all-out focus for research and policy, suggesting that it is neither a necessary nor a sufficient condition for raising investment and generating 
growth (Altenburg and Drachenfels 2006; Khan 2005 and 2008; Moore and Schmitz 2008). What is necessary and appropriate is seen to depend on the circumstances. This view is expressed most clearly in the work of Rodrik and colleagues on growth strategies, which stresses that reform is contingent on the economic circumstances of the country and that the binding constraints differ from country to country (Rodrik 2005; Hausmann et al. 2007). This view has gained increasing acceptance but the question of how best to identify the binding constraints remains wide open. 1

Even more open is the question of how to overcome the constraints once identified. This is the question which this report seeks to address. Obviously the answer depends to some extent on what constraint one is dealing with. There are however two general 'lessons' that one can derive from reading across recent debates on enhancing growth and that provide a useful steer for this study. First, the suggestion to draw on political and not just economic analysis; second, the warning not to search for solutions that last forever. Let us start with the latter.

The distinctions between short-, medium- and long-term are well rehearsed in social sciences, but are rarely given sufficient attention in policy debates, partly because of the preoccupation to find and adopt best practice. Best practice thinking tends to diminish the importance of context and time. This is acknowledged in some parts of the growth debate that recognise the importance of (often heterodox) solutions for a particular stage or a particular turning point. Take, for example, the transitional institutions identified by Qian (2003) in his analysis of China's growth trajectory. Or take the conclusion that igniting economic growth is different from sustaining it and that igniting growth requires a limited range of (often unconventional) measures that need not overstretch the executive capacity of the state (Pritchett and Rodrik 2005).

Such a step-by-step approach is also behind the questions on sequence and dynamics of institutional reform, posed by Khan (2008) and Moore and Schmitz (2008): does 'getting the institutions right' come first or do investment and growth lead to demand for institutional transformation? In other words, do investors follow or lead regulatory reform? Or is an iterative process at work? If so, what are the key stages in this process? We believe these questions need to be posed because some of the successful economies, such as China and Vietnam, have been able to initiate investment and growth without prior institutional transformation (Qian 2003; Malesky 2008). India's transition from low to high growth occurred prior to institutional reform (Kohli 2005; Rodrik and Subramanian 2004). Explicit or implicit in these analyses is the idea that there are different requirements for different stages. As will be shown later, this has influenced the way we have gone about the research presented in this report.

The other useful steer emerging from recent debates is the acknowledgement that a more political and not just economic approach is required. This is significant in a

1 Available approaches include growth diagnostics which seek to identify constraints holding back the economy at large (Hausmann et al. 2007) and value chain analysis which disaggregates further and seeks to identify the weak links that hold back particular parts of the economy (Schmitz 2005; Humphrey and Navas-Aleman 2009). 
debate which has tended to be dominated by economists. The acknowledgement of politics is visible in the recent debate in and among aid agencies, in particular in the importance given to growth coalitions (consisting of actors from public and private sectors, and from national and foreign organisations). There is a sense that there is plenty of advice but that little is put into practice because of lack of political support. Growth coalitions are thought to be important to overcome the 'implementation problem'. ${ }^{2}$ The 'political turn' is also visible in the academic debate which has suggested that state-business relations matter for economic growth. This is not a new debate: the importance of state-business relations has been stressed in analyses of capitalism in Latin America and Asia where it has been seen to contribute to success (see for example Amsden 1989; Evans 1995) but also excess and failure (see for example, Winters 1996; Hutchcroft 1998). ${ }^{3}$ Neoliberalism embraced eagerly the negative experiences and the spectre of rampant rent-seeking, and crony capitalism made state-business relations a suspect topic in the development debate. This is now changing; there is a growing (but often grudging) recognition that for a government that seeks to foster economic growth it is neither realistic nor desirable to keep business at arm's length. The new constructive realism is visible in several research programmes which are supported by DFID 4 and which examine the relevance of state-business relations for economic growth. For example, Sen and Te Velde (2009) suggest that state-business relations have a positive impact on economic growth in Africa, based on an analysis of the visible, institutionalised and formal relationships.

While this is an important finding, the more challenging question is whether such a positive influence comes from less visible relationships which are not (yet) institutionalised and work informally. Even though such relationships continue to be pervasive, a reassessment of how they affect investment and growth in contemporary developing countries has yet to be carried out. ${ }^{5}$ This is where this study seeks to make a contribution. The strongest evidence for the importance of informal state-business relations for investment and growth comes from the history of Mexico (Haber et al. 2003; Bates 2004). Inspired by this case, Moore and Schmitz (2008) suggest that 'hand-in-hand arrangements' between politicians/policymakers as holders of political power and investors as holders of economic power need to be put centre stage in order to understand why investment and growth can increase in adverse circumstances. They draw attention to enormous differences that can often be found within countries and ask how one can explain substantial investment and growth in particular industries and localities of countries that are thought to have poor investment climates at the

2 This is based on our own experience in receiving and giving advice on growth and competitiveness issues.

3 For a useful review of state-business relations, see Schneider (1998).

4 The research programme 'Public Action and Private Investment' of the Centre for the Future State; the State-Business Relations Cluster of the Consortium for Improving Institutions for Pro-Poor Growth; and the Research Stream on State-Business Relations of the Africa Politics and Power Programme. See www.2.ids.ac.uk/futurestate/; www.ippg.org.uk and www.institutions-africa.org.

5 The same point is made by Kelsall and Booth (2009) with particular reference to Africa. They suggest that the literature on clientelism and neo-patrimonialism has tended to focus on the negative effects and that a reassessment is required, specifying the conditions that lead to positive and negative outcomes. 
national level? Did hand-in-hand arrangements play a role in bringing about this investment? How and when did these arrangements emerge, what stages did they go through, what were the key factors that made them effective?

These are precisely the questions addressed in this study which investigates the case of Egypt. Politically Egypt is a heavyweight, seen by many as the motherland of the Arab world and strategic mediator in the conflict-ridden Middle East. Economically it is relatively weak. While showing signs of improvement since 2004, Egypt has recorded low rates of growth and low levels of competitiveness for a long time. External advice on how to change this was not lacking. Egypt was at the receiving end of much donor advice on the investment climate and carried out some reforms to improve the investment climate. The levels of private investment nevertheless remained disappointingly low. There were however interesting exceptions which we investigate in some depth in this study. More recently, since a change of government in 2004, general levels of private investment have picked up and in some sectors the increase has been particularly strong. The central concern in this study is to understand why investment in some sectors was so substantial (before and after 2004), paying particular attention to the relationships between policymakers and investors.

This concern led us to concentrate on four sectors: food and furniture (old sectors) and communication and information technology (new sectors). We had some idea from our previous research and advisory work that investment in these sectors had increased substantially and that the relationships between policymakers and investors were close. What we did not know was how the relationships had emerged, when and how they mattered for investment, and how relationships and outcomes varied between these sectors. This research report presents the findings on these questions. Accordingly, the main sections of this report are concerned with the emergence of these relationships and with their impact.

Running through the core empirical sections is the comparison between the four sectors. As will become apparent, this comparative dimension is critical to understanding what worked and what did not and why. Whenever possible we also compare 'our' four sectors with industry at large but we are not in a position to do this systematically, partly because there is so much diversity and this complexity increases when one includes changes over time. Yet capturing the main changes over time is what we have tried to do, particularly in our four sectors. In short, we rely on both inter-industry comparisons and inter-temporal comparisons. Imperfect as they are, they are essential to the journey of discovery. This is an exploratory project which is question-driven, not method-driven.

Two issues need to be clarified from the outset. First, our focus on the relationships between policymakers and investors does not mean that we ignore the danger of such relationships being abused. On the contrary, in the course of this research report we examine factors that influence whether the effects are inclusive or exclusive. Second, our focus on public-private relationships in specific sectors does not mean that we consider the general investment climate irrelevant, far from it. We believe that improving the regulatory framework is a good thing to do. But the substantial intra-country differences raise questions about the explanatory power of an investment climate approach which concentrates on the national level, and they lead us to look for alternative explanations. In this study, we have opted to 
examine the relevance of what one can call 'relationship-based governance' in contrast to the 'rules-based governance' which is the focus of investment climate reform. In the context of this research, rules-based governance means that investors can rely on rules such as the legal protection of property rights, the legal enforceability of contracts and clear tax regulations to reap the benefits of their investment. In contrast, relationship-based governance means that the above issues are granted through relationships between business and state actors. ${ }^{6}$

Rules-based governance seems an important long-term goal. The question is how to get there. Could it be that relationship-based governance is a means of accelerating the process? Our research leads us to a cautious 'Yes, but'. In other words, we need to specify the circumstances in which relationship-based governance can lead to more investment and more investors and create demand for clearer and better rules.

The report consists of four Parts. Part I has four sections. Following this introduction, Section 2 sets out the national context: it gives an overview of investment trends and changes in rules-based governance. Section 3 provides the conceptual framework for the analysis of relationship-based governance. Section 4 presents the hypotheses and methodology for the sectoral studies. All these sections are short but essential to prepare the ground in terms of national context, concepts, methodology and hypotheses. Then we come to the core of the Report. Parts II and III present respectively the findings from two long-established sectors (food and furniture) and from two new sectors (communication and information technology). Both Parts show how the relationships between key policymakers and investors emerged in the selected sectors, and what impact these relationships had in terms of policies for these sectors and for investment. The final Part IV distils the common patterns and the differences between these sectors, draws out the main conclusions for the investment climate debate, and specifies issues to be addressed in future research.

\section{Rules-based governance and industrial investment in Egypt 1970-2007}

This section provides the national context for the sectoral studies and addresses three questions: what have been the main trends in private industrial investment in Egypt since the 1970s? What were the main changes in rules and regulations over this period? Is there a relation between changes in rules-based governance and investment?

6 This distinction is also used by Li (2003) but for a different purpose, namely the analysis of transaction costs between private actors, whereas our focus is on the relationships between state and private actors. 
There are no reliable time series data on industrial investment but by piecing together the available data (Abdel-Latif 2007), one can derive the following overall trends:

- Industrial investment as a percentage of total investment has declined since the 1970s. Public and private industrial investment accounted for over 30 per cent in the 1970s and decreased to around 10 per cent in 2005.

- Private industrial investment as a percentage of total private investment decreased from 26 per cent in 1992-97 to 11 per cent in 2000-03, suggesting that the private sector was losing interest in investment in industry.

- Annual growth rates of both public and private real industrial investment have fluctuated enormously over the period 1970 to 1996, but the overall trend was one of decline (see Figure 2.1). Public investment decreased more than private investment following the implementation of Egypt's new economic reform program (ERSAP) starting from 1991.

- Private industrial investment (in real terms) remained steady but at a low level from 1998 to 2002 and then declined during 2002 and 2003 due to a wave of divestiture (Sakr 2003). A change of trend is observed starting from 2004 as investment increases, first making up for lost investments in the previous couple of years, then achieving positive rates of growth from 2005 (Figure 2.2).

The poor investment performance over long periods does not mean that the government failed to make changes to the regulatory framework. Tables A1 and A2 in the Appendix list and explain the main changes. Some of them were substantial, for example the laws ending expropriation (nationalisation) in the 1970s, the legal provision for equal treatment of local and foreign firms introduced

Figure 2.1 Public and private industrial investment: annual growth rates, 1973-1996 (\%)

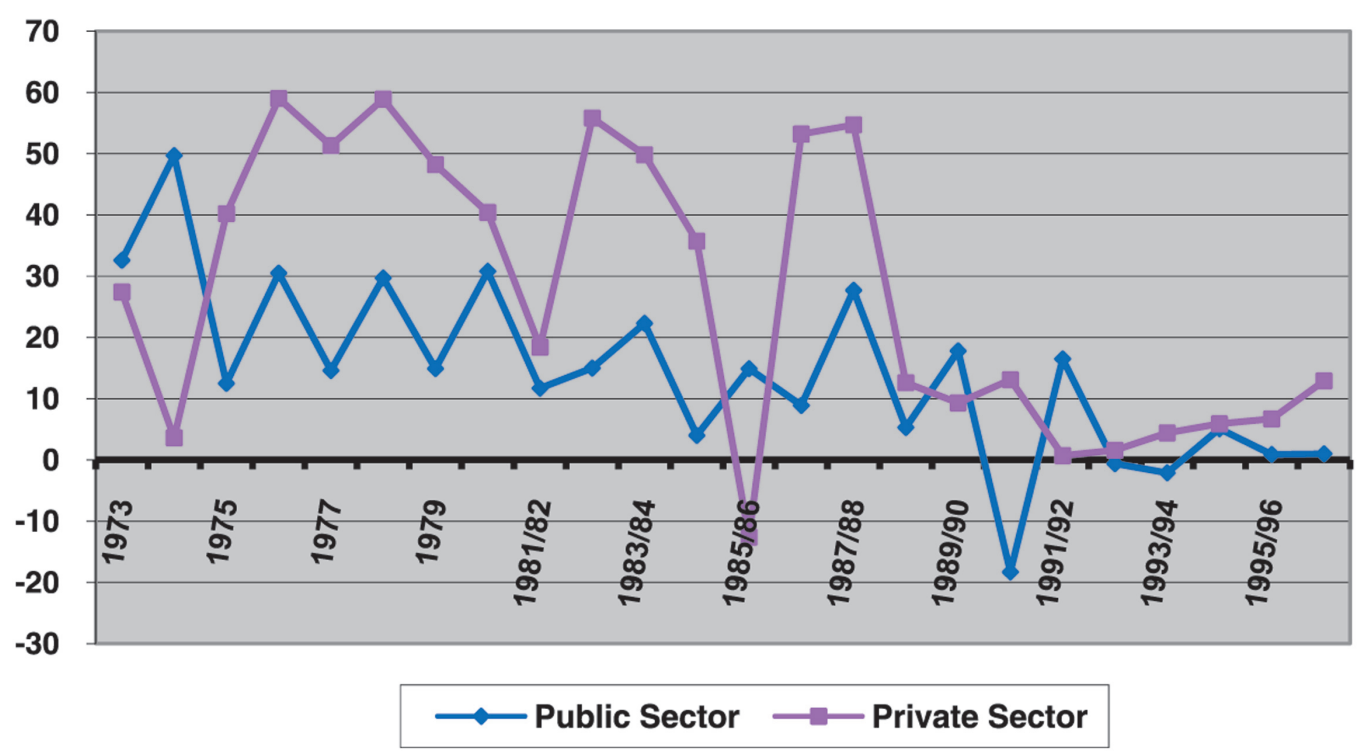

Source: Ministry of Planning (currently Ministry of Economic Development) 


\section{Figure 2.2 Annual growth rate of real industrial investment, 1998/99- 2005/06 (\%)}

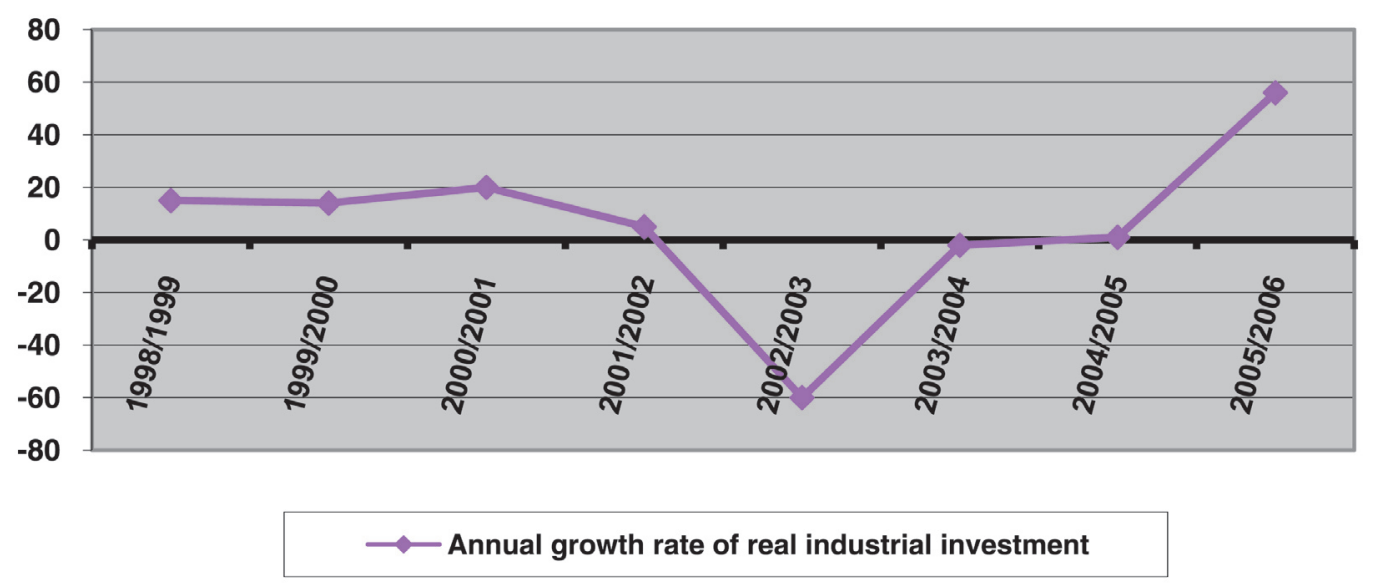

Source: Ministry of Planning (currently Ministry of Economic Development)

in the 1980s, structural adjustment in the 1990s, intellectual property and labour laws in the early 2000s. These and other measures failed to have an impact on private investment partly because

- Some of them were dealt with on paper but not followed through; there were contradictions between new and old laws, the dispute settlement remained weak, and carrying out the reforms was not in the interest of an overstaffed and underpaid bureaucracy (El-Mezlawy 2006).

- Some areas were not dealt with at all, notably customs administration, taxation rules, competition law and judicial reform (Handoussa et al. 2003).

- Government was perceived to be anti-business (interviews with business people carried out by authors in first half of 2004).

The resulting poor investment and growth was not just an economic problem. The combination of a rising number of angry young people, unable to find jobs, and a disgruntled business community, feeling that it was held back by an overblown and often dysfunctional state bureaucracy, made the regime fear for its future. This helps to explain why, in mid-2004, the President changed the composition of the Cabinet in a major way. For the first time since 1952, members of the business community were appointed to ministerial positions. The new Cabinet swiftly introduced a number of regulatory changes, notably the simplification of customs and of taxation. As seen in Figure 2.2, investment responded immediately. Does this support the belief in rules-based governance? The government certainly presents itself as a successful reformer of rules and regulations.

A closer look suggests an explanation which has several layers. There can be little doubt that the simplification of customs and taxation helped - the business community had requested them for some time. But other dimensions central to rules-based governance have not improved, notably inconsistent legislation and weak contract enforcement. Our post-2004 interviews with owners and managers of large and 
small enterprises suggest that the most critical change lay not in the rules for business but in perceptions by business people (Abdel-Latif 2008). The widely publicised membership of business people in the Cabinet led to greater trust in government. Yousfi and Humphrey (2008) add a further layer of understanding, derived from interviews that concentrated on perceptions. They suggest that what mattered most were not the changes in rules but new ways of relating with government agencies. Interviewed industrialists felt that government agencies, such as GAFI (General Authority for Investment), had developed a capacity for dialogue and adjustment to the constraints faced by business. The perception was that relationships had changed from controlling with distrust to promoting with good will.

This overview of the national context has hidden the enormous intra-country differences. Both before and after 2004, substantial differences in investment and growth can be observed. Figure 2.3 illustrates a sample of such differences between industrial sectors.

\section{Figure 2.3 Annual real investment in some of the manufacturing industries, 1995-2008* (in million Egyptian pounds)}

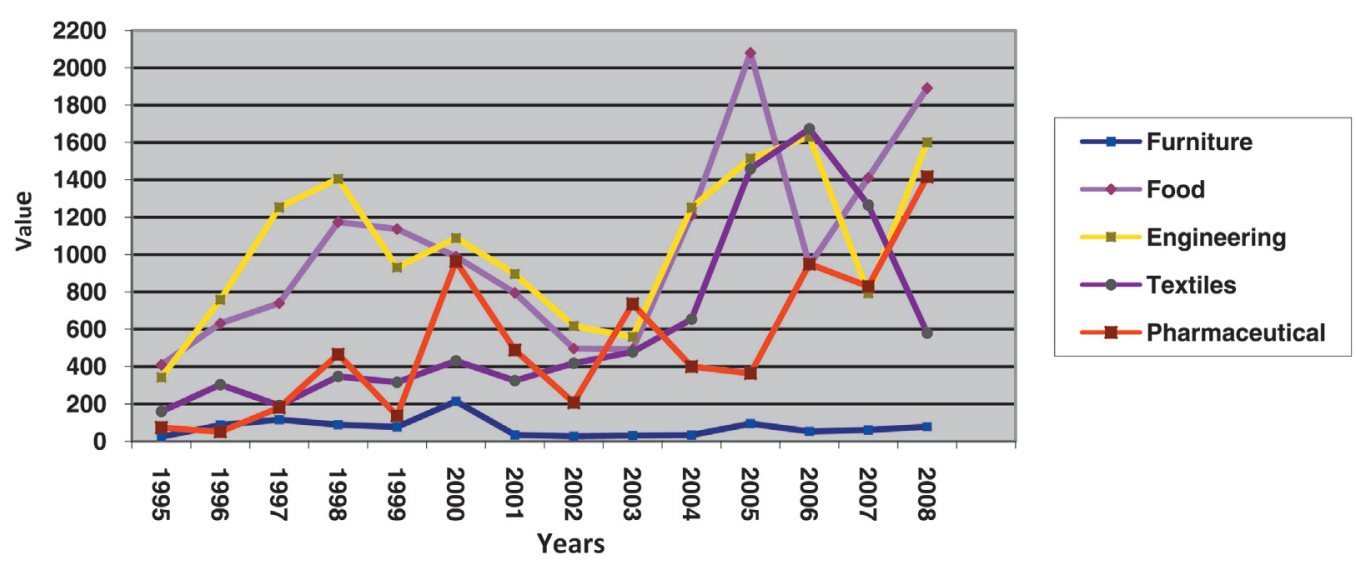

*data up to November 2008.

Source: GAFI - Nominal investment data deflated by authors.

A proposition that underlies this study is that a great deal can be learnt from investigating these differences. This is why we concentrate on sectors which did better than others and we ask whether and how this superior private investment performance is related to public action. In order to do this we need to make our conceptual framework explicit because it provides us with the language to investigate what went on between private and public sectors and because it provides us with a reference point for analysing changes in the real world.

\section{Conceptual framework}

The question that drives our analysis is how we can explain that investment in some industrial sectors increased substantially more than in others, giving particular attention to the relationships between policymakers and investors. Such 
an exploration is made difficult by the attribution problem: investment is influenced by a number of factors. The advantage of intra-country (as opposed to intercountry) comparison is that the general investment climate can be held constant. But how do we take into account the business opportunity (profit potential) as a driver of investment? Most of the investment climate and state-business literature chooses to ignore this question. In this study we cannot entirely resolve the attribution problem but we will address it in the empirical analysis and specify at what point and in which way particular state-business relationships matter.

The purpose of this section is to spell out the conceptual framework, distinguishing between different types of state-business relationships, different stages they go through and different ways in which and points at which they might have an impact on investment.

There is no agreed terminology on state-business relationships. They range from hostile to supportive. Support can come in two ways: through the regulatory framework defined by the state or through arrangements with particular groups of enterprises. We have already used this distinction in the previous sections where we distinguished between rules-based governance and relationship-based governance. When Moore and Schmitz (2008) refer to 'universalistic versus particularistic' or 'arms-length versus arm-in-arm' relationships, they make essentially the same two-fold distinction.

The words are different but the distinction is the same. For example, the conventional investment climate reform aims at rules-based governance which implies arm's length or universalistic relationships between business and the state. In this study we investigate whether and how relationship-based governance works, which means interrogating arm-in-arm or particularistic relationships. In doing so, we pay particular attention to the common interest between both sides. We will refer to this relationship based on common interest between policymakers and investors as CIPI. This is our central concept and therefore needs explaining. ${ }^{7}$

CIPI is a relationship based on mutual interest. The investor perceives that the policymaker has a stake in the investment, in the sense that making it happen and succeed would enhance the policymaker's reputation, career or power. In turn, the policymaker perceives that the investor needs assurance that complementary action by the state (complementary infrastructure, services, loans, or policies) will take place. Both sides would lose out if the investment does not occur.

The hypothesis underlying this study is that CIPI is critical to stepping up investment and growth. We seek to understand how CIPI emerges and whether/ under what conditions it has the hypothesised effect. In other words, we are not assuming that the effect is always beneficial to the economy and we are aware that such relationships can be, and indeed have been, abused (discussed further in Moore and Schmitz 2008). We believe that the 'whether, how, under what conditions' is best unravelled by adopting a process approach; in other words,

7 We do not use the term public-private partnership (PPI) because it comes with a lot of 'baggage' in the sense of different meanings for different purposes, for example cooperation in the implementation of infrastructure projects. 
observing how CIPI evolves over time and observing at what stage what kind of effect kicks in. The problem is that the literature gives us little guidance for doing this. We have therefore asked what the process might look like and built a model consisting of hypothesised stages. This heuristic device gives us vocabulary and reference points for analysing real processes. Whether real processes develop as set out in the model, will be examined in later sections.

The dynamics of reaching CIPI and impacting on private investment is hypothesised to evolve in seven phases: phase one - initial relations; phase two - common interest-building stage; phase three - common interest-maturity stage; phase four - the tipping point; phase five - the sectoral knock-on effect; phase six - the inter-sectoral knock-on effect; and phase seven - beyond the peak of $\mathrm{CIPI}$. An attempt to capture the hypothesised phases of CIPI from birth to decay or continuation is presented in Figure 3.1.

The three critical phases in the whole process are phases two, four and seven: phase two where the common interest is actually being built, phase four when the investment starts to respond (the tipping point) and phase seven (beyond the peak) because it addresses the future of CIPI and the possible alternative scenarios. The detailed description and characteristics of each phase are presented in Table A3 in the Appendix. The main elements of each phase are as follows.

Phase One prepares for the critical Phase Two of building common interest. Common backgrounds (education, social relations etc.) between policymakers and investors facilitate this introductory stage considerably. It speeds up the move into the more serious Phase Two by reducing the duration, transaction costs, ambiguity and uncertainty typically involved in testing the waters between the two parties. Policymakers already know the private investors and so tend to trust what

Figure 3.1 The CIPI path

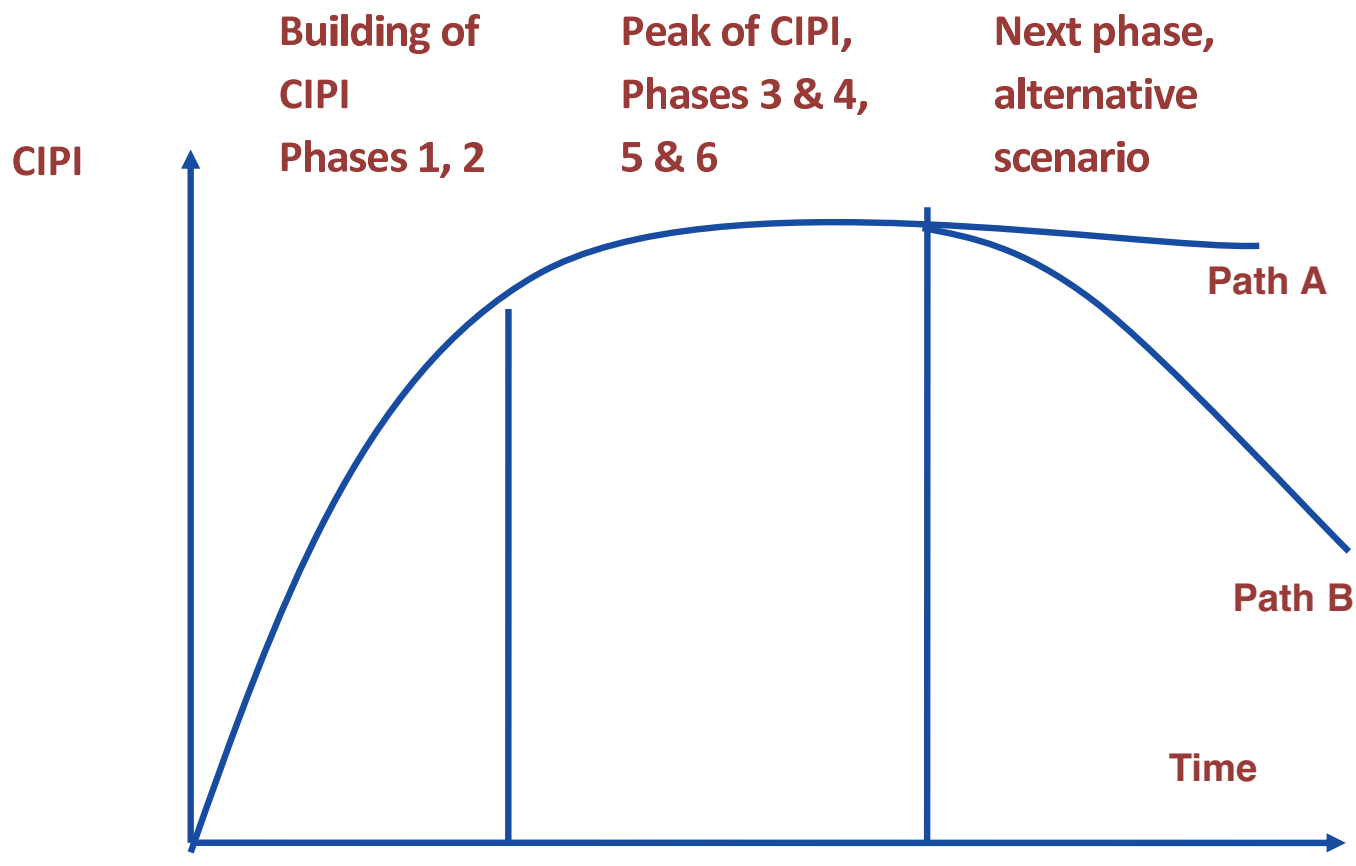


they say. By the same token, based on previous relations, the private investors trust the promises of the policymakers even if not implemented right away.

Note that in the real world, Phase One does not necessarily lead to Phase Two. The reasons are: (a) key players in the private sector with vision and strategic thinking capabilities may not necessarily emerge right away or may simply not exist; and (b) although trusting the private investors, policymakers may not necessarily be willing to induce policy changes of any significance, i.e. not be willing to take any risks, and so they may not encourage the move to the next step.

The building of common interest in Phase Two is the most critical stage of all. It takes place mostly in informal settings, behind closed doors, because the two parties need to be sure of the outcome of what they are negotiating before taking it to the public arena. Negotiations typically involve real partnership between the public and the private sectors in the sense that the private sector promises targets and specific responsibilities in return for policy changes by the government.

Phase Three is the phase when policy formulation steps out from behind closed doors to actual public announcement and adoption. It is further enhanced if a formal mechanism for the role played by the private sector in policy formulation is in operation. What is critical is for investors to feel that the changes will take place and that the system is not going to betray them by introducing policy changes that will hurt them. Mutual trust is the critical step here. Actual implementation of changes is an extra bonus but not a precondition for investment to respond.

Phase Four, labelled 'the tipping point', is when investment actually starts responding. The response here is not a simple increase in investment but rather a significant increase that marks the beginning of a new trend where investment is taken to much higher levels. Only as such would it qualify as the tipping point. It is initiated by new investments made by leaders and then followed by others in the sector.

Phases Five and Six are periods over which the knock-on effect of Phase Four can be observed. In Phase Five local investment in the sector concerned pulls in FDI (foreign direct investment). In Phase Six, the confidence to invest spreads to other sectors. Some of the policy changes induced by CIPI in one sector also benefit other sectors. The investment in one sector induces investment in others. A new stage is reached, in which the atmosphere of more trust in policymakers is contagious and encourages others to invest.

Phase Seven is the period beyond the peak of CIPI or beyond the completion of its first round. Here we can distinguish between two very different paths. Path $A$ is the path where CIPI is maintained at a high level and Path $B$ is the one where a collapse in CIPI is experienced. In scenario A, collaboration and mutual support between the key investors and policymakers is maintained. Both parties feel that their objectives have been realised and feel that there is potential for more. The policymaker is becoming more powerful and the investors are reaping the profits of their increased investments. The relationships between the two sides become more formal, taking on projects and developing policies beyond the initial sector reforms. The example triggers replication in other sectors. It encourages investors 
from other sectors to establish CIPI with policymakers. In scenario B, the actions of the policymaker are interpreted as undeserved favouritism to the sector in question. It gives rise to criticism by other government officials, business associations and, most important, the media. This jeopardises the political career of the policymaker. For this or other reasons, there ceases to be a common interest between policymakers and investors. CIPI collapses. The key empirical question is whether investment also goes down. It could be that once the tipping point is reached, investment is less dependent on the relationship with specific policymakers. In other words, CIPI is particularly important at the earlier stage of triggering the initial increase in investment. This transitional feature of CIPI has its advantage: the relationship between investors and policymakers is less likely to be abused.

The purpose of presenting these seven phases is not to prescribe what policymakers and investors should do. On the contrary, it is meant as a framework for understanding what actually goes on in the real world. Central to such understanding is that due consideration is given to processes and phases. For example, the framework invites us to examine whether and how a transition from informal to formal relationships has occurred - or to look out for a tipping point at which the investment kicks in.

The empirical research will need to identify the contingent factors that influence whether the process evolves as set out or differently. For example, the organisational capacity of the private sector can be such a contingent factor. Presumably an alignment of interests is difficult to construct with a disorganised private sector. Then there are contingent factors arising from the nature of the sector - new versus old sectors, lumpy versus continuous investments, etc. These and other factors influencing the dynamics will emerge in the course of the empirical research.

\section{Hypotheses and methodology}

The contextual Section 2 stressed that, over the last ten years, investment varied substantially over time and between sectors. These inter-sectoral and intertemporal variations have opened up the space for new research. This section shows how we have used this space and specified the design of the project: choice of sectors, hypotheses and data collection.

\subsection{Choice of sectors}

The choice of sectors was influenced by the overall questions of how statebusiness relationships evolved and how such relationships influenced investment. We had a sense that relationships in old sectors had different roots and evolved differently from those in new sectors. This was the reason for choosing two old sectors, food and furniture, and two new sectors, communication and information technology. When using the term 'old' we do not imply outdated but mean having a long history. 
In order to deepen the insights we opted to compare a successful with a less successful old sector and a successful with a less successful new sector. In the early stage of the research we compiled and analysed secondary data on investment which suggested that contrasting the food and furniture industries would be useful (see Figure 2.3). Similar differences in investment were also observed between communication and information technology, favouring their analysis as separate sectors even though there were institutional reasons at the outset for analysing them together. We should, finally, add that the choice of sectors was also influenced by pragmatic considerations: we knew from our previous work that there were good prospects of getting access to the key players in industry and government in these sectors.

The inter-sectoral (and inter-temporal) contrasts are critical to gaining insights from the Egyptian experience, but this research report does not amount to a fullyfledged comparison of four sectors. Much of it consists of selective contrasts in order to bring out the (ir)relevance of particular factors. In the course of the research we found that, on some issues, we had to further disaggregate by subsector and region to unravel causal relationships.

\subsection{Hypotheses}

The hypotheses can be divided into two groups: one concerned with the creation of CIPI, and one concerned with the impact of CIPI on investment. Their specification can be derived from the conceptual framework presented earlier and will be explained further when we present the findings.

\section{A. Hypotheses relevant to the creation of CIPI}

A.1 State-business relationships become effective only when there is a common interest in a sector's growth and common understanding of its problems.

A.2 Common interest between policymakers and key investors (CIPI) has its roots in a previous informal relationship at the educational, social or business levels (separately or combined).

A.3 CIPI creation is a short-term process and is fuelled by changes in government figures.

A.4 Initial interactions between key policymakers and investors are informal and then become institutionalised as the alignment of interests becomes clearer.

\section{B. Hypotheses relevant to the impact of CIPI on investment}

B.1 CIPI plays its role through providing proxy governance benefits to specific sectors or subsectors.

B.2 CIPI plays a critical role in the success or failure of attracting investment to specific sectors and/or subsectors.

B.3 CIPl's proxy governance benefits influence investors' decisions to invest more than the general enabling environment does. 
B.4 CIPI has an inclusive positive impact on the sector only where the private sector has high organisational capacity.

B.5 CIPI-induced investment reaches a tipping point which is a specific point in time when investment starts responding in a significant way (taking off).

B.6 The tipping point is followed by a knock-on effect, whereby local investment in the sectors concerned attracts FDI and stimulates investments in other sectors.

B.7 Disturbance of CIPI through conflict of interest between private investors and government will not affect investment if it has already taken off.

\subsection{Operationalising the key variables}

One of the greatest challenges in researching the above hypotheses is to measure the key variable CIPI and its impact on investment. Four problems arise. (1) Public-private interactions, whether occurring at a specific point in time or observed over time, are difficult to capture because information is not readily available and often confidential. This makes CIPI, the advanced stage of such interactions, an unconventional and elusive variable that is difficult to measure. (2) CIPI carries from the outset the suspicion of possible corruptive behaviour thus making policymakers and investors alike unwilling to explicitly discuss it. (3) Assuming that CIPI does have an impact on investment, it is difficult to isolate its contribution from all other factors of relevance. (4) There are no clear criteria for identifying the 'tipping point' or the point of big increases in investment that mark the take-off of the sector (of key interest to policymakers) and differentiating between this point and other increases in investments previously observed.

In this project we try to deal with these four problems in the following way:

- While investment is measured in quantitative ways, the relationships between policymakers and investors are assessed with qualitative data collected through detailed interviews that do not have a fixed format but rather vary between direct and indirect questions as per the nature of interviewees (the sources of information and nature of interviews are explained in the next subsection).

- The construction of CIPI is assessed through a descriptive analysis of the extent and type of the relations between policymakers and private investors, including common social, educational and business backgrounds, NGO affiliation, etc. that existed before policymakers took office.

- Reaching CIPI is assessed in terms of constructive and actionable proposals made by business people, the speed of response by policymakers in addressing the issues of concern to investors, the tangible policy changes and actions, and the level of formalisation of public-private interactions through the establishment of formal committees and fora that discuss private sector concerns. 
- As for identifying the impact of CIPI, this is assessed through its contribution to creating 'proxy governance' in favour of the sector/s or investors in question, through various policies and actions. A list of perceived actions for empirical monitoring consists of: 8

- Protection of specific property rights 9

- Specific policy changes of technical relevance to the sector

- Reduction of transaction costs and uncertainties in relation to transaction costs

- Reduction of public duties

- Provision of support services and infrastructure

- Adoption of a clear long-term vision for a particular sector.

- The tipping point is to be empirically identified by four complementary methods:

(a) comparison of new investment levels at the potential tipping point to a previous trend of investment and clear recognition of unprecedented increases in investment; (b) supportive evidence for continuing interest in the sector in the specific tipping point year - such as sharp increases in exports or overall demand for products; (c) perceptions and speculations of investors and policymakers about the potential of the sector and its attractiveness to investors detected in interviews; and (d) the extent to which the value chain of the concerned sector has been completed making it possible for the sector to 'take off'.

\subsection{Sources of information}

The research relies on a combination of quantitative and qualitative data. The quantitative information comes from official sources such as GAFI (General Authority for Investment), GOEIC (General Organization for Export and Import Control) and the MCIT (Ministry of Communications and Information Technology), and quasiofficial sources such as the FEC (Food Export Council), FUEC (Furniture Export Council), IMC (Industrial Modernization Center) and various business associations and industrial chambers within FEl (the Federation of Egyptian Industries). The qualitative information is particularly critical for understanding the statebusiness relations and comes from a total of 61 interviews. Table 4.1 shows how these interviews were distributed between government and business and between the old and new sectors. The category 'business leaders' consists mainly of investors but also includes a small number of heads of business associations /industrial chambers - most of whom were leaders of both enterprises and associations/chambers. In addition to the interviews, we made short enquiries and held conversations with numerous people on specific aspects so as to fill gaps in our understanding; for example we spoke with 20 exhibitors at an IT trade fair about their participation in business associations and chambers and their experience in dealing with specific government agencies.

8 These are just examples for empirical testing but do not exhaust the whole potential list.

9 To a small group as opposed to general protection of property rights through law. 
Table 4.1 Interviews in old and new sectors

\begin{tabular}{lccc}
\hline Actors & Old Sectors & New Sectors & Total \\
Policymakers & 10 & 8 & 18 \\
Business leaders & 22 & 21 & 43 \\
Total & 32 & 29 & 61
\end{tabular}

In research on relationships it is important to hear both sides. This principle guided our empirical research but it needs to be mentioned that some respondents worked on both sides - at different times! These were business leaders who had been asked to set up or run government agencies. Not surprisingly, these interviews proved most useful. More generally, some interviews were more important than others. Particularly critical were the interviews with the top decision-makers in government and in business. Obtaining access to them was in some cases difficult, requiring a good deal of time-consuming networking and negotiation.

Interviews were conducted in both formal and informal settings. Confidentiality was promised to the respondents. We used neither tape recorders nor research assistants for these interviews so that respondents would feel at ease and talk openly. In most cases this seemed to work but it is of course impossible to know what information our respondents held back. Whenever possible, triangulation was conducted across interviews; and information obtained in interviews was cross-checked with other sources, including legal documents and published and unpublished reports. 


\section{Part II Findings from old sectors}

The presentation of findings is organised into three blocks: findings from the old sectors, findings from the new sectors and lessons from the comparison commonalities and differences.

\section{Sectoral context: food and furniture}

The reasons for including these two sectors were given earlier. The purpose of this section is to contextualise the empirical findings presented later. This is done on the basis of information collected in the course of the interviews and various studies and reports (IMC 2003; IMC 2005; IMC 2006; Wood Chamber 2005).

\subsection{The food sector}

The food sector consists of around 5500 enterprises with 2000 formal and the rest informal. The industry is divided into six main sub-divisions by product group:

(1) processed fruits and vegetables; (2) dairy products; (3) bakery and confectionery; (4) meat, chicken and fish processing; (5) all types of oil; and (6) tea, coffee and tobacco. Seventy per cent of food industries fall into the small enterprise categories. The largest enterprises within each sub-division operate within an oligopolistic market setting. Key players use state of the art technology of production. The last few years have seen a significant improvement in export performance in terms of values and rates of increase, a process led by 70 enterprises.

Most of the inputs of the sector are locally available. An improvement in integration with agriculture in the last few years has been observed. The value chain has been strengthened with new internationally reputable retail chains recently opening in Cairo and Alexandria to provide outlets for food producers. A technology centre specialising in food industries has also been activated. One of the big assets of the food industries business community is its high organisational capacity.

The main challenges facing the sector are:

- The regulatory system is not unified. Several conflicting laws influence the sector, which increases transaction costs.

- Industrial control over the sector involves agriculture, health and local supply authorities. All government organisations related to these can visit factories under the guise of industrial control.

- Technical specification and standardisation is low and this contributes to waste of production inputs. ${ }^{10}$

10 For example, waste of tomatoes in the production of tomato paste reaches up to 60 per cent because the crop does not meet specification for industrial production. 
- The informal sector is big and produces low-quality products that compete with the formal industry in the local market through selling products that often do not meet health standards.

- Reclaimed land has become very expensive.

\subsection{The furniture sector}

The furniture sector includes a core of 15 large enterprises, specialising in western-style furniture, and many thousands of small enterprises, most of which produce traditional furniture or parts thereof. Damietta is the region with the highest concentration of enterprises (most of them tiny) and is specialised in hand-crafted classic furniture. In terms of organisation and technology, the sector is very heterogeneous.

As for the value chain, all raw materials for the industry are imported. Local production of accessories is limited and not developed and thus poses an obstacle to expansion of the sector and large-scale production. The sector lacks standardisation in production (measurement of doors and windows and kitchen cabinets, etc.), which slows down the growth of the industry.

The main challenges facing the sector are:

- Intense competition and friction between enterprises reduce the chance of integration within the sector.

- Imported wood is not of high quality and a technology centre has not yet been established.

- The typical small workshop structure of the industry is seriously delaying its progress.

- Standardisation of measurements (for instance for doors, windows, chairs) is not yet achieved - except in Damietta).

- Exporting firms face serious competition from East Asia.

\section{Emergence of CIPI in old sectors}

The hypotheses presented earlier drive the presentation of findings which are organised in two groups: emergence of CIPI (Section 6) and effects of CIPI (Section 7). The latter shows to what extent and in what circumstances CIPI matters. This section shows how it emerged. Was it informally and accidentally? Consciously constructed? Did it take a long time? What were the key stages? Who were the key players? Throughout Sections 6 and 7, we proceed by recalling the hypotheses and then presenting the findings.

Hypothesis A.1: State-business relationships become effective only when there is a common interest in a sector's growth and common understanding of its problems. 
Empirical investigation revealed many incidences of public-private interactions - in all four sectors and others ${ }^{11}$ - going on sometimes for years with no real positive impact on the sector. Policymakers and investors were speaking different languages, and did not see common ground or have any interest in listening to the other side. In the course of the interviews it became clear that mutual interest in and common understanding of the problems to be solved were a necessary (but not sufficient) condition for effective interactions. When mutual interest becomes clear, serious efforts start to be made on both sides. Key investors in specific sectors make promises to invest and increase exports and employ people, and policymakers see the promise of receiving some credit for the potential advances. This not only gives them personal glory but also improves their chances of remaining in office or being promoted. Evidence and specific examples of advantages gained through CIPI are presented later.

Empirical analysis revealed that the willingness of the policymakers to take action in favour of a certain sector seems to be conditional upon, and proportional to, the potential of the sector itself and the extent to which it can achieve visible and tangible results in terms of increased investment, exports and job creation that would give the policymakers credit. In fact it was stated by one highly prominent policymaker, on a confidential basis, that even though the support of the Ministry of Trade and Industry is offered across the board to all manufacturing industries, it concentrates on a number of specific sectors or subsectors because they have higher potential. This means that CIPI is reached faster for sectors with higher potential. Food industries, for example, received much more attention from policymakers than the furniture sector because the former is a bigger contributor to industrial output, employment and exports - and, most importantly, has more growth potential.

Differing levels of government interest are observed not only between sectors but also within sectors. For example, according to interviews, the processed fruits and vegetables subsector receives more interest than meat processing. The main reason seems to be meat processing's present limited scale of production and export. This point was emphasised by the investor interviewed from this specific subsector. His exact words were 'the Minister of Trade and Industry does not have time to deal with our problems, we are still too small a subset of food industries especially in comparison to processed fruits and vegetables, and so cannot be on his priority list at the present time'. This implies that CIPI is weaker in the meat processing subsector. In spite of the complexity of the investment decision one can conclude that this lower level of CIPI in meat processing explains, at least partially, why this food industry subsector has received less interest from investors than processed fruits and vegetables, even though it is not less profitable in the conventional economic sense. While such subsectoral issues need to be recognised, the food sector as a whole was of interest to policymakers because it combined economic viability and political importance.

11 Such as the garment, auto components, auto, and marble and granite industries. 
The interviews suggest, however, that mutual interest of policymakers and investors in the sector is not sufficient in itself; it has to be combined with common understanding of the problems that need to be solved. In the case of the food sector, the common understanding of problems and potential solutions was greatly facilitated by the fact that several new policymakers (starting in 2004) came from the private sector and the Minister of Trade and Industry himself was, until he became Minister, a prominent businessman in the food industry.

By comparison, the furniture sector as a whole was not a promising sector for constructing common interest. It did not have sufficient growth, export and employment potential to be of major interest to policymakers. Interviews with policymakers revealed the sector to be perceived by government officials as one of 'limited potential at least in the short run'. There were two interesting exceptions. First, a few individual exporting companies were able to construct close relationships with policymakers due to the owners' prominent positions in semi-public organisation which - as will be shown later - generated exclusive rather than inclusive benefits.

The second exception was the Damietta furniture cluster which benefited greatly from a growth alliance based on common understanding and mutual interest between local investors and policymakers. Damietta had an international reputation and high profit potential in classic labour-intensive furniture production. However, it required new investment in skills, equipment, organisational arrangements and marketing to be able to position itself in the international market for such specific products and bring tangible increases in exports and employment, not to mention an improved image of Egypt. The perception of individual gain from collective endeavour led to significant joint action in 2003-04. The parties involved were a group of keen investors, the governor of Damietta, the old Minister of Industry and the Industrial Modernization Center (IMC). Each one of these had their own interest in making Damietta a success story. The investors saw high profit potential in their industry that would be further enhanced if the industry received technical and marketing support. The governor was new at the time and saw enormous political mileage in helping local enterprises to establish an association and push his region to excel in exports and investments. The old Minister of Industry, with limited achievement until then, saw in Damietta an opportunity to associate his name with a success story. Finally, IMC, a new institution with few achievements at the time, and suffering from lots of criticism regarding its relevance to Egyptian industry, saw the potential for a success story in industrial promotion. The frequency of interaction helped to create a common understanding of the problems and agreement on priorities for action. So a local form of CIPI emerged, attracting international attention from analysts and practitioners in cluster development.

In conclusion, the interviews brought home that all sectors have interactions between government and business but often these remain inconsequential. We hypothesised that common interest in a sector's growth and common understanding of the sector's problems are essential for more effective relationships. The interviews showed that such common interest and understanding is more pronounced in the food sector than in the furniture sector (except for the Damietta furniture cluster). The effect this has on public policy for these sectors and on investment will become clearer when subsequent hypotheses are examined. 
Hypothesis A.2: Common interest between policymakers and key investors (CIPI) has its roots in a previous informal relationship at the educational, social or business levels (separately or combined).

\section{Empirical evidence from the food sector}

By informal linkages we mean the relationships between the policymakers and members of the business community before the policymakers came to office. They range from personal relations - such as attending the same school, being family members etc. - to professional relations -such as working in the same field, or having been business associates, or affiliated to similar political parties and/or NGOs. Figure 6.1 shows the kind of informal linkages found between key policymakers and important investors in the food industry.

Figure 6.1 Informal linkages between members from the business community and government members specific to food industries

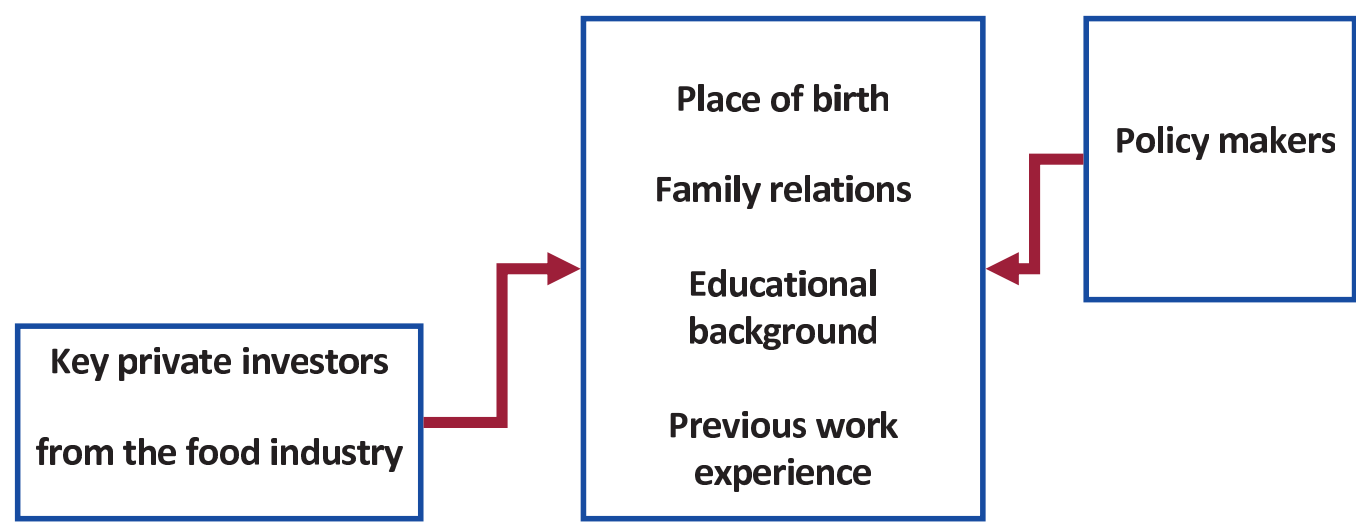

Four such linkages were investigated in some detail. Two key government officials admitted frankly, but confidentially, that informal relations existed before the current CIPI. Most respondents, however, regarded this as an awkward subject, so finding evidence of previous informal relationships was not straightforward. Only one of the key investors openly admitted that such informal relations have had an impact on government interest in food industries (the full value chain). The others firmly denied that these connections from the past had any relevance. However, their responses to other questions concerning their relationships with policymakers revealed the importance of those informal relations at least in having access to the policymakers for problem-solving. To be clear, the point made here is not that such informal relationships are illegitimate. The objective is purely analytical: knowing the existence of such relationships helps to understand CIPI and potentially also investment decisions.

\section{Empirical evidence from the furniture sector}

Interviews revealed that, in the case of furniture, there were no previous informal linkages between policymakers and investors. However, new links have been 
established between The Minister of Trade and Industry and two key investors in the industry. One is currently the head of the Furniture Export Council 12 while the other is the director of the Industrial Modernization Center (IMC). ${ }^{13}$ According to formal and informal interviews, the links between policymakers and these private players were due to the leadership positions held by the private players in semipublic institutions and their ability to articulate a vision for their own subsector. Similarly, in the case of the furniture cluster of Damietta, there were no previous informal relationships, yet a strong local CIPI was established in the period 2002-04.

\section{Informal relations amongst policymakers}

Empirical investigation revealed that the present structure of the Egyptian Cabinet has deeply-rooted informal relations at its core. Members from the business community have taken ministerial positions in the Egyptian government in 2004 for the first time since 1952. These include the Ministers of Finance, Investment, Trade and Industry, and Agriculture. They already knew each other from before at the general business level and through common affiliation to different bodies membership of the HSBC board (one of the largest banks operating in Egypt), the American Chamber of Commerce and the Egyptian Center for Economic Studies (ECES). These links are relatively easy to demonstrate, other connections are less visible. The above-mentioned Cabinet members chose to appoint other members from the business community to public and semi-public positions - as shown in Figure 6.2. In most cases these appointees were friends and acquaintances. For example, the Minister of Trade and Industry and the Chairman of the Federation of Egyptian Industries (FEI) are old friends at the individual and family levels, both born in the same city (Alexandria). Similarly, the Minister of Investment and the Head of the General Authority for Investment (GAFI) are close friends and old business partners. Other Cabinet members know each other from their previous university work. The Prime Minister and the Ministers for Communication and for Administrative Development were all professors in the Faculty of Engineering of Cairo University and worked together on a previous project. So there is a group of Cabinet members and appointees with a strong common background at the social and professional levels.

In conclusion, the hypothesis is only partially confirmed. CIPI has its roots in informal relationships in the food sector, but not in the furniture sector. However, there are strong informal relations between key policymakers. These informal linkages between key people in government facilitate speedy implementation of policies and have a bearing on relationships with the business community. The latter point is worth elaborating on even though it goes beyond the hypothesis examined here.

12 Export Councils are semi-government organisations under the authority of the Ministry of Trade and Industry with membership from the business community. The role of councils is further analysed below.

13 IMC is an independent institution founded on the basis of an EU fund but currently operating under the authority of the Ministry of Trade and Industry. The centre specialises in providing technical support to enterprises and has substantial funds for this purpose. 
Figure 6.2 Cabinet community members appointing other members from the business community in key public and semi public institutions

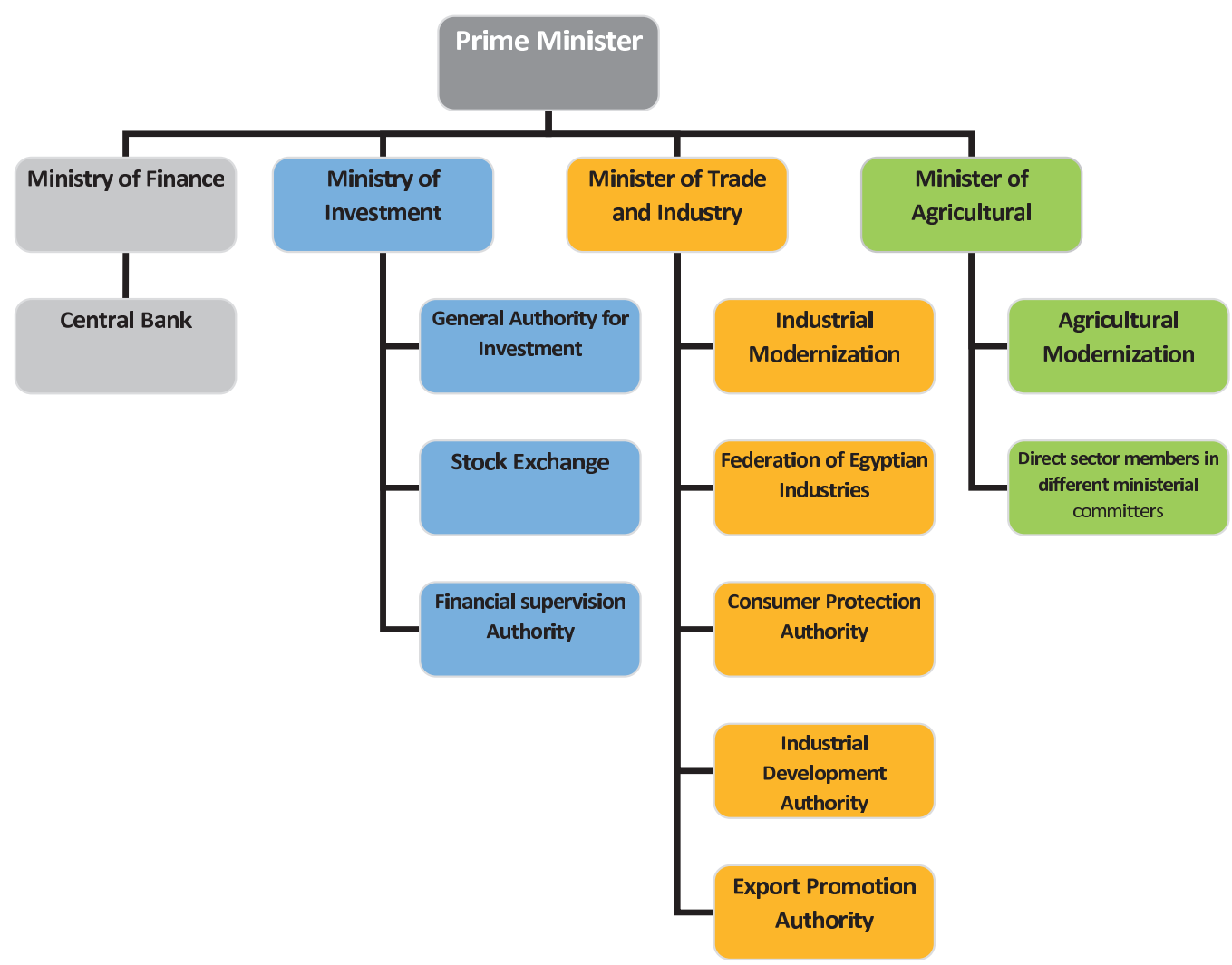

Source: Interviews and secondary sources.

\section{The environment of trust and policymakers' ability to take action}

It has been confirmed through all the interviews that the mere existence of businessmen in the Cabinet, irrespective of their sectoral affiliation, has created a bridge between the two sides. Leaving sectoral specificities aside, policymakers now speak the same language as their former colleagues in the private sector and thus understand their problems. This has helped to build trust between the two sides and generated willingness to take action. The willingness has translated into ability to take action because there is network of policymakers that allows quick decisionmaking, including changes in policies. The network is referred to in Figure 6.3 as the investment circle, the network of quick decision-making. The benefits of the circle lie in quick response of the whole group to the request of one policymaker.

As already argued in Section 2, this resulted in both a change in the perception of the business community by the government from controlling with distrust to promoting with good will. It also resulted in quicker and more coordinated public action, if pushed by any of the members of the group of policymakers. For example, the Minister of Finance has made rapid and unorthodox changes in customs policy in response to requests by the Minister of Trade and Industry. The interviews with business people revealed several other such incidences of coordinated government action. 
Figure 6.3 The Investment Circle - the network of quick decision-making

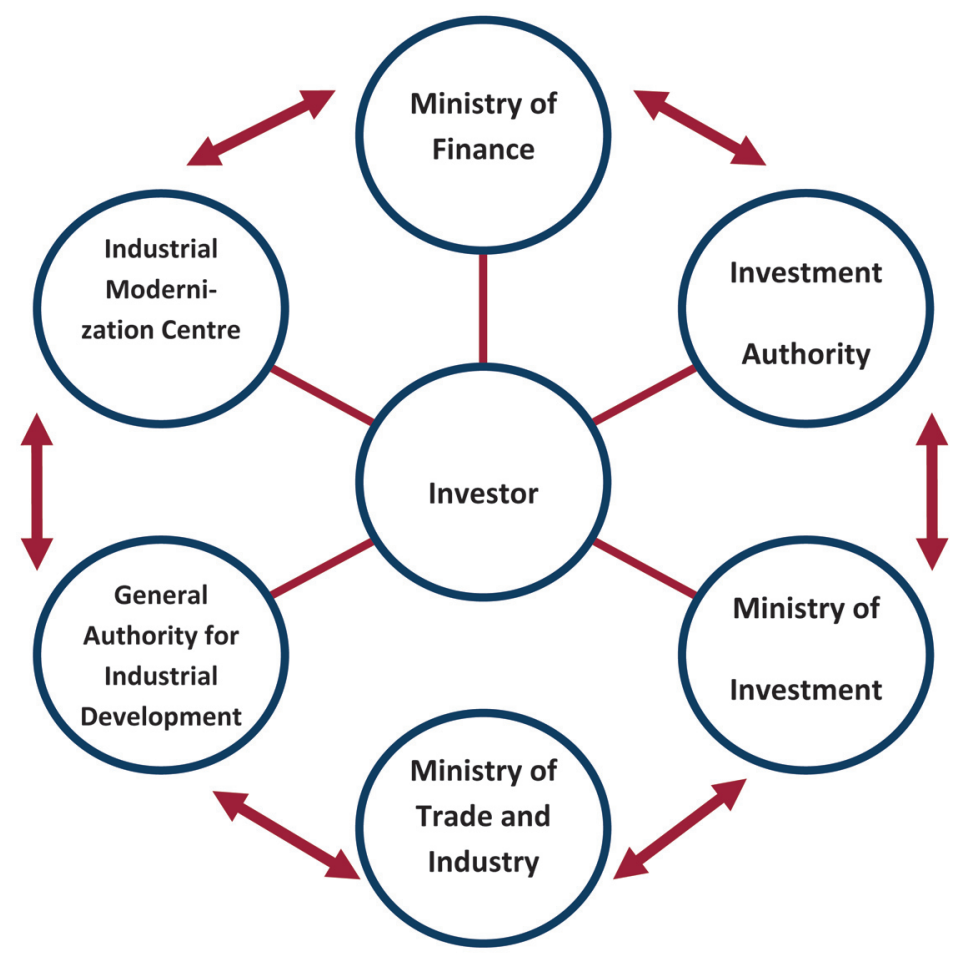

This, however, does not mean that there are no problems. Different players can have different priorities so friction can still emerge, as detected from the interviews. For example, many constraints of relevance to food industries are still pending because they have their roots in agriculture and the Minister of Agriculture is not adopting the required corrective policies. A case in point is the issue of scarcity of reclaimed land. Despite the existence of CIPI in the food sector, agricultural policy changes have been slow because senior officials in the Ministry have a different understanding of the sectoral problems. They see the reclaimed land from an agricultural angle (combining delta and desert land in one package, attempting to minimise the institutional differences between them). And they tend to underestimate the benefits of reclaimed land to food processing. So the common understanding of problems referred to earlier is also necessary within government. All this leads to a conclusion which may seem obvious but was not captured in our original hypotheses: the effectiveness of sectoral CIPI is enhanced if it (the relationship based on common interest, understanding and trust) extends into the 'engine room' of economic policymaking.

Hypothesis A.3: CIPI creation is a short-term process and is fuelled by changes in government figures.

As shown above, the inclusion of business people in the 2004 Cabinet marked a watershed in state-business relations. It appeared to be a sudden change, taking most observers by surprise. This gives the impression that creating CIPI can be a quick process brought about by the state. This conclusion would, however, be misleading. 
From the late 1980s when the private sector started to play a tangible role in the Egyptian economy, haphazard attempts to narrow the gap between the government on one side and the business community on the other were initiated by individuals on each side, at some level or other. It started off with individual private sector members trying to get closer to the government and lobbying for government support to the private sector. The individuals became well known in Egypt and probably derived some personal benefit but there was no impact on investment or any other aspect of their industries.

In the early nineties, some specialised associations were created to support the case of the private sector. Some were product-specific, such as the 'Clothing Exporters Association' which was created in 1993 to seek changes in policy that would enhance the exports of ready-made garments. Others were of a more general nature. The most important of these organisations, however, is the Egyptian Center for Economic Studies, whose members consist of the most prominent members of the business community (some of whom are currently in high positions in government, including the Cabinet). It was established in 1992, specifically to study the issues of concern for private investors, suggest general and sector-specific policy changes and make these suggestions reach the top levels of government circles. The slogan of ECES was 'private initiative for public action'. The role of the centre became stronger over the years as some of its members started to take public positions and the political affiliation of its members became directly linked to the ruling party.

What is agreed upon by our interviewees, and stressed in particular by a prominent member of the Clothing Association, is that during the early days in these organisations, there were private investors on one side and bureaucrats in the government on the other side with very weak bridges between them. The two sides were speaking different languages. Then the government started to hear but did not listen. It took a long time for common understanding of problems to be reached and thus willingness to act to take place. It was a long process.

Efforts for bridging the gap between the private sector and the government were not only initiated from the private sector side but also from some government officers who saw the future benefit of such collaboration, even if it showed little promise of success at the time. An example of such attempts is the establishment of the Commodity Councils back in the early 1990s by the Minister of Internal Trade at the time. The Councils were quasi-public bodies with no decision-making authority. They were a formal set-up designed to allow representatives of private and public producers to discuss the problems affecting their sectors and bring these to the attention of the authorities. The Councils, however, proved to be ineffective as producers were only interested in their individual problems with no sectoral or strategic dimension of any kind. It was not until their transformation into Export Councils under the present Minister of Trade and Industry that they became a more effective consultation mechanism.

The important conclusion at this stage is that creating CIPI is not an overnight process. It takes time. The process is initiated at some level or other when the private sector starts to engage with the government but it could take years to develop and become effective, depending on the country and even the sector. According to all interviewees, 2004 marked a turning point for Egypt. While most 
analysts see a change across the board, later sections of this paper show considerable sectoral differences in terms of public-private relationships, organisational capacity and investment.

Hypothesis A.4: Initial interactions between the key policymakers and investors are informal and then become institutionalised as the alignment of interests becomes clearer.

Speaking a common language and translating private sector requests into a language that the government can understand and accommodate is a big challenge for both sides. CIPI is at the heart of this translation process. What follows are two examples in which this was achieved through a negotiation process which started informally and was later institutionalised.

\section{Example 1: Reclaimed land allocation to big investors}

Reclaimed desert land is in high demand by big agricultural exporters and agroindustrialists in Egypt because, unlike delta land, it is virgin land that satisfies the conditions of traceability required by the EU. It also proved to be suitable for the cultivation of a huge variety of fruits and vegetables.

The government originally adopted a system of land ownership - similar to the existing delta system - limiting individual land ownership to a maximum of 300 feddans. ${ }^{14}$ Individual investors bought the land and started using it for export purposes. The success of desert plantations led to a call for allocating more land to these people to facilitate economies of scale and guarantee supply to customers.

This need could not be satisfied for three reasons:

- The aforementioned limitation on individual land ownership.

- Land prices went sky high because of overall limited supply and government insistence that buying the land was the only option for land accessibility.

- The fact that more than 70 per cent of the reclaimed land was divided into plots of 3-5 feddans and sold at give-away prices to fresh university graduates from various disciplines. It was meant to be a push by the government to reduce unemployment and it was given a lot of political weight.

The private sector sought to change this policy in several ways:

- Removal of restrictions on individual land ownership.

- Provision of other routes to land acquisition beyond purchase, such as longterm leasing and other means adopted in other countries.

- Reaching a legal arrangement whereby investors are allowed to cultivate the huge areas of reclaimed desert land owned by graduates. This last point was

14 In the case of delta land it is 50 feddans (one feddan is 4,200 square metres). 
particularly crucial because the young graduates proved to be unsuccessful in planting the desert exactly because this requires considerable expertise and capital investments. Big investors could afford these but graduates could not.

From an economic point of view, there was a strong case for finding a solution that would provide big investors with access to this land. From a political point of view it was very sensitive because it involved granting rights to the rich and taking them away from the poor. The challenge was to find a solution that would be economically viable, politically acceptable and benefit all sides.

The solution found was to transform the basis of graduate land ownership into shares in a joint stock company so that the land would be planted by the big investors and provide returns to graduates on their stocks. This agreement was reached through informal negotiations behind closed doors between relevant investors and policymakers. Furthermore, a new agricultural modernisation council was created with membership drawn from big investors in agriculture and fruit and vegetables processing and the Minister of Agriculture. The intention was mainly to introduce even more changes in the same area such as removal of all restrictions on individual land ownership. Announcement of the new system took place only after informal - and secret - negotiations had taken place and all alternatives were analysed. This policy change was long overdue and would not have seen the light without CIPI.

\section{Example 2: Cancellation of energy subsidy}

Energy has always been subsidised in Egypt at the consumer level as well as the industrial level. This subsidy has enabled Egypt to attract investment - local as well as foreign - to sectors that are energy-intensive but created a skewed and unhealthy investment pattern. In addition, it caused a huge burden on the government, in particular at times of high international energy prices.

For years, calls have been made for cancellation of the subsidy in a gradual way so as to reach economic energy prices but it has always been opposed by industrialists on the grounds that such a move will destroy their competitive advantage and cause a loss of jobs because enterprises will close down. The topic has been politically very sensitive.

The close informal relations between the Minister of Trade and Industry and the Chairman of the Federation of Industry facilitated the bold move by the Minister to cancel the subsidy. Informal negotiations behind closed doors with key players in the industry within FEI under the supportive umbrella of the Chairman - who is an industrialist belonging to the textile and ready-made garment sector - built support for the call to cancel the subsidy, despite its immediate negative impact on industrialists generally. Involving the industrialists in the negotiations and discussing the issue with them before announcing the cancellation has had an extremely positive impact as hardly any resistance emerged when the actual Ministerial decree was announced. In fact, FEl's Chairman publicly announced FEl's full support for the Minister's decision immediately after its public declaration. All businessmen interviewed stated that the fact that the issue was discussed with them before announcement and via members from their own community made all the difference. 
It is interesting to note finally that the food industries and textiles and clothing industries have been exempted from removal of the subsidy, which is supposed to take place over three years. CIPI is strong in these two sectors. The business benefit is obvious. And the Minister was interested for political reasons - the two sectors are major employers.

\section{The impact of CIPI in old sectors}

Section 6 examined the hypotheses concerned with the emergence/creation of CIPI. This section examines the hypotheses concerned with the impact of CIPI. The impact of central interest is of course that on investment - and correspondingly several hypotheses are concerned with this 'ultimate' impact. We start, however, examining the more immediate impact of CIPI, asking whether it improved the provisions made by the state for the sector(s) in question. More specifically, we ask whether changes in what we call 'proxy governance' have been made. These include, for example: protection of specific property rights; specific policy changes of technical relevance to the sector; reduction of uncertainties in transaction costs; reduction of public duties; provision of support services and infrastructure; adoption of a clear long-term vision for a particular sector.

Hypothesis B.1: CIPI plays its role through providing proxy governance benefits to specific sectors or subsectors.

From 2004 onwards, there was a general improvement in the business environment in Egypt, observable in, for instance, the new tax law, reduction of customs duties, and other policy changes (see Table A2 in the Appendix). All interviewees from the food and furniture sectors - as well as respondents from other sectors - agreed that this improvement was because the business community and policymakers were finally speaking the same language and sharing a common understanding of the obstacles. They understood the need for urgent policy changes for all manufacturing industries. As stressed earlier, the good relationships between certain key policymakers made it possible to act fast. There was not only the willingness but also the ability to take swift action.

These horizontal measures have attracted international attention and are reflected in Egypt's improved 'Doing Business' indicators over the period 2006-08 (www.doingbusiness.org) but they were not prompted by the previous poor position in the international Doing Business rankings (interviews). It is less well known that there were a number of selective interventions focused on specific sectors. They are less well known partly because neither government nor business people like to talk about them - because of the risk of accusations of favouritism and corruption. Our concern was to establish whether these interventions had their roots in CIPI.

The difficulty of researching this question became immediately apparent. Only two key interviewees - one businessman and one policymaker - explicitly admitted that many recent policy changes were geared towards specific sectors on the grounds of CIPI. Despite the absence of consensus, however, the view of the two 
interviewees is supported by other collected evidence through indirect questions and more importantly through documented policy changes. While it needs to be pieced together, there is strong evidence to confirm the hypothesis that CIPI concentrates on some sectors more than others.

Here we concentrate first on the food sector. Table A4 (Appendix) lists the policy changes adopted during 2004-2007 that were specifically aimed to benefit the food sector. The interviews with business leaders from the food sector and policymakers revealed - directly and indirectly - that most of these policy changes were due to the common interest between the two sides. The policymakers were willing to grant these changes because they needed new private investment that would help increase exports and, above all, employment in a labour-intensive industry. And the investors recognised this. (We will see later whether investment did increase.) Interviewees revealed that several new policies and initiatives were triggered or facilitated by CIPI. These included: protection of specific property rights such as land allocation to big investors; policies of a specific technical nature such as giving priority to harmonisation of food standards for 2000 items; having private sector members from the food business community on the board of public institutions; and, the reduction of transaction costs for investors.

In the case of the furniture industry, it was shown earlier that CIPI was weak for the sector as a whole. Indeed, there is little proxy governance for this sector to report. The exception however is again the furniture cluster of Damietta which as established earlier - had developed a strong form of local CIPI which lasted from 2002 to 2004 (the reasons for the subsequent decline in that CIPI are discussed later). During 2002-04, support for the cluster was stepped up significantly. ${ }^{15}$ This support took various forms. According to investors from the region interviewed, the Governor made himself readily available to help solve problems faced by the entrepreneurs. IMC offered significant levels of technical support to upgrade the skills of workers and prepare Damietta producers to present their work at specialised international trade fairs (such as 'Index' in Dubai and 'Salon du Meuble' in Paris). According to the Chairman of the producers' association, effective support was provided by Expo Link (an institution specialising in arranging participation in international fairs) to make sure Damietta producers presented their work as per international standards and as one group with a collective image. ${ }^{16} \mathrm{~A}$ new logo of 'Made in Damietta' was also developed. This is an example of proxy governance of direct benefit to a specific subsector that led to increased external demand for Damietta products, leading in turn to increased investments to meet that demand. Proxy governance to that subsector was taken back, however, under the new Cabinet and new IMC administration indicating the fragility of such proxy governance.

In conclusion, the interviews and actual policy changes confirm that CIPI has led to proxy governance benefits for the food sector. It was difficult, though, to get investors to explicitly admit the role of CIPI in granting these sector-specific

15 Under the leadership of the previous Minister of Industry and previous management of IMC.

16 Previously, individual Damietta exhibitors were scattered all around the fair, thus making no impression at all on visitors. 
benefits. However, indirect questions revealed the key role of CIPI. The interviews also indicated that sector-specific CIPI contributed to changes across the board in traditional elements of the business environment.

Hypothesis B.2: CIPI plays a critical role in the success or failure of attracting investment to specific sectors or subsectors.

This part of the empirical investigation was quite demanding and sensitive. To say that relationships with policymakers have a critical impact on attracting investment seems to suggest corruption and impropriety so all interviewees inevitably denied this was the case. The real situation could therefore only be inferred from what they said, and needed to be cross-checked several times for validity. To unravel the chain of causality, a detailed exploration into the reasons behind success or failure in attracting investment had to be conducted at the level of each investor interviewed in order to ascertain how significant proxy governance facilitated by CIPI had been.

It became clear from the outset that all business interviewees from the food and furniture sectors see 'profit potential' as the number one reason for investing. Upon deeper investigation, however, profit potential is revealed as a complex variable that includes more than just the conventional economic profit (total revenue minus total cost of an enterprise or return on invested capital). It also includes present and future uncertainties about public policy in relation to the sector, such as the perceived importance of the sector to the government, or availability of sector-specific infrastructure and support services, etc.

Nevertheless, all the respondents confirmed that, in the absence of a minimum of 'conventional economic profit', investors would not even consider investing.

Elements of CIPI emerged in the interviews with food investors as soon as questions were raised concerning the constraints facing investors. Each investor was then asked about the actual role of CIPI. Only one investor explicitly stated that he would not have expanded his investments if it were not for CIPI. All the others denied that CIPI and proxy governance would ever be the sole reason behind investment. However, they were then asked whether they would have invested anyway even if favourable policies and bridges of trust with the government had not been established. None answered with an explicit 'no'. This seems to point to the important role played by CIPI in unleashing the full profit potential of the sector through unblocking the way forward and reducing the risks faced by potential investors.

Interviewees' answers to more specific questions on constraints to investment supported this conclusion. CIPI is perceived by all interviewees to have reduced uncertainties in the food sector in an unprecedented way and to have facilitated solutions to chronic problems related to the sector. However, the strength and effectiveness of CIPI varied by subsector, and processed fruits and vegetables (preservation, freezing and dehydration) benefited most from the problem resolution provided by CIPI, for reasons explained later.

The strength of CIPI and its effectiveness varied greatly within the furniture industry. The clearest positive evidence comes from the Damietta furniture cluster, supporting the conclusion that CIPI plays an indispensable role in unblocking problems that were holding the cluster back. Such problems can affect many 
elements that lie beyond the conventional economic profit but that still, to investors, represent an indispensable part of the profit potential of the sector.

All interviewed investors and policymakers confirmed that CIPI was essential for boosting investments in Damietta in the period 2002-04. In the words of one of the respondents, 'between them, the Governor, IMC and the producers' local association solved most problems'. This helped local firms to respond to rising export demand which was the main reason for the investment boom in the region. Interestingly, investment continued after 2004 despite the decreasing relevance of CIPI later on - an issue explored later. The key point to register here is that CIPI was behind unleashing the profit potential beyond conventional economic profit, and encouraged investment in the region.

What then can we say in conclusion about the role of CIPI in accelerating private investment? In the case of the food industry, Figure 2.3 (Section 2 above) shows that investment since 2004 has oscillated but risen substantially (average annual rate of growth in the period 2004-08 exceeded 60 per cent while reaching only 7 per cent in the whole period from 1995-2003). ${ }^{17}$ We have shown here that it would be wrong to attribute the causality of the investment rise to CIPI or to any other individual factor, as the investment decision is quite complex and involves a number of factors. What is confirmed here, however, is that in situations where the profit potential is good but not realised, CIPI is essential for unblocking the way forward in the short and medium term. The furniture industry as a whole did not experience an increase in investment so the hypothesis cannot be examined in the same way. We can however record that, at a broad sectoral level, there was no CIPI - a feature examined in more detail later when we discuss the organisational (in)capacity of the private sector. The key point to retain here is that CIPI was strong in the case of the Damietta furniture cluster and had a substantial positive impact on local private investment.

Hypothesis B.3: CIPl's proxy governance benefits influence investors' decisions to invest more than the general enabling environment does.

It can be inferred from almost all interviews with private investors that they do not give much weight to the investment climate 'at the macro level', at least not in the short and even medium term. While not necessarily made explicit this was a common message. Investors are specifically interested in the business and investment climate 'at the micro level', i.e. at the level of their business and its future. They care about reducing the uncertainties related to their specific investments and seek reassurance that they can reap future benefits from investments made today. If this can be achieved without introducing any improvements in the general investment climate then they will invest, provided that the sector itself is promising.

It is interesting to note that a similar observation is also made by foreign investors. If the investors' individual logistics problems are solved and they have a positive

17 Calculated on the basis of data reflected in Figure 2.3. 
vision of the (sub)sector, they are willing to invest even in the absence of a general enabling environment. This was explicitly stated by the General Manager of the multinational food company interviewed. According to him, the advance announcement of energy prices to be paid by food processors in the next five years was a key factor supporting the company's investment decisions, irrespective of the status of the investment climate at the macro level.

An additional supporting example, though showing discouragement of investment, comes from the auto component sector. One of the key investors in that domain said that foreign investors are discouraged from coming to Egypt because there is still little transparency regarding future customs on cars, and this directly affects the profitability of investment in the auto sector. The issue is not about removing/reducing or increasing customs but rather about simply knowing what they are likely to be. The issue is one of 'reduction of uncertainty', which lies at the heart of an investment decision. ${ }^{18}$ The reduction of uncertainty here is very specific to the auto sector and not to the economy as a whole, which further confirms that foreign investors focus on what is of direct relevance to their specific businesses when making investment decisions.

In the food sector, CIPI has been a facilitator and a catalyst that improves the conditions of the sector. Uncertainties are reduced and willingness to invest increases. Investors see a way of benefiting from the potential of the sector in the short and medium term. Practically speaking, in the eyes of the investors, CIPI seems to obviate the need for a general enabling environment in the short and medium term. More importantly, it creates a level of trust in and credibility for the government - in relation to the specific sector - that might never be reached in a developing country even if all the elements of a typical general enabling environment were there on paper.

However, big national and foreign investors interviewed mentioned that such short- and medium-term proxy governance benefits provided by CIPI would not be enough in the long term. More elements of what is conventionally regarded as an enabling environment are needed. These responses confirm the conventional literature conclusion that an enabling environment is necessary for sustainable development but they do not confirm it as an immediate policy priority.

Hypothesis B.4: CIPI has an inclusive positive impact on the sector only where the private sector has high organisational capacity.

This hypothesis was tested through a close analysis of the organisational capacity of the food and furniture sectors and assessment of the extent to which actions triggered by big players through CIPI arrangements benefit the big players only, extend to benefit the whole sector, or even go beyond to impacting other sectors as well. All interviews and collected evidence revealed that the benefit to the sector as a whole triggered by individual CIPI actions seems to be influenced by

18 The importance of the uncertainty element in the investment climate definition has been emphasised in Moore and Schmitz (2008). 
the organisational capacity of the sector. The more organised the sector as a whole, the more CIPI benefits are likely to extend to the whole sector and not just the small group involved in triggering the action.

As seen in Table A4 in the Appendix, the food sector has enjoyed a lot of positive policy changes triggered by CIPI that also benefit the whole sector. In the case of furniture, on the other hand, other than adding furniture to the export support umbrella of the government and making the sector generally more visible, the sector as a whole has benefited very little. The difference in the organisational capacity in the two sectors seems to explain - at least partially - the different observed impact of CIPI in the two sectors. Similar examples are also found in other sectors. ${ }^{19}$ Table 7.1 presents samples of different effects of 'exclusive' relationships in the food and furniture industries.

\section{Table 7.1 Exclusive relationships and their exclusive/inclusive effects}

\begin{tabular}{|c|c|c|c|}
\hline $\begin{array}{l}\text { Area of } \\
\text { intervention }\end{array}$ & Specific action & $\begin{array}{c}\text { Benefit to } \\
\text { specific groups }\end{array}$ & $\begin{array}{l}\text { Benefit to the } \\
\text { whole sector }\end{array}$ \\
\hline \multicolumn{4}{|c|}{ Food Industry } \\
\hline $\begin{array}{l}\text { Protection of } \\
\text { specific } \\
\text { property rights }\end{array}$ & $\begin{array}{l}\text { Complete change of the system } \\
\text { for reclaimed land allocation from } \\
\text { small slot allocation to fresh } \\
\text { graduates to large slots cultivated } \\
\text { by big investors and guaranteed } \\
\text { return and employment for fresh } \\
\text { graduates }\end{array}$ & Yes & Yes \\
\hline $\begin{array}{l}\text { Specific policy } \\
\text { changes }\end{array}$ & $\begin{array}{l}\text { Harmonisation of local standards } \\
\text { with international standards for } \\
2000 \text { food items }\end{array}$ & Yes & Yes \\
\hline \multicolumn{4}{|c|}{ Furniture Industry } \\
\hline $\begin{array}{l}\text { Reduction of } \\
\text { uncertainties }\end{array}$ & $\begin{array}{l}\text { Creation of an informal ad hoc } \\
\text { mechanism for solving big } \\
\text { company problems one by one }\end{array}$ & Yes & No \\
\hline
\end{tabular}

Whether and how the public-private relationships has exclusive or inclusive effects is thought to depend at least in part on how the private sector is organised. What follows is a brief analysis of the organisational capacity of the food and furniture sectors.

\section{Organisational capacity of the food sector}

A great asset of the food industry is its high level of organisation and leadership. The sector is led by a small group of highly qualified investors with charismatic

19 Specific examples of limited benefit of CIPI because of poor organisation of the sector are also witnessed in the ready-made garment sector and the cement industry. 
personalities and ability to think at the strategic level. The Food Chamber is the only Chamber within the Federation of Egyptian Industries that has a qualified manager and highly paid personnel. It is also the only Chamber that has given a vice chairman position to a female and that has a multinational company on its board. The Chamber is highly active and sets an example to all others. An important feature of the Chamber is that it has almost 100 per cent membership of the entire formal food sector. This makes the Chamber an inclusive organisation even though informal enterprises (of which there are many) are not included. There is also active participation of all food subsectors (through their representatives) in the committee meetings of the Chamber, irrespective of their subsector affiliation (dairy, meat processing etc.) - members are assigned specific roles in addressing the issues of long-term interest for the sector as a whole. The same applies to the Food Industries Export Council. All areas of interest to exporters are addressed through sub-committees of members, and problems of individual exporters are discussed by the Council and, when appropriate, raised with government agencies.

These organisational features, the participatory spirit and the actual practices have been confirmed through both interviews and personal observation. One of the authors has attended several food Chamber and Council meetings and observed both the formal proceedings of meetings and informal discussions; there was no sign of explicit or implicit suspicion by members of 'exclusive' arrangements involving the sector leaders. Similarly, no respondents outside the group of big investors have accused any Chamber or Council members or business leaders of abuse of power or of following narrow self-interest at the expense of the sector's interests overall.

The high level of organisational capacity and participatory practice does not necessarily mean that all subsectors and enterprises will benefit equally and at the same time. It does, however, mean that (1) issues of common interest to all, such as a unified food law and one food authority, receive proper attention and are pushed forward; and (2) all subsectors have the chance to voice their aims and concerns and be heard. Of course, some voices are louder than others and those representing the sector vis-à-vis the policymakers are influenced by their own subsectoral experience.

\section{Organisational capacity of the furniture sector}

The situation in the furniture sector is very different. The Furniture Chamber is poorly organised and comprises less than 10 per cent of producers. Both the Furniture Chamber and the Furniture Export Council are dominated by a group of 15 enterprises who have little concern for the rest of the sector. The leaders of this group have close connections to the policymakers and have been able to obtain benefits for themselves and the small group of enterprises that dominate the Chamber and Council. These benefits include preferential treatment from government bureaucracy and substantial funds to obtain several rounds of technical support services for their factories. These funds came from the IMC - an institution which is funded by the EU and the Ministry of Industry and Trade - at a time when one of the leaders of the furniture industry was chairman of the IMC (2004-07). 
Information on exclusive practices is hard to obtain but a clear picture emerged from talking to several furniture manufacturers, an 'excluded' key player, two policymakers, staff of the IMC and project officers of the EU interacting with the Furniture Export Council. They confirm the exclusivity of the benefits to the small group of big investors. The vast majority of the other producers are small and not heard by policymakers. Benefits available in principle to all through the IMC and other institutions are not even known to the small investors.

The Damietta group was amongst those businesses excluded from the (supposedly national Chamber and Council), but this group had formed its own local organisation in 2003; the 'Association for Upgrading the Furniture Sector of Damietta' was set up to bring together and mobilise local enterprises and represent their interests with all institutions. This association was important to the revival of the region despite problems within the local business community and the bias against it by the national leaders of the furniture sector.

To conclude, empirical research in both the food and furniture sectors has confirmed the validity of this hypothesis. While CIPI is by definition an exclusive arrangement, its impact on the sector is not necessarily exclusive as well. It can be inclusive where the organisational capacity of the sector is high. The food sector supports this - particularly when compared with the furniture sector. However, the comparison also highlights the need to specify whose organisational capacity is being considered. In a way, the exclusive 'club' of big furniture-makers was highly organised to pursue their own narrow aims - but it had little organisational capacity to represent and promote the sector as a whole. Perhaps it is better to examine two features that do not necessarily go together - organisational capacity and legitimacy (which comes from being elected by a broad-based organisation). Some sectors have neither, for example the Egyptian granite and marble industry. Such organisational features of the private sector are of great importance to policymakers in the public sector. Relationship-based governance is very difficult when the private sector has no organisational capacity and legitimate leaders.

Hypothesis B.5: CIPI-induced investment reaches a tipping point which is a specific point in time when investment starts responding in a significant way (taking off).

The hypothesis has two components: (1) there is a substantial increase in investment - at a specific point in time, the 'tipping point'; and, (2) this investment tipping point is caused by CIPI. The first component was empirically tested in relation to the food industries on the basis of unpublished (privileged) secondary data from primary collection sources (the General Authority for Investment, the Food Export Council, and the General Organization for Exports and Imports Control), in addition to detailed analysis of (6-digit HS code) ${ }^{20}$ trade map export data. The conclusions of the analysis have been further cross-checked in interviews with investors in the food industries.

20 Export data is typically presented in product group codes referred to as HS codes. The more digits, the more specific the product is (for example a very specific type of cheese within the cheese group). 
Figure 7.1 shows the potential tipping point for the food industry. ${ }^{21} 2004$ is the year when the changes started taking place. In the subsector of processed fruits and vegetables (not shown separately), the change was particularly pronounced, reflecting both its attraction as a subsector for investment, and its leadership of food industries as a whole - more than 70 per cent of all food sector investment in most recent years.

\section{Figure 7.1 Annual real investment in food industries, 1995-2008* (in million Egyptian pounds)}

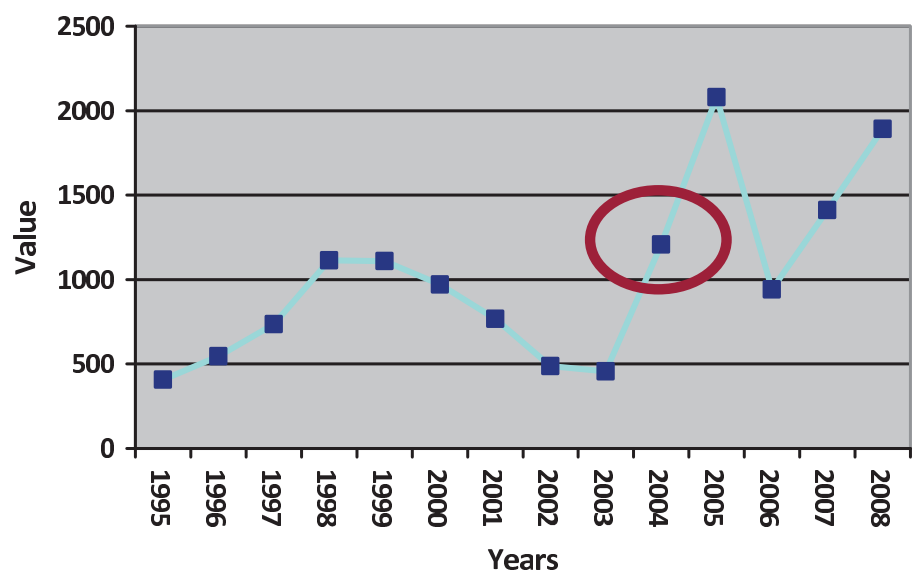

Total Real Investment

*Until the end of November 2008

Source: GAFI - Nominal investment data deflated by authors

In addition to the impressive positive change in investment trend observed in the period (2004-08) - 43 per cent of all investments in the sector between 1970 and 2006 took place between 2004 and 2006 (Abdel-Latif 2007) - large increases in food exports from 2004 to date have also been observed, as can be seen in Figure 7.2. Some food enterprises interviewed stated that they increased their investments by 300 and 400 per cent in order to meet increasing demands for exports. More importantly, the food industries value chain has been strengthened by a stronger retail chain, food standards conforming to international standards, a national food authority and unified food law. In other words, the institutional infrastructure is almost complete, indicating that the sector can take off on its own. All the above supports the existence of a tipping point around 2004. However, it is important to note that not enough time has elapsed to confirm a complete change in trend.

Is the upward trend in investment due to CIPI? Stating an immediate causal connection would be foolish. The investment increase in 2004 is too close to the Cabinet changes of 2004, in the wake of which CIPI emerged in the food industry. As argued in the discussion of Hypothesis B2, CIPI cannot be considered a cause

21 According to interviews, 2006 has been associated with mergers and acquisitions of enterprises that are not captured by basic statistics on investment from GAFI. 
Figure 7.2 Trend of Egyptian food industries exports, 2002-2008

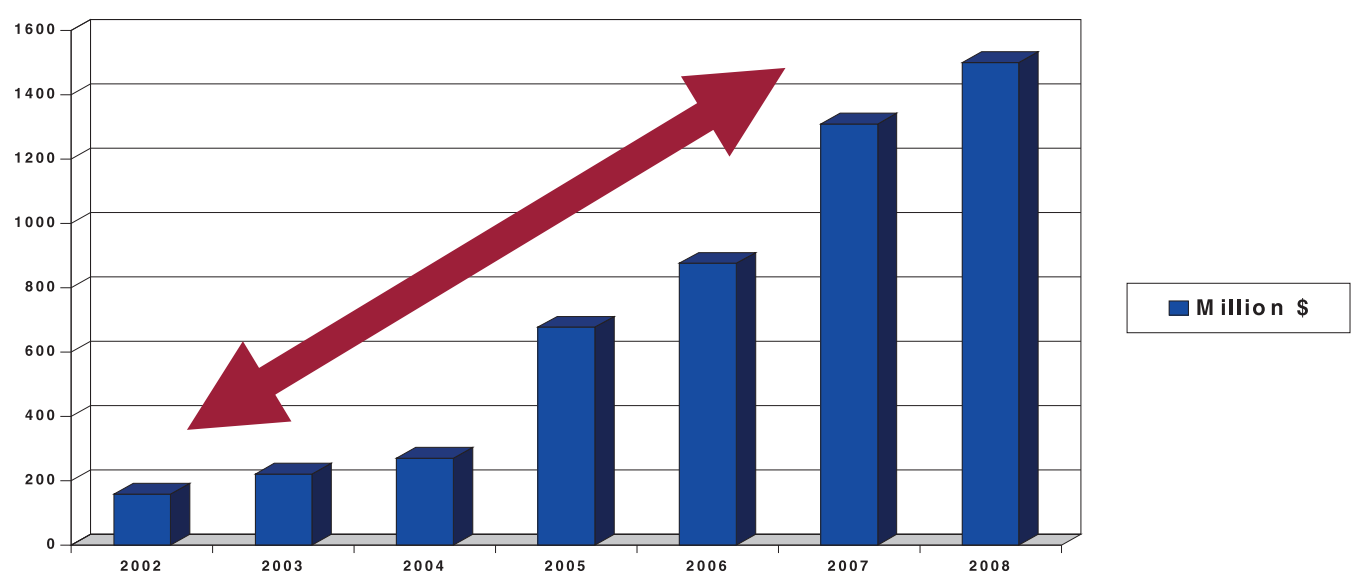

Source: Calculated by authors on the basis of export data provided by the General Organization for Exports and Imports Control (GOEIC) and the Food Export Council

but it seems to have been a facilitator and catalyst. While interviews confirmed the link between willingness to invest and CIPI, the tipping point itself in the case of the food industries seems to have its roots in a previous year. In fact, it is likely that the change started in 2003, triggered by increases in international demand and Egypt's increased food exports. Here, the driving force for the investment was international demand, but the ability to respond to increases in demand over several years and remove supply constraints was strengthened by CIPI. In this sense, CIPI seems to have played a role.

Perhaps it is useful to add a word of caution concerning the data on which the analysis is based. According to GAFI (the source for the investment data), the data capture the investments registered with GAFI only and do not include investments registered at the governorate level. The figures are therefore an underestimate and it is not clear whether the relative importance of the two sources changes over time. This makes it difficult to be precise in the tipping point analysis.

In conclusion, no definite conclusion confirming or denying the tipping point hypothesis can be reached on the basis of the available quantitative and qualitative data. It is however clear that investment increased due to rising international demand for food products and that CIPI helped to remove the supply constraints.

Hypothesis B.6: The tipping point is followed by a knock-on effect, whereby local investment in the sectors concerned attracts FDI and stimulates investments in other sectors.

The first component of the hypothesis was examined - for the food industry - on the basis of interviewees' statements and statistical analysis of the available unpublished (privileged) data collected from primary sources. 
Interviews revealed that large Arab and other foreign investments in the form of new investments and mergers and acquisitions have taken place in the food industries from 2004 on. A multinational investor interviewed emphasised that increased confidence of local investors actually triggered FDI. His exact words were 'no one would invest in a sector or country where private local investment is not willing to go'. Of course, foreign investors make their own assessment and stated that, in the food sector, Egypt has the following advantages compared with other countries in the Middle East.

- Despite initial investment advantages in other countries, their operational costs are high - for example in the case of Dubai (employment of expats) or Saudi Arabia (high cost of electricity).

- Existing food processing in other Arab countries is not as developed as in Egypt.

- The land is good: the fertile Nile Delta plus the huge potential of reclaimed desert land.

- Only Egypt has the full value chain for a sustainable food processing industry - particularly traceability conditions and the backward linkages to agriculture.

Figure 7.3 shows the yearly investment in food industries in the period 1995-2008,22 disaggregated by Egyptian, Arab and foreign (non-Arab) investments. It only captures the new investments and not the mergers and acquisitions, even if involving enlargement of facilities.

Figure 7.3 Annual real investment in food industries, 1995-2008* (in million Egyptian pounds)
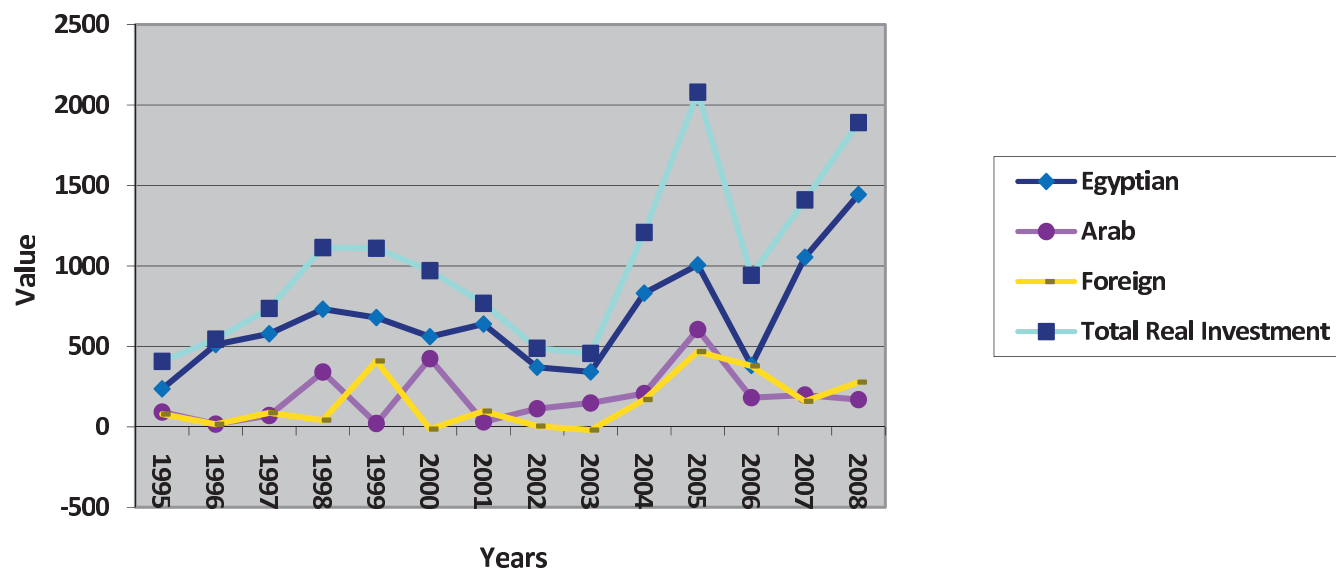

* Until the end of November 2008

Source: GAFI - Nominal investment data deflated by authors

22 The detailed distribution for investment in processed fruits and vegetables could not be obtained by researchers. 
Four observations can be made:

- the trend in Arab and Foreign investments is similar to that of Egyptian investment;

- the years 2004 and 2005 show higher investments than all other years, indicating something special about those years;

- the investment data do not include the mergers and acquisitions, which represent an important component of investments in the food industries, according to interviewees;

- even if interviewees' statements support the knock-on effects, the data do not allow a firm conclusion to be drawn on the sequence in which national and foreign investment occurred. In conclusion, examining the hypothesised knock-on effect from national to foreign investments needs more complete investment data, a longer time-frame and more interviews with foreign and Arab investors.

It is even more difficult to come to a conclusion on the sectoral knock-on effect from the food to other sectors. The theoretical argument in the conceptual framework suggests that a knock-on occurs because the bottlenecks removed by CIPI in one sector would also help other sectors and thus stimulate investments in these sectors. The empirical study could not reach a specific conclusion on this issue. While increases in investments occurred in a number of other sectors from 2004 onwards - as previously seen in Figure 2.3 - it is difficult to isolate the impact that CIPI in the food industry had on these investments.

As argued in Section 2 concerned with the national context, the new government of 2004 adopted a number of policy reforms in the areas of taxes and customs and made the business community feel less apprehensive about government. This has had a positive impact on overall investment levels. To what extent are these increases side effects of CIPI activity in individual sectors? To what extent are they a response to new horizontal policies? And to what extent are they the outcome of overall environment changes? These questions are very difficult to answer because isolation of each factor is impossible. However, we know that statebusiness interactions were particularly effective in the food sector and it is therefore likely that these interactions influenced not only the vertical governance issues (relevant to the food sector) but also the more horizontal ones.

Hypothesis B.7: Disturbance of CIPI through conflict of interest between private investors and government will not affect investment if it has already taken off.

This hypothesis concerns the final phase of the CIPI process. As set out in the conceptual framework (Section 3), beyond the tipping point CIPI can either be maintained (scenario A) or be disturbed and collapse (scenario B). In the latter case, the question is what happens to investment once the alignment of interest between policymakers and investors is disturbed.

Initially, scenario A of continuing collaboration between policymakers and private investors seemed to prevail because the positive surge in investment and exports 
strengthened the political position of the policymaker most directly concerned (the Minister of Trade and Industry). However, from late 2007 to early 2008, signs of conflict began to emerge as retail food prices were soaring and complaints were raised in the People's Assembly on the impact on the poor. The Prime Minister and Minister of Trade and Industry were being publicly questioned on the issue in the People's Assembly as well by public and private newspapers and active consumer protection groups. Such political pressure can force politicians and policymakers to distance themselves from the industrialists but there was not sufficient time to observe whether this would occur. In any case, circumstances changed again. The high food prices that had caused the tension began to fall in late 2008 and the global financial crisis and economic downturn began to dominate government-business discussions. Tracing public-private interaction in the food sector and tracing the implications for investment are very difficult in these circumstances. The elapse of more time will not necessarily provide a clear conclusion because so many things changed at the same time.

The furniture sector as a whole never reached the tipping point and so the hypothesis concerning investment in the final phase does not apply. However, we can examine the hypothesis for the case of Damietta. As pointed out earlier, this furniture cluster was propelled forward by CIPI and experienced a substantial increase in investment over 2003-04. In subsequent years, CIPI weakened and experienced a partial breakdown due to the change of Minister of Industry in 2004 and the change of management and strategic direction of IMC in 2005. The relationships of mutual interest that existed between local entrepreneurs, the previous leadership of IMC and the old Minister were eventually discontinued.

As a result, Damietta as a cluster no longer received the same technical support as before. The impact of such exclusion would ideally be analysed through quantitative data on new investments in and exports by Damietta enterprises. These data were impossible to obtain because there were no separate statistics for Damietta and exporters were not providing export data. However, news of international fair participation by Damietta producers and interviews with players on both sides (government and business) suggest that the region continues to excel in exports and increase investments. This seems to indicate that the weakening of CIPI did not have a negative impact on the sector, although it might have slowed it down a bit. This seems to indicate that when the potential profit in the subsector is high, the proxy governance granted through CIPI is only needed temporarily to take the cluster to a new level.

This case highlights that CIPI is fragile and that the advantages derived from it can be easily taken away. Nevertheless, while it works, it can be effective in raising investment to a higher level. Once achieved, CIPI does not necessarily have to continue. A new economic and political dynamic takes over. 


\section{Part III Findings from new sectors}

\section{Sectoral context: communication and information technology}

Although the communication and IT sectors are related and operating within the same institutional framework, it is important to distinguish between the two when discussing their nature, structure, stages of growth and main players. The brief overview that follows is based on interviews and sectoral reports. ${ }^{23}$

\subsection{The communication sector}

The communication sector consists of two subsectors: communication infrastructure and diversified applications for mobile and fixed line systems, such as ringtones, banking services, advertisements and prepaid phone cards among others. The composition of the two subsectors is very different, giving the communication industry a bipolar structure. At one end, there is a small number of large enterprises that have made huge investments in the mobile, fixed line and internet networks and operate in oligopolistic or monopolistic markets. At the other end, there is a large number of small enterprises that have invested in internet cafes and various applications on mobile and fixed line systems. Table A5 in the Appendix gives a more detailed picture of how the communication sector is composed. This report concentrates on the large enterprises that build the communications infrastructure and networks. Without their big investments, few other communications or IT enterprises can progress.

Fixed line, mobile and internet companies can only operate through licences granted by the government. There are currently three mobile companies (Mobinil, Vodafone and Etisalat) and one fixed line company (Telecom Egypt - 80 per cent public). In addition, there are 12 main internet companies, also requiring government licences. Such licences are acquired through a competitive tendering process. Figure A1 in the Appendix gives an overview of all licences. In our later analysis, we will pay particular attention to the negotiation of mobile licences because the private investments required are huge, and understanding state-business relationships is critical for understanding how these investments were secured.

The communication sector went through four phases of development:

- phase one (1985 to 1995) marking the beginnings of efforts by the government to introduce CIT and involve business people in the process;

- phase two (1995 to 1999) when internet services were privatised and the two mobile companies, Mobinil and Vodafone, started their investments in Egypt;

23 The sectoral reports include: BSAC (2001); ESCWA (2007); MCIT (1999-2007); MCIT (2005a); MCIT (2005b); ITIDA (2006); ITIDA (2007). 
- phase three (1999 to 2004) when most of the institutional framework of CIT was put in place following the establishment of the new Ministry of Communications and Information Technology (MCIT) and the appointment of Dr Ahmed Nazif as Minister for CIT; and, finally,

- phase four (2004 to date) witnessing a change of Minister of CIT, the introduction of a third mobile operator and attempts to tender for a second fixed line. A more detailed picture of the main changes and of the main private and public players of relevance to each phase is presented in Table A6 in the Appendix.

\subsection{The information technology (IT) sector}

The IT sector has four subdivisions: hardware, IT services, software development and IT-enabled services. The hardware subdivision of the IT sector consists of all equipment related to CIT - computers, printers, phone sets and other equipment. IT services involve all kinds of systems integration (hardware and software services tailored to the needs of a specific project or specific applications). A smaller but important subsector is software development which is considered to be the heart of the IT sector. IT-enabled services include call centres and the outsourcing of business process interpretation. This area is receiving a lot of attention from both investors and the government and seems to be expanding fast. It does not require huge investments and at the same time addresses two of the country's main problems - unemployment and low export revenues. A more detailed structure of the IT sector is presented in Table A7 in the Appendix.

IT companies do not require licensed permission as in the case of communication activities. The main critical component in IT is software programming which relies primarily on human intellectual efforts and skills. The nature and structure of the sector is such that the diversity of products is very high. In Egypt, it is also almost completely demand-driven, with the government being the biggest customer (representing 50 to 60 per cent of the market). This makes the government system for ordering IT services, whether through direct orders or tendering procedures, of key relevance to IT investment decisions.

The IT sector went through the same time phases as the communication sector but progressed more slowly. From early 1985 to 1999 , there were scattered investments in the IT sector, mostly in hardware and to a limited extent in software. The years 1998 and 1999 drew more attention to the IT sector with the creation of MCIT but there were as yet no incentives for investment in the sector. It was from 1999 onwards that policies - such as free internet for all, a PC for every Egyptian on subsidised and easy payment terms, no tariffs on imported CIT equipment, etc. - were adopted by Minister Ahmad Nazif to stimulate the IT sector. The Information Technology Industry Development Agency (ITIDA), the institution to regulate the IT sector and support its development, was conceived in 2004. Other initiatives such as e-government made the government an active buyer of IT services, thus encouraging IT investments to meet this demand. Table A8 in the Appendix shows the main changes and main players in more detail.

The impediments to growth faced by the IT sectors are: 
- limited scope for and scale of subcontracting IT jobs from big to small companies because contracts are practically non-enforceable;

- few effective norms, procedures or quality standards for IT operations; 24

- the pool of well-trained human resources is limited in all disciplines (programming, network engineering, technical consultancy and other technical services);

- reliance on family enterprise makes it difficult to capture large contracts offshored by US or European customers.

The institutional framework within which CIT operates involves communication law \#10 of 2003 and the rules of three institutions - the Ministry of Communications and Information Technology (MCIT), the National Telecommunications Regulatory Authority (NTRA), and the Information Technology Industry Development Agency (ITIDA). The Minister of MCIT is the Chairman of the Board of both NTRA and ITIDA; he also chairs the Board of Telecom Egypt, the main provider of fixed lines. Tables A9 and A10 in the Appendix show the institutional framework in more detail and provide a critique of the communication law.

\section{Emergence of CIPI in new sectors}

This section is driven by the same hypotheses and follows the same procedure as those adopted in the corresponding section for the old sectors. In presenting the evidence from the new sectors, it is important to distinguish between the different phases mentioned in Section 8 (and Tables A6 and A8 in the Appendix).

Hypothesis A.1: State-business relations become effective only when there is a common interest in a sector's growth and common understanding of its problems.

Examining the case of the communication and information technology sectors is not just an additional case study. There is a qualitative difference in that these are new industries. Their economic viability had yet to be explored and, equally, the viability of political support needed to be tested. So examining this hypothesis is particularly challenging. Let us start with the question of whether there was a common interest.

As stated earlier, mutual interest means that the investor perceives that the policymaker has a stake in the investment, in the sense that making it happen and succeed would enhance the policymaker's reputation, career or power. In turn, the policymaker perceives that the investor needs his or her assurance that complementary action by the state (legislation, infrastructure, services) will take place. Both sides would lose if the investment did not occur.

24 The Software Engineering Competence Centre, established in 2001, has as one of its functions to set and verify IT standards but it has had only very limited effect - according to our respondents. 
The policymakers connected to the CIT industries were not the usual career politicians or bureaucrats. As will be documented later, they came from a small pool of specialised Egyptian professionals who believed that the new technologies had a chance in their ancient country and saw a chance of carving out a career through supporting the new industries. They could not and did not deal with all subsectors at once and initially gave most attention to the build-up of a communications infrastructure for which they particularly needed the involvement of companies who could make big investments. They could also see that, provided these companies were allowed to make good profits, the government would be able to extract duties which could then be used to support other subsectors. The deals that were made with these companies will be detailed later. The point to be made here is that the interests of the policymakers varied between subsectors, depending on their potential at particular stages communications first, IT later. Policymakers' interests also varied between enterprises of different size, notably in IT. The policymakers were particularly keen to attract multinational companies to Egypt, notably Microsoft, thinking that this would lend their work prestige and credibility. Efforts to support small and medium-sized Egyptian enterprises came later and were weaker.

The big communications and IT companies were willing to make their substantial investment because they saw the gains that could be reaped from being the first players in new markets. Realising this potential required certain deals with the government, such as keeping further competitors out of the Egyptian mobile phone market for $\mathrm{X}$ years, or preferential treatment in tenders for government IT contracts. The deal-makers on the government side were judged to be credible by the investors. It was not difficult for them to see that the policymakers' careers would depend on the deals being put into practice.

What comes out of the interview material is a picture of a fairly sophisticated industrial policy focused on establishing a new communications and IT industry. This is surprising in a country with a poor record in industrial development and industrial policy. There were two key ingredients to this. The first ingredient has already been mentioned - the mutual interest of policymakers and investors. The second ingredient was the common understanding of the problems to be solved. The interviewees from the private sector stressed that the policymakers they were dealing with had a good understanding of the technical and economic obstacles to be overcome. The examination of the next hypothesis will detail where this expertise came from.

In conclusion, the first hypothesis is confirmed. Common interest between policymakers and investors and common understanding of the problems to be solved were indeed critical for establishing the new industries. The evidence will emerge more fully in the course of the next sections. These sections will also show that this growth coalition was not free from conflict, that there were conflicts within and between both sides and that success in terms of investment and growth was uneven among the subsectors and types of enterprise. Exploring these differences will help to bring some analytical clarity to what has worked where and why.

Hypothesis A.2: Common interest between policymakers and key investors (CIPI) has its roots in a previous informal relationship at the educational, social or business levels (separately or combined). 
By informal linkages, we mean the relationships between the policymakers and members of the business community before the policymakers came to office. They range from personal relations, such as attending the same school or being from the same family or clan, to professional relations such as having worked in the same field, or having been business associates, or affiliated to the same party or association. Figures 9.1 and 9.2 provide both a general and a specific look at such informal relations in the case of CIT.

First, it is observed that these relations are more professional in nature than in the case of the traditional sectors where relations were of a more social nature.

Several of the 'architects' of the CIT industry came from the Faculty of Engineering of the University of Cairo. More critical, however, was a common work experience in a single public institution - the Information and Decision Support Centre (IDSC). Established in 1985 to support decision-making in the Cabinet with up-to-date information, IDSC was the first institution to introduce Egypt to the information era and also operate with private-style management and pay high salaries to its staff. Some of those IDSC professionals later became the key players in CIT, whether on the investor or policymaker sides. Other important players in CIT had been suppliers of equipment and services to IDSC and later occupied important positions in government. All this is shown in Figure 9.1 which tries to capture where the key policymakers came from.

Figure 9.1 Pathways of key policymakers in CIT

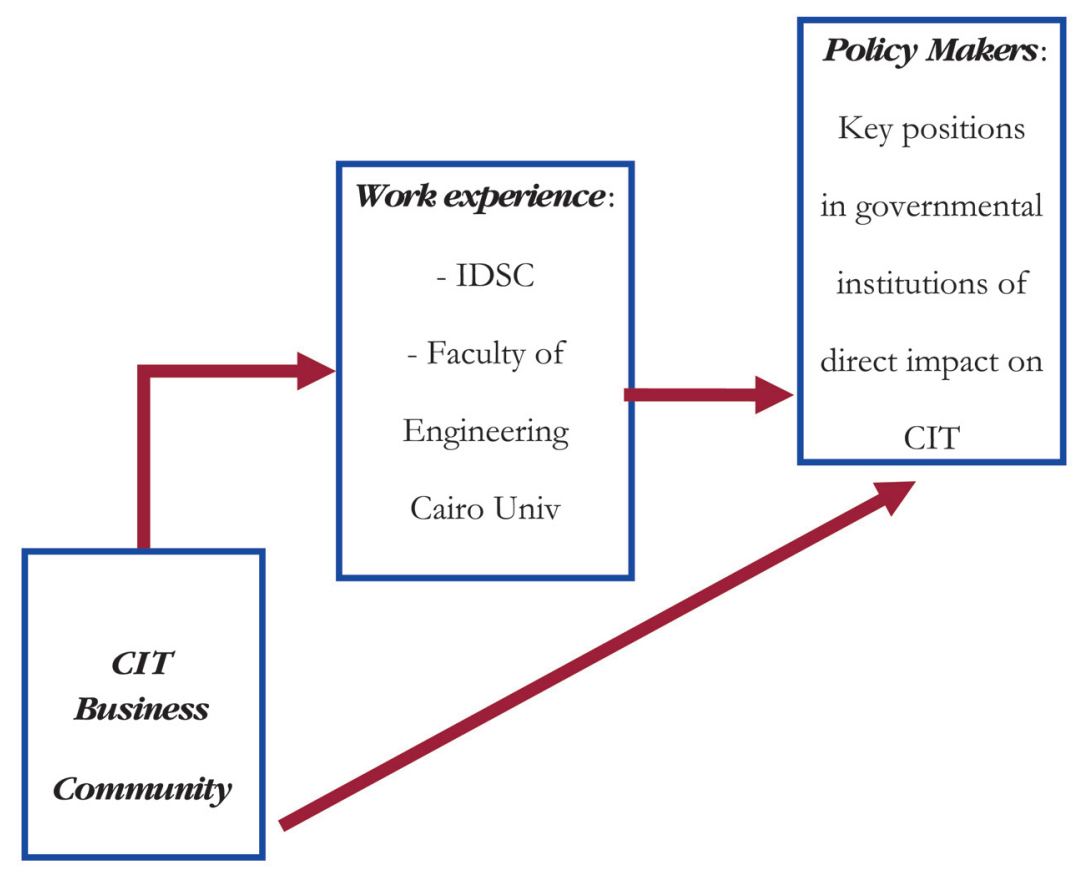

The main overall point, however, is that there were strong informal relationships between policymakers and investors, that they knew each other from common professional experience and that in many cases they had been connected to the IDSC. Figure 9.2 shows the relevance of this connection for major decisionmakers in the public and private sectors. This common history is central for understanding the interconnectivity of the CIT network, encompassing key 
policymakers and industrialists. All interviewees on the public and private sides acknowledged that this informal link facilitated CIPI and was critical for directing the attention of a generally conservative government to a new sector.

There is further scattered evidence on strong informal relations between investors and policymakers. In the early phases (one and two - from the early 1980s to 1999), two major industrialists, Naguib Sawirass and Mohamed Nosseir, were major investors in CIT and had strong connections with the Prime Minister at the time and with other government people. The two mobile phone consortia (the Mobinil group and the Vodafone group) were led by the same two Egyptian industrialists. Several of our prime sources mentioned the importance of their involvement for the substantial investment in the communications industry in the early phases; however, our respondents were unwilling to elaborate on their relationships with politicians and policymakers, presumably because these had a murky history.

Even multinational companies built informal relations with government officials that contributed to investment, such as in the case of Microsoft. Several interviewees said that advantages given to Microsoft by the government were due to the strong relationship between the company's representative and the first Egyptian Minister of CIT, Ahmad Nazif. Microsoft was the first to answer his call for moving to the Smart Village (at the time when there was nothing but desert land). This move then attracted other multinational and big Egyptian companies, creating what is now an impressive cluster of CIT companies in the desert but near Cairo. Microsoft also arranged for a legendary visit by Bill Gates to the same Smart Village. In return, Nazif signed an agreement with Microsoft that was favourable to the company - as further analysed below.

To conclude, there is strong evidence in support of the hypothesis, more so than in the traditional sectors. Despite the fact that both communication and IT are new sectors, previous informal relations exist not only between policymakers and investors, but also among policymakers themselves. Some of those investors were invited by the top policymakers to occupy - for a finite period - important positions in government institutions. In contrast to the traditional industries, previous informal relations are more professional in CIT than social, rooted in previous common work experience.

Combining the results of examining the first and second hypotheses, we can conclude that there was a public-private alliance with strong informal roots, common interests and a common understanding of the challenges to be addressed. These attributes, however, were not sufficient to instigate action. Recall the circumstances: in the 1990s, Egypt's traditional industries were struggling to compete and the prospect of establishing entirely new 'high tech' industries seemed audacious, if not absurd, at the time. The ability to take action arose from the fact that the alliance extended into the centre of power -the presidency of the Republic. Both the President and his son, chairman of the influential policy committee of the National Party, supported the new initiatives. We could not interview them to ascertain whether this support came from a concern to improve security (for which $\mathrm{CIT}$ is critical) or to promote industrial development. It was probably both.

We can however conclude that the support was sustained over time, seen most clearly by the fact that the first Minister of CIT, Ahmed Nazif, eventually became 
Figure 9.2 Relationships between key policymakers and business leaders in CIT

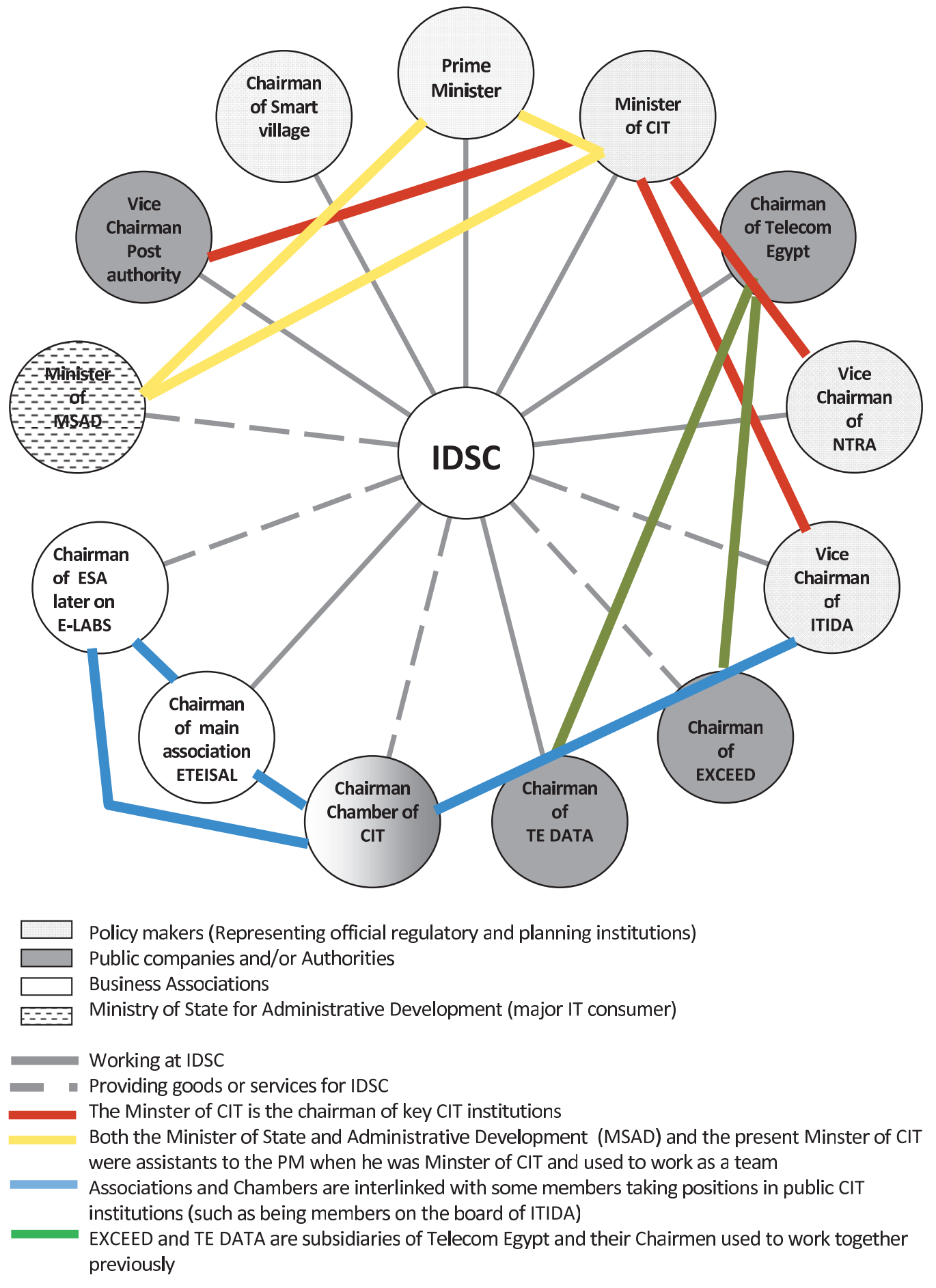

Prime Minister in 2004. This made a difference, particularly in terms of completing the institutional infrastructure in the IT sector. The need for an institution responsible for developing the IT sector and upgrading the capabilities of IT enterprises was recognised by policymakers and called for by investors early on, but the decision to establish ITIDA was only taken in 2004 and the institution became operational 
in 2007. This action was long overdue, taken only when Nazif became Prime Minister. He could not pull it off earlier because the Minister of Finance and other Cabinet colleagues remained unconvinced of the case for promoting an IT industry. Only when Nazif became Prime Minister and created an alliance among several ministers was he able to take action. Figure 9.3 shows the investment-friendly circle of decision-makers relevant to CIT - similar to that supporting the food industry.

Figure 9.3 The network of key public decision-makers in CIT

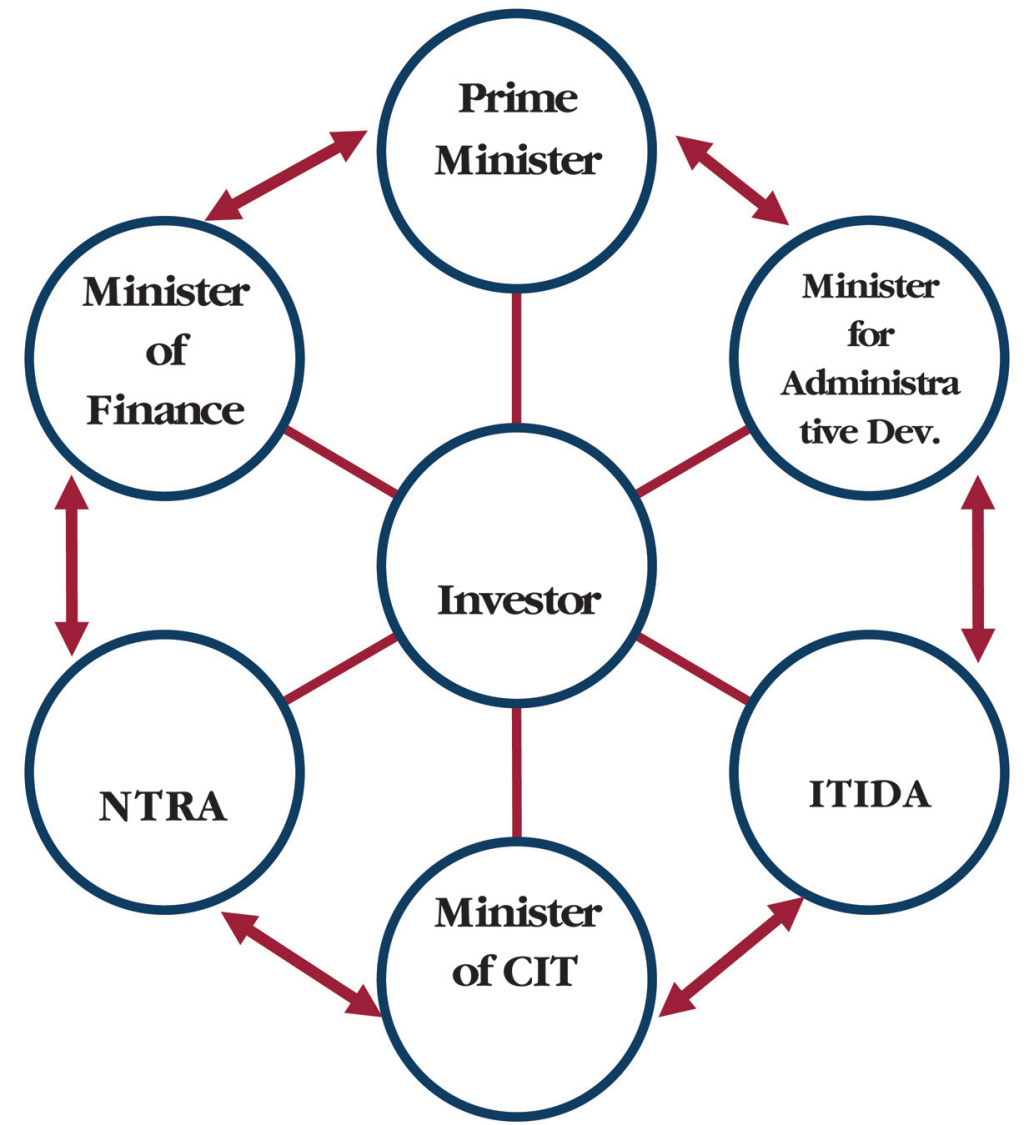

The existence of this network does not mean that it always works smoothly. Frictions arose between policymakers due to different priorities and rivalries. For example, the Minister for Administrative Development and the Vice Minister of Communication both wanted to be seen as 'fathers' of the e-government project and thus slowed it down even though it was central to the build-up of Egypt's IT industry. Relationships can also become too close and closed. The Minister of CIT is chairman of three organisations - Telecom Egypt, NTRA (regulating body) and ITIDA (promotion body). While this brought advantages to some stages of the decision-making processes, one of the interviewed policymakers felt that this arrangement did not allow sufficient space for new thinking and talents. Some respondents from the IT sector felt that re-energising was needed. While advances in the communications industry had been rapid, the IT sector had progressed only slowly. It is difficult for us to judge whether the lower importance given to the IT sector was due to its lower profit potential or the greater difficulty of dealing with a fragmented sector. 
Hypothesis A.3: CIPI creation is a short-term process and triggered by changes in government appointments.

When asked about the origin of the CIT sectors, all respondents singled out the big contribution made by Ahmad Nazif as the first Minister of CIT. It was his initiative to (a) create a strong government team with the required knowledge and experience and (b) work with the private sector in developing infrastructure, legislation and capacity. It is therefore tempting to conclude that the creation of CIPI was a quick process.

A more detailed examination reveals that the process took over ten years. While Nazif's appointment was a milestone in the formation of a sectoral CIPI, the process started in 1985 with the establishment of IDSC. Its managing director at the time was an IT professional from the private sector. He promoted the concept of CIT and planted the idea of establishing a CIT industry in the country. Since he was directly affiliated with the Cabinet and the Prime Minister, he was in a position to do so.

Phase two (1995 to 1999) witnessed intensive efforts to initiate the institutional reform favouring CIT. A White Paper suggesting steps to initiate Egypt's journey down the CIT track was prepared with a number of private business people who also led the Egyptian Software Association. IDSC was involved in this process as well. The White Paper asked for a separate committee within the old Ministry of Transportation and Communication to be responsible for CIT - on the grounds that the new CIT required more professional expertise and deeper business involvement than available in the old Ministry. It was on the basis of this recommendation and intensive lobbying by private sector players reaching up to the President of the Republic himself and his son, that a fully fledged separate Ministry of CIT was established. So there was a history of involving Egypt's top business people (who had gained CIT experience locally or abroad) and obtaining political support from the highest level. The 1998 conference to present the strategy for developing CIT was chaired by the President personally.

To conclude, as in the case of the traditional sectors, this hypothesis has only been partially confirmed. CIPI is fuelled by changes in government figures but is not necessarily a short-term process. In the case of the new sector(s), the appointment of a new Minister - who had a strategy of working with the business leaders - was a milestone, but it was preceded by ten years of exploration and building a state-business alliance focused on CIT.

Hypothesis A.4: Initial interactions between key policymakers and investors are informal and then become institutionalised as the alignment of interests becomes clearer.

In the course of examining the previous hypotheses, it became clear that there were strong informal ties between key players from the public and private sectors. These informal ties were not of the traditional type (same family, clan or town) but of the modern type - same professional background. This came from having studied CIT-relevant subjects (often at universities in the US or Western Europe), 
or from having worked together on CIT-relevant projects in the University of Cairo, in IDSC or the private sector. Some of our respondents had moved between these organisations. They shared a passion for exploiting CIT opportunities and to do this in or for Egypt. They were proud to be members of a professional elite that cared about their country but at the same time did not neglect personal ambition. The rewards were profit and power. The successes and failures of this alliance in establishing a new industry are analysed later. Here we concentrate on the issue expressed in the hypothesis: to what extent and at what stage was the informal interaction institutionalised?

Before the establishment of the Ministry for CIT in 1999 the interaction was largely informal - even though there were some formal meetings such as workshops or conferences. The new Minister then took the interaction to a new level. He set up working groups which were tasked to develop action plans for specific issues such as infrastructure, legislation, and so on (see Table 9.1). The working group participants included government officials, business people, consultants, researchers, and expatriates. Our respondents stressed that these working groups were critical for translating the Minister's CIT vision into a credible plan for action. They provided the essential inputs for the national CIT development plan, which was both ambitious and down to earth, and was officially announced in 1999.

The brainstorming through working groups started as an informal arrangement behind closed doors involving a handful of players. It quickly became semiinstitutionalised in the sense that meetings were no longer behind closed doors and minutes were taken, but the process was never formally established. What is interesting to observe is that although this brainstorming remained informal, it was applied later in other plan preparations as well.

The main objectives of the 1999 national plan as announced by MCIT are presented in Table A11 in the Appendix. The table also shows the objectives set out in the government's CIT strategy for 2007-10. This explicitly specifies publicprivate partnership as a mechanism for implementation. In a way, this formalises the concept of working groups. It is not, however, fully institutionalised and remains an ad hoc mechanism used whenever relevant. For example, working groups consisting of key public and private sector players, were used in the process of developing the official development strategy for the IT sector for the period 2007-10.

The strategy of involving the key private sector players and constructing a common interest continues to be used by key CIT policymakers in both informal and formal ways. For example, major private companies are on the Board of ITIDA but controversial issues are discussed beforehand with these companies and deals are made - in order to ensure their support in the decision-making and implementation process (interview with first ITIDA chairman).

A more structured transformation of the informal processes into formal ones is seen in the establishment of a CIT export council - similar to the ones established for the food and furniture industries and other sectors. It is an official channel for private sector opinions to be conveyed to the government concerning the export of IT products and services, and is gaining increasing interest from policymakers because of the potential to raise export revenues. 


\begin{tabular}{|c|c|c|c|}
\hline Issue addressed & Objectives & Members & $\begin{array}{l}\text { Total duration } \\
\text { and frequency }\end{array}$ \\
\hline Infrastructure & $\begin{array}{l}\text { Development of } \\
\text { infrastructure to cater to } \\
\text { needs of all operations }\end{array}$ & $\begin{array}{l}(25-40) \\
\text { key }(15)\end{array}$ & \\
\hline Legal & $\begin{array}{l}\text { Reach the legal } \\
\text { framework that backs the } \\
\text { development of the sector }\end{array}$ & $\begin{array}{l}(10-12) \\
\text { key }(5)\end{array}$ & $\begin{array}{l}\text { A total of six months } \\
- \text { meetings once a } \\
\text { week at beginning } \\
\text { then once a month }\end{array}$ \\
\hline Quick wins & $\begin{array}{l}\text { Business offerings to be } \\
\text { immediately provided to } \\
\text { the market }\end{array}$ & $\begin{array}{l}(15-20) \\
\text { key }(8)\end{array}$ & \\
\hline Human resources & Human resources needs & (15) & Inactive \\
\hline
\end{tabular}

To conclude, the research on the communication and information technology sectors confirmed the hypothesis. As in the case of the food industry, initial interactions between policymakers and investors were informal and were then institutionalised - but only partially so. The working groups were like temporary task forces. They proved effective in bringing together the key public and private sector players and were imitated later in other CIT initiatives and other Ministries. However, this is different from the permanent institutionalisation through Councils which has also occurred (Food Council, CIT Council). Interestingly the ad hoc and temporary institutions were particularly effective when major new challenges arose.

\section{Impact of CIPI in new sectors}

In this section the validity of each of the hypotheses presented in Section 4 is tested against reality in the CIT sectors; only the sequence in which they are examined is altered.

Hypothesis B.1: CIPI plays its role through providing proxy governance benefits to specific sectors or subsectors.

As in previous hypotheses, we need to distinguish between different phases and make it clear whether we are analysing the communications and information technology sectors separately or together. It helps to start with the latter and with the period dominated by Ahmad Nazif as the first Minister of CIT. All interviewees agreed that he managed to grant quick policy advantages to CIT as a whole in the form of lower taxes on computers and IT equipment, easy customs clearance, quick approvals from different ministries and national security authorities. This has had a positive impact on attracting investment into the industry as a whole. Nazif's 
ability to push for policy changes came from two sources: (1) his previous work in IDSC in close collaboration with private investors and (2) the fact that the President personally gave him the green light for action because he was convinced of the importance of CIT for Egypt. 'He kept the hands of the government away from the sector' were the exact words of one of the key interviewees about the positive role played by the first Minister of Communication. What he meant was that Nazif was able to sidestep the old government bureaucracy.

Proxy governance took many different forms. In the communication sector it consisted of granting licences to some investors and not others, granting specific technical or cost advantages to protect one or more players against the competition, and also introducing or postponing licences for new communication applications. Proxy governance in the IT sector was different. It consisted more of early informal access to the information and technical terms relating to tenders before those tenders were formally announced. It also provided informal access to the government authorities involved in actually setting the technical terms for tenders for IT projects, while remaining potential and actual applicants for the same tender/s. More traditional types of proxy governance in the form of policy changes favouring the IT sector such as lower taxes on IT equipment and others were also evident.

Interviews with government officials and investors - who insisted on remaining anonymous - mentioned many specific examples of such proxy governance prompted by CIPI.

\section{Examples from the communication sector}

The examples and most of the details presented in this section are first-hand, coming from respondents who participated in the negotiations between government and companies.

\section{The entry of Mobinil as a second licensed mobile company}

The first example refers to the year 1997 and concerns the competition for a licence to operate a mobile phone network in Egypt. The original scheme was for one licensed mobile company to compete with the publicly owned Telecom Egypt. Vodafone and Mobinil consortia were competing for this one licence. Vodafone won the tender by offering a higher licence fee and superior technical terms. Upon losing the tender, Mobinil managed, through the strong personal relations of its consortium leader, the industrialist Naguib Sawiress, and with support from specific government officials, to strike a deal with the government whereby Mobinil became the second licensed mobile company - instead of Telecom Egypt - in return for paying the exact same licence fee as Vodafone. Vodafone now had to compete with another private company and not a public company as originally planned. This means that the technical terms of the whole tender were changed ex post, putting the old winner Vodafone at a disadvantage.

To further add to the disadvantage of Vodafone, Mobinil took over the 700,000 subscribers to the original public company Telecom Egypt and the existing infrastructure at cost price and got permission to start operating before Vodafone. 
The deal violated all the rules but was forgotten over time, as Mobinil proved to be a worthy competitor to Vodafone and the arrangement with two private mobile companies proved successful. The price was, however, the exclusion of Telecom Egypt for good from any mobile activity, which is seen by some analysts as restrictive.

With help from its own political connections and technical justification, Vodafone managed to get concessions from the government as compensation for the unanticipated change in the government position, notably that no further competitor would be allowed for at least five years. Once agreed upon in private negotiations, it was then publicly announced as a government decision. Since the decision benefits the intruder Mobinil just as much as it does Vodafone, the latter still felt unfairly treated by the whole process. This last point raises the question of why Vodafone went on with the deal despite this unfairness and the answer lies in the profit potential of the whole project, a point which is further discussed below.

\section{The third mobile company joining the market in 2007}

The third mobile line was tendered in 2007. From many competitors, it was Etisalat that won the tender with a huge licence fee, 600 per cent more than the one paid by Vodafone and Mobinil back in 1996, which reflects a more experienced Egyptian government as a negotiator. Proxy governance in this case consists of advantages granted to the newcomer after winning the licence to reduce the risk of entry to, and grant some level of competitive positioning in, an already established market. According to the experts interviewed, it is not uncommon for such support from the government to exist; what is uncommon is for the government, represented in NTRA, to pressurise the existing mobile companies and Telecom Egypt to grant permission to use their physical networks at a low price. The norm is for the existing companies to strike commercial deals with the new competitor and not be forced to concede low prices.

The NTRA is believed to be granting those advantages because the new player is a major gulf company connected to the Emirates royal family which, in its turn, has strong relations with the presidential family in Egypt. Also, pressure from above is made easier by the fact that the institutional structure is centralised around the person of the Minister of Communication. It is interesting to note that, while the companies were pressurised, the end result is of benefit to consumers as three companies are now competing to provide the service and overall prices in the mobile market decreased as a result. Despite all the complaints, neither Mobinil nor Vodafone considered divestiture because the profits are still substantial.

The overall point is that these were major state-business deals that required big public commitments and resulted in big private investments. In spite of considerable risks, the projects went ahead because both sides had a clear understanding of the political, economic and technical aspects and both sides accepted and respected that there was a common interest. The private companies realised that the government had to make this deal work because the government executives' reputation for getting things done was on the line. These public executives were confident that the private companies would not pull out because the profit potential was high. The tenders give the impression of governance based on rules but relationships play an important role in the final stage of the process. 
It remains to be seen whether a similar deal - based on a strong public-private relationship and common interest - emerges from the tender for a fixed line, to be decided in 2009.

\section{Examples from the IT sector}

In this section the validity of each of the hypotheses presented in Section 4 is tested against reality in the CIT sectors; only the sequence in which they are examined is altered.

The IT sector is different from the communication sector. It is more heterogeneous and each subsector has a different constellation of players. Also, investment requirements and barriers to entry are much lower. These differences have implications for the nature of proxy governance relevant to the IT sector. Unlike communication, where proxy governance rotates around granting licences, in the case of IT, it consists more of early informal access to the information and technical terms relating to tenders before those tenders are formally announced. It also provides informal access to the government authorities who are actually participating in setting the technical terms for tenders for IT projects, while remaining potential and actual applicants for the same tender/s. Proxy governance remains, just as in the case of communication, a way of attracting private investment that otherwise might not materialise.

\section{Government tenders for IT products}

Government departments are the main customer of the IT industry, accounting for 60 per cent of all demand, and all government orders come through tendering. CIPI seems to play a very critical role here. Having been assured confidentiality, interviewees from the investors' group explicitly admitted that their close relations with policymakers are critical for succeeding in the IT domain. In fact, one of them emphasised that the reason that small enterprises do not get many opportunities is because they lack the networking and connections that help them overcome government shortcomings in handling the logistics and technicalities of tenders for IT projects.

The tenders typically: (1) give very little time for potential applicants to put together an adequate team to provide the necessary complete solutions (diversified specialisations); (2) ask for far too many objectives to be fulfilled within one assignment and within a very short period of time. With these problems, the government-standard consultants or consultancy companies that can help.

Through CIPI-based connections, big players in the market learn about the tenders long before they are officially announced and are often asked on a friendly basis to contribute to the definition of the technical specifications. The result is a better-defined tender but, at the same time, a much higher chance for the relevant players to win the tenders. Often such government tenders are of considerable size and winning them can assure a company's operation for years.

This feature of the IT market in Egypt has been cross-checked with a number of interviewees. The overwhelming view is that small companies with considerable 
expertise prefer to work in the export of IT products and services to neighbouring Arab countries or overseas. Domestic demand from the private sector is small. And competing for government contracts requires connections that small enterprises rarely have. In the words of one of the big successful local investors, 'if you know about the government tender when it is officially announced, it is already too late'.

All this could be interpreted as inefficient and corrupt. Sometimes this is precisely what it is. But this hardly captures the essence of what is going on. In many cases, the government departments are unable to specify the tenders adequately on their own. By working out with specific companies exactly what they need, their own capacity is enhanced and they are more likely to obtain the IT systems they require. The suppliers are willing to invest time in this process because the likelihood of obtaining the contract is considerably enhanced though not assured. It is a transitional arrangement from which both sides gain.

\section{Grants from ITIDA's funds}

In order to fund ITIDA (the government agency in charge of promoting the IT sector), the government decided that 1 per cent of revenues of the three mobile companies should go to ITIDA. It is a kind of tax. Given that this is an extra burden on the mobile companies that was not agreed upon initially with the government, ITIDA's Chairman informally agreed to give these companies priority in the allocation of ITIDA funds for capacity-building. For example, if these companies have plans to train workers in an IT-related domain but have no budget for it, ITIDA finances it as part of this informal understanding.

In other words, the Ministry has an interest in developing the IT sector, has a problem in financing it, and seeks a sustainable source of income to do so. The mobile companies understand the government's need and accept the 1 per cent levy in return for influence in development of the IT sector. At the same time the 1 per cent levy gives them access to public funds for development projects that exceed their yearly budget. There is common interest and common understanding of the problem and the solution. A way of funding an important support institution has been found. It would not qualify as best practice in public finance and it may need to be changed at a later stage but, at this stage, it works.

\section{Microsoft agreement with the Egyptian government}

The agreement between the Egyptian government and Microsoft was a case of proxy governance in the form of granting specific property rights. The first Minister of CIT, Ahmed Nazif, signed an exclusive agreement that gave Microsoft the status of preferred supplier to government departments and assurance that only licensed products (no piracy of any kind allowed) would be purchased. In exchange, Microsoft set up a subsidiary in Egypt (a very visible investment in Smart Village), offered discounted prices and reinvested part of the revenue from software sales in Egypt in training for customers' employees. Originally signed for five years, the agreement was renewed for another five.

Interviewees were split between those who focus on the direct advantages of the agreement (cheaper software and trained employees) and others, who see the 
resulting monopoly of Microsoft in the IT market as unhealthy, especially since the first tier of Egyptian partners for Microsoft (ten companies) also win most government tenders for customised software and thus leave little room for small companies. The exact words of one of the interviewees were, 'the government is invaded by Microsoft'. A third group of interviewees regard the Egyptian government as too weak to negotiate a better deal with the world's biggest software company.

To conclude, we examined the hypothesis that CIPI played its role through providing proxy governance benefits to specific (sub)sectors. While confirmation of the hypothesis could only be inferred from discussions with the interviewees in relation to the traditional industries, in the case of the new sectors, information could be obtained directly from the respondents - but usually only on a confidential basis. The difficulty of extracting information arises because formally there is governance by rules, in particular through tenders. Such tenders are indeed held but relationships often matter at the most critical stage. Proxy governance was clearest in the communication sector where CIPI led to arrangements, concessions and commitments of mutual interest; the investments at stake were huge. In the IT sector, proxy governance helped to compensate for deficiency in institutional capacity. In some cases, the special arrangements extended to foreign companies. The impact in terms of actual investments is examined later.

Hypothesis B.2: CIPl's proxy governance benefits influence investors' decisions to invest more than the general enabling environment does. ${ }^{25}$

The key finding concerning this investment is that both national and multinational companies (usually the hardest to attract) started making substantial investments in Egypt well before the 2004/5 horizontal policy changes aimed at improving the general business environment. All investors interviewed, particularly the ones entering in the 1990s, stressed that their investments were based on future profit opportunities perceived either by them or their collaborators inside and outside Egypt. However, the arrangements made with state actors were considered critical in providing assurances (against concessions) that returns from the investments could be reaped.

The clearest evidence in support of the hypothesis comes from the cases of Vodafone and Mobinil. These two mobile companies commenced operation in the second half of the 1990s - long before the general improvements in the business environments. While their early investments in the 1980s were scattered, small and of limited risk, their investments in mobile lines involved major capitalintensive physical infrastructure.

Equally interesting is the fact that these investments involved foreign partners and even multinational companies as well. In other words, it was not merely local investment that started early on, in the absence of an enabling environment, but also FDI, which is known to be cautious and volatile. At the time, the traditionally defined business environment was plagued with all sorts of problems and serious attempts at reform had not even started. Even some of the core institutions of direct relevance to CIT, such as a regulatory body, did not exist at the time. 
Even when the telecommunication law \#10 of 2003 was introduced - long after the companies started operating - it had a lot of deficiencies that left the investment climate directly relevant to the sector loaded with ambiguities and grey zones that discouraged investment. An Egyptian legal expert exposed these deficiencies in general comments and a critique of specific articles, presented in table A6 in the Appendix. Yet companies continued to invest and still do.

The key message here is that investors operated on the basis of CIPI-induced proxy governance which addressed their immediate needs more than the general business environment did. In the short and medium term this turned out to be effective. Improving the general business environment is not therefore superfluous; it remains a valid ambition for the long term.

Hypothesis B.3: CIPI has an inclusive positive impact on the sector only where the private sector has high organisational capacity.

In order to examine this hypothesis we need to start by introducing the private collective actors in CIT. The main business association is EITESAL (Egyptian Information Telecommunications Electronics Software Alliance), founded in 2004 as a result of the merger between the Egyptian software and hardware associations. EITESAL has about 250 members. Then there is the Chamber of Communication and Information Technology (under the Federation of Egyptian Industries) which is a semi-public institution and has around 400 members.

Interviews revealed that:

- representation in the business community and collective efforts seem to be of more relevance to the IT sector than the communication sector, the latter consisting of a small number of companies anyway;

- the current representation for the business community is weak, as even the CIT Chamber - the institution with the greatest representation - represents at best 20 per cent of the IT community;

- the organisation of the Chamber into vertical domains (banking, hotels and tourism, transport, health and others) is useful and leads to well-attended seminars for particular target groups;

- overall, however, both the Chamber and the Association seem to have very modest organisational capabilities;

- the most influential members are big players in CIT, and the Association and Chamber seem of limited benefit to small investors as the leading members of the Association seek to achieve objectives relevant to their enterprise through close connections with policymakers in the Ministry and other institutions of relevance to CIT. In other words, exclusive arrangements are observed in the operation of these NGOs and the Chamber.

This has not always been the case. In the early phases, the Egyptian Software Association (ESA, now merged into EITESAL) sought to represent to the whole IT sector and helped with pushing forward some of the key policy changes needed for the development of the sector as a whole. At the time, the community was very 
small, consisting mostly of the pioneers driving Egypt into the new information era. In contrast, EITESAL and the Chamber seem dominated by the interests of the big players and, according to some of our respondents, do little to support the majority of small enterprises. There are also complex connections between leadership positions in the EITESAL and the Chamber and official positions in ITIDA (the key government institution supporting the IT sector), which facilitate exclusive arrangements.

Stronger participation from below can be found in E-LABS. This small association was established in 2003 and has 33 members. It is very specific in focus (e-learning content and system development firms), objectives (help members participate in key national large-scale e-learning projects) and operation (focus on collective efforts, in order to attain the critical mass required to enable member companies to enjoy economies of scale, while maintaining individuality and independence). E-LABS is well connected - its key founders have strong ties with the Minister of CIT. The association helps the Ministry set the technical terms of reference for its e-learning projects. Members know information about the tenders early on plus detailed technical information that increases their chances of winning. Sure enough, in the first round of Ministry projects in the e-learning content domain, 90 per cent were won by members of E-LABS and 70 per cent in the second round. The NGO sees no harm in providing this privileged information to its members (servicing its members) because the whole tendering process and applications assessment is transparent and thus there is no favouritism in the final decision-making.

To conclude, given its extremely oligopolistic nature and limited number of players, the communication sector is of little relevance to this hypothesis. The IT sector has a functioning Association and Chamber but representation of enterprises and organisational capacity of the collective bodies are low. Their leaders tend to use these organisations for advancing their individual concerns. Collective concerns, in particular those of small enterprises, are not promoted, except in one sub-sectoral association. Exclusive arrangements have come to dominate in the sector- in contrast to earlier periods when representation and arrangements were more inclusive.

Hypothesis B.4: CIPI plays a critical role in the success or failure of attracting investment to specific sectors and/or subsectors.

The most striking examples of CIPl's role in attracting investment to the communication sector come from the government agreements with Vodafone and Mobinil and the process of introducing the third mobile company. In IT projects, a different type of proxy governance also revealed the role of CIPI in attracting investment. The details for these cases were presented in the analysis of Hypothesis B1. What needs to be stressed here is the absence of direct causality for investment. CIPI unleashes the profit potential but it is the existence of the profit potential in the first place that creates the real motive for investment. The high profit potential ${ }^{26}$ overrides the risk once the most directly relevant protection of property rights is granted and process facilitation takes place. This is the most critical role for CIPI.

26 Investment in CIT generally has a high return, according to all interviewees' and general information on the sectors. 
An example in support of the above argument is the case of Vodafone which continued with the agreement with the government despite the obvious bias towards the other company Mobinil and the ex post changes to the tender terms. Officials interviewed in Vodafone clearly stated that this multinational company continued to invest because of the profit opportunity that came with being a pioneer in the Egyptian mobile market, at the time still a virgin market with a 75 million population. Vodafone International started to enter new markets as its old market in the UK approached saturation. It was the profit potential here, as ever, that attracted the investor. However, as set out earlier, the government made entry into the Egyptian market difficult. The problems were resolved through concessions on both sides. Without CIPI, the negotiation would probably have failed. The Chairman of the bidding consortium was a businessman with strong political and business connections to key figures in government. In other words, CIPI facilitated the process of negotiating and finding credible mutual assurances - not for ever but for five years. The arrangement was temporary but sufficient to trigger the major investment - to be evidenced later.

To conclude, the finding in CIT is the same as in the food sector. CIPI seems to play a critical role but is not the underlying cause for the investment. CIPI helps to remove obstacles and provide assurances which then trigger the investment.

Hypothesis B.5: CIPI-induced investment reaches a tipping point which is a specific point in time when investment starts responding in a significant way (taking off).

The communications sector is different from other sectors as the main component, 'the infrastructure', does not result from a continuous flow of investment but comes in big lumps at different points in time. With this reservation in mind, it is observed in Figure 10.1 that big increases in investment occurred in both 1998 and 2006. The first is associated with the introduction of the physical infrastructure of the first two mobile companies (Mobinil and Vodafone), while the second is associated with entry of the third mobile company (Etisalat).

Figure 10.1 Annual real investment in communications, 1997-2008* (in million Egyptian pounds)
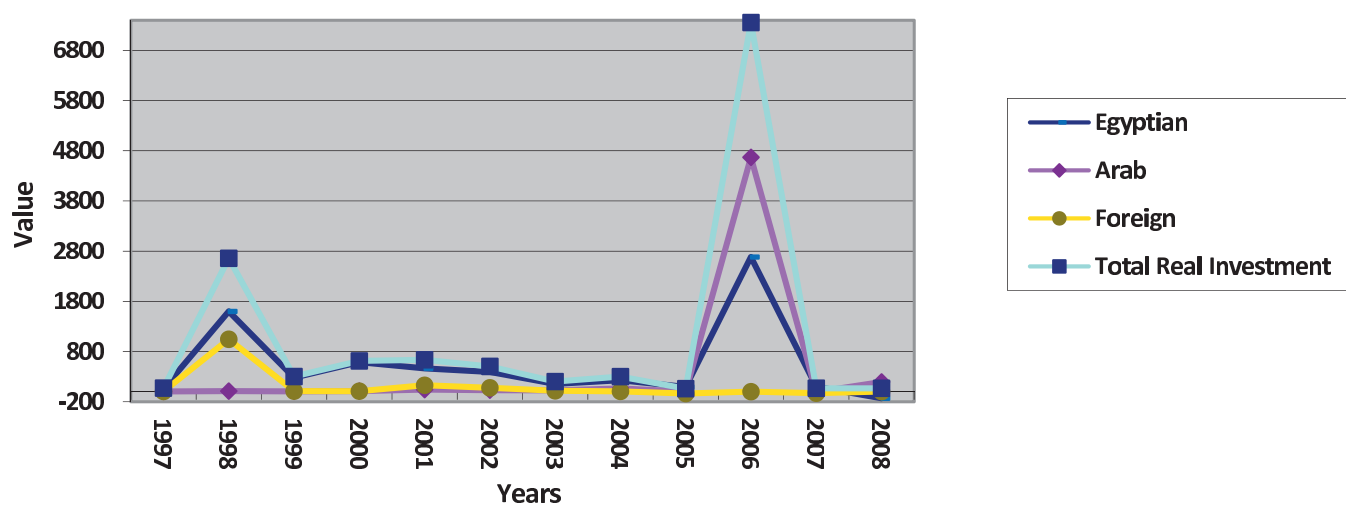

* Until the end of November 2008

Source: GAFI - Nominal investment data deflated by authors 
Between 1998 and 2006, and after 2007, there were significantly fewer, yet larger, investments. These were still categorised as 'comunications' but classified as communication applications on mobile and fixed lines (such as entertainment, ringtones, banking, advertisements, prepaid phone cards and others). 1998 qualifies as the tipping point because the investments that followed would not have been possible without this first initial infrastructure base (see also the transformation in the communications infrastructure presented in Table 10.1).

Investment in IT is demand-driven and the government is the main customer (no less than 60 per cent). Total IT investment, however, is difficult to measure because there is a sizeable informal sector involving individuals working from home who are not accounted for in official statistics. Keeping these technical reservations in mind, there was a boost in IT investment in 2005 (Figure 10.2), particularly in the areas of hardware, software applications and IT-enabled services (specifically, call centres).

Figure 10.2 Annual real investment in IT sector, 1997-2008* (in million Egyptian pounds)

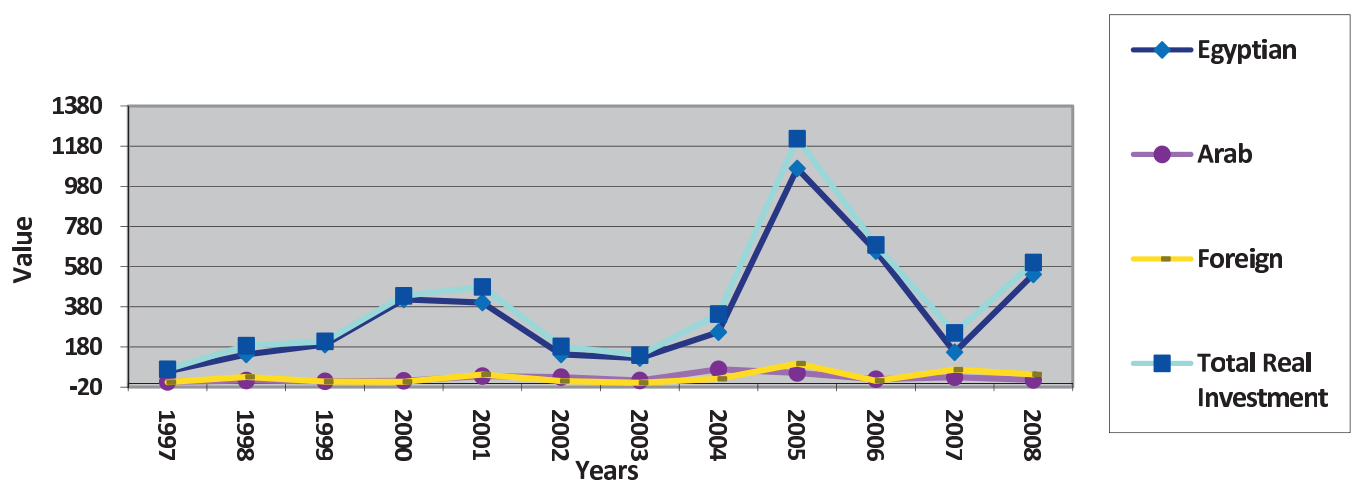

* Until the end of November 2008

Source: GAFI - Nominal investment data deflated by authors

Can 2005 qualify as a tipping point? As with the food industries, not enough time has elapsed to reach a conclusion. However, while inconclusive, it seems plausible to suggest that 2005 was the tipping point for the IT sector. From a technical point of view, the IT sector depends on investments in communications (notably ITenabled services such as call centres) and the latter did indeed precede IT investment. Initiation of the e-government project in 2004 also preceded the rise of IT investment. So, in terms of sequence, it all makes sense but we cannot rush to conclusions because the substantial increase in investment in 2005 is followed by a substantial decrease in 2007 . More time needs to elapse before conclusions can be drawn.

As stated in Section 3 on the conceptual framework, the notion of the tipping point leads us to ask whether there was a one-off increase in investment or a turning point signalling that the industry had reached a new higher level and had reached 'take off'. Most interviewees were optimistic in this respect, suggesting that the rapid advances in the communications sector and the completion of the 
institutional framework of direct relevance to the IT sector - notably, establishment of ITIDA - would increase the attractiveness of the sector for investment. Others drew attention to remaining obstacles, such as the underdeveloped quality standards for IT operations, the limited pool of well-trained human resources, and the reliance on family enterprises.

All however stressed that the government - by working closely with the private sector - played a key role in the past and would continue to play an important role. In the words of one respondent, who had played a major role in the establishment of the IT sector on both the private and public sector sides, 'the IT sector is on the runway ready to take off but hasn't taken off yet'. In his view, if there is a change of Cabinet and a new Prime Minister who is less interested in CIT takes over, the sector might slow down as it still needs a lot of institutional upgrading. This statement cautions against drawing a conclusion on this hypothesis, but can also be seen as reiterating the role played by CIPI in overcoming the institutional weaknesses, and constraints upon growth of the sector.

Indeed, while the tipping point remains hard to pin down, there can be no doubt that Egypt now has a substantial CIT industry in which national enterprises play a major role. A new industry has been created in the course of a decade. In most industrial sectors, Egypt has fallen behind comparable countries but in CIT it pulled ahead (IMC, 2005 and unpublished sectoral studies commissioned by IMC in 2004). Some of the advances in CIT are captured in Table 10.1.

Hypothesis B.6: The tipping point is followed by a knock-on effect, whereby local investment in the sectors concerned attracts FDI and stimulates investments in other sectors.

While the first part of the hypothesis found some confirmation in the case of the food industry, in the case of CIT there seems to be a knock-on effect in the reverse direction. Foreign firms, in particular multinationals, invested first. They were then followed by local investors, either in the form of partners to multinationals or independent local players, and by more foreign investors. This is mainly due to the high technology features of the industry itself.

In the communication sector, the first approved mobile company was Vodafone International. Its approval led to the entry of Mobinil, which is an Egyptian company but with a French multinational partner. Together they made the big investments in infrastructure. The third mobile line winner is an international company from the United Arab Emirates, so the sector is encouraging more foreign players. The attractiveness of the Egyptian market is confirmed by the huge fees paid to the government to get the licence. The third line company paid US $\$ 3$ billion to get the fee while Mobinil and Vodaphone paid only US $\$ 0.5$ billion each, but that was a decade earlier. The smaller investments in communications applications were all local and relied on the existing communications infrastructure. In other words, heavy investment in the technically demanding areas came mostly from foreign investors while the rush of local investment was in the less technically sophisticated domains.

In the IT sector, following the agreements between Microsoft and the Egyptian government, further agreements followed with Oracle, IBM and others. Additional 
Table 10.1 Some key performance indicators of the CIT industry, 1999-2007

\begin{tabular}{|c|c|c|c|c|}
\hline Sector/subsector & Unit & 1999 & 2007 & $\begin{array}{c}\text { Growth rate } \\
1999-2007(\%)\end{array}$ \\
\hline \multicolumn{5}{|c|}{ Communications } \\
\hline $\begin{array}{l}\text { Telephone fixed } \\
\text { lines in operations }\end{array}$ & Million & 4.9 & 11.16 & 127.8 \\
\hline $\begin{array}{l}\text { Total cellular mobile } \\
\text { telephone subscribers }\end{array}$ & Million & 0.654 & 29.368 & 4390.5 \\
\hline Fixed lines Tele-Density & $\%$ & 7.6 & 15.14 & 99.2 \\
\hline $\begin{array}{l}\text { Total cellular mobile } \\
\text { Tele-Density }\end{array}$ & $\%$ & 1 & 39.77 & 3877 \\
\hline Waiting list for fixed lines & Thousands & 1265 & 25.934 & -98 \\
\hline $\begin{array}{l}\text { Total public pay phone } \\
\text { cabins }\end{array}$ & Thousands & 13.305 & 56.444 & 324.2 \\
\hline \multicolumn{5}{|c|}{ Internet } \\
\hline Internet users & Million & 0.3 & 8.29 & 2663 \\
\hline Internet users/100 inh. & $\%$ & 0.58 & 11.225 & 1835.3 \\
\hline Int. internet bandwidth & MBps & 0.02 & 14556 & 72779900 \\
\hline $\begin{array}{l}\text { Int. internet bandwidth/ } \\
10,000 \text { inh }\end{array}$ & MBps & 0.038 & 1.974 & 5094.7 \\
\hline \multicolumn{5}{|c|}{ Information technology } \\
\hline $\begin{array}{l}\text { Established companies in } \\
\text { IT and communications }\end{array}$ & Company & 266 & 2327 & 775 \\
\hline $\begin{array}{l}\text { Established companies in } \\
\text { IT and communications/ } \\
100 \text { thousand inhabitants }\end{array}$ & Company & 0.42 & 3.151 & 650 \\
\hline IT clubs & Club & 30 & 1593 & 5210 \\
\hline
\end{tabular}

Source: Ministry of Communications and Information Technology (1999 and 2007 monthly indicators)

examples of foreign investment can be found among the new entrants to the promising field of call centres. The first to invest was Exceed, a big company owned by Telecom Egypt and the multinational company Orange. They were followed by Indian investors and others seeking to benefit from cheap Egyptian labour. There were also Egyptian investors establishing call centres for the domestic market.

In conclusion, largely due to technological and financial barriers, foreign investment played a significant role, particularly in the early phase, and then pulled in national investment. In the communications sector this was more pronounced than in the IT sector. The knock-on effects for investment in other sectors is difficult to assess for the same reasons as those relating to the old, long-established sectors. 
Hypothesis B.7: Disturbance of CIPI through conflict of interest between private investors and government will not affect investment if it has already taken off.

Not enough time has elapsed for a full examination of this hypothesis. However, there is some evidence to support the hypothesis in the case of communications but it is doubtful with respect to IT.

In 2007 there were serious conflicts between Vodafone and Mobinil on the one hand and the government on the other, due to the preferential treatment given to EITESAL, the new entrant to the mobile market. However, the two established companies continued to operate and the three companies are now involved in tough competition within an oligopolistic setting. The high profits involved (35 million subscribers to mobile services up to the end of 2008 and the potential for more) are the main reason for investment to continue even though the earlier arrangement made possible by CIPI is disturbed. The rooting of investment in heavily capital-intensive infrastructure discourages divestiture.

As regards the IT sector, the discussion of Hypothesis B6 showed the importance of CIPI for overcoming constraints. While much has been achieved, there are further obstacles to be overcome. A strong alliance between top policymakers and investors remains important. Some IT sector interviewees expressed concerns for the sector's future if there were to be a change of Prime Minister. So it remains to be seen whether the hypothesis is confirmed. Only time will tell.

It is also possible that, even if the old alliance remains in power, it may cease to be as effective as in the earlier phase. While relationships in the earlier network were close, there was fluidity. On the government side, some rigidity has crept into the system with the centralisation of power in the Minister of CIT. Apart from being Minister, he is also the Chair of the Board of the regulatory authority NTRA, and Chair of the Board of the promotion agency ITIDA. As indicated earlier, some of our respondents thought that this slowed down the decision-making process and that 'new blood' was needed. Again, only time will tell whether and how CIPI survives and benefits investment and growth in the CIT sectors. 


\section{Part IV Conclusions}

This report contributes to a broader Centre for the Future State research programme into how public action can stimulate private investment. Conventional approaches to improving the investment climate by strengthening formal political and market institutions have had limited impact. The Centre's PAPI programme explores the potential for informal relationships between politicians/policymakers and private investors to compensate for weak formal governance arrangements in the short to medium term. This report investigates the role played by such relationships in Egypt, with particular reference to two old sectors (food and furniture) and two new sectors (communication and information technology).

Despite efforts from the 1970s onwards to improve the investment climate in Egypt, the level of private industrial investment remained low and erratic. However, from 2004 onwards there were increases in investment in most industrial sectors. These coincided with a change of government in mid-2004, and the appointment of businessmen to ministerial positions for the first time since 1952. The government introduced a number of important regulatory changes, long demanded by the business community. But this does not explain why investments were higher in some industrial sectors than in others, or how important remaining constraints including corruption, slow judicial processes and poor contract enforcement were overcome. There is also the puzzle of why some industrial sectors experienced substantial investment and growth even before the business-friendly government of 2004 came to power.

This research report has shown that informal relations between key policymakers and investors played an important role in increasing levels of private investment in the sectors concerned but also warns against overstating this role. In order to bring out the full spectrum of findings, Section 11 draws out the commonalities and differences between the sectors and Section 12 brings out the implications for policy and future research.

\section{Commonalities and differences}

As stressed in the brief assessment of the literature in Section 1, there is little research on whether - in contemporary developing countries - informal statebusiness relationships matter for investment, how the causal connections operate, under what conditions they are effective, where the informal relationships come from, how their institutionalisation affects outcomes, and what all this means for policymaking. What follows are our answers to these questions. Some of these conclusions are clear, based on strong evidence; some are tentative, recognising that the evidence is only indicative; and on some issues, we have no answers at all, but offer better questions for future research.

\section{Causes and triggers}

Previous sections emphasise that common interest and common understanding of problems to be solved are essential for effective state-business relationships - for 
which we used the abbreviation CIPI. The research shows clearly that CIPI is not the sole direct cause of an increase in private investment but plays a critical role in unleashing the profit potential of specific sectors. It can unblock the way forward in the short to medium term where governance of the economy is problematic. The food sector in particular showed that the direct reason for the increase in investment was increased demand but the ability to overcome general supply constraints and make effective investments owes much to CIPI. Whether the power of demand would eventually have removed these constraints is hard to tell. It would certainly have taken more time.

\section{Overcoming barriers}

CIPI provided what we called proxy governance, consisting of measures tailored to the specific needs of the (sub)sector. CIPI also facilitated difficult, politically sensitive decision-making, such as the removal of restrictions on the access of big investors to reclaimed desert land, and removal of the energy subsidy. This emerged most clearly from the analysis of the old sectors.

The barriers that needed to be overcome were more formidable in the case of the new sectors. CIPI played a critical role in helping Egypt to establish impressive communication and information technology industries, virtually from scratch. Specifically, it helped the country overcome the initial barriers to entry, whether of a technical nature, security-related, ${ }^{27}$ or even just the mental blocks (translated into red tape) of conservative technocrats. Later on, it helped to get over the institutional deficiencies, limited experiences and capabilities of Egypt. Such actions and surges would have been difficult if not impossible in a country that in many ways was falling behind Asian competitors and even some other countries in the region.

Multinational companies have played a significant role in the creation and sustainability of the CIT industries in Egypt. Their most important role was in the initial phases of development of the new industry. CIPI played a critical role in providing proxy governance of direct relevance to these multinationals, thus attracting their investments. While the role of these companies at a later stage remains controversial, they lent credibility to the efforts of the public-private growth alliance in the early stages.

While not all CIPI actions were necessarily in the right direction, and corruption may not have been completely avoided, the fact remains that Egypt now has a substantial and viable CIT industry. The role CIPI played in developing the industry is gradually receding as the institutional framework becomes more developed and industrial structures and capabilities become stronger.

\section{Willingness and ability to take action}

In both the old and new sectors, the close alliance between high-level policymakers and big investors was able to play a key a role because the alliance extended into

27 National security issues (due to technical issues relating to wavelength and interactions with defence and intelligence etc.). 
the Cabinet and, in the case of the CIT industries, up to the President. This helps to explain why willingness to take action translated into a capability to take action. It is impossible to determine how effective the alliance would have been without this extension to the top.

The willingness of policymakers to take action in favour of a certain sector is conditional upon the potential of the sector itself, and the extent to which it can deliver visible and tangible results in terms of economic growth, exports and job creation for which policymakers can take credit. This explains why policymakers took particular interest in the food sector (especially the processing of fruit and vegetables). In the case of the CIT industries there was also the prestige and pride in establishing a new industry in a country which is famous for its ancient history but not for future-oriented high-tech industries. Media criticism seems to deter ministers from offering exclusive support to particular firms but we are not in a position to determine how strong this restraining force was.

\section{Exclusive relationships and inclusive effects?}

Although CIPI initially offers exclusive benefits, it can have an inclusive and positive impact, but only where the private sector has effective leadership and broad-based organisation. Thus, in the well-organised food sector, exclusive relations between policymakers and key investors had a positive impact on large parts of the sector. In contrast, the leaders of furniture sector have not sought to develop a broad-based organisation and this seems to explain why the benefits arising from a close relationship with policymakers were appropriated by a few leading enterprises. However, the local-level experience of Damietta shows that the gains extend further when the private sector leaders represent a broad-based organisation. This connection between the spreading of gains and the way the private sector is organised requires, however, further comparative research. The role of other contingent factors needs to be considered.

\section{Beyond the tipping point}

One of the main concerns was to establish whether CIPI just lit a straw fire or had an enduring effect. The answer was clearest in the CIT industries where a new industry had been established. The most visible sign is the Smart Village, a cluster of CIT enterprises and support institutions, not far from Cairo but out in the desert. However, examining the durability of these enterprises through investment data and identifying a tipping point proved difficult for a number of reasons: first, not enough time had passed, particularly in the food industry; second, investments are lumpy and yearly changes look erratic; and, third, investment data (obtained from GAFI) are not complete. The investment data provide only tentative evidence that the industries embarked on a new dynamic. Adding qualitative evidence from the respondents' own judgements suggests that the communications industry and the furniture industry of Damietta had taken off, while the jury is still out on the IT industry and the food industry.

Another way of getting at this issue was to examine whether a weakening or collapse of CIPI would slow down investment and growth. There is no common 
answer across the industries examined. The Damietta furniture industry continued to grow after the local CIPI came to an end. In the communication industry, where CIPI was put under severe strain, the growth of the sector continued because there had been earlier sizeable investment and demand continued to grow, albeit at a slower rate. In the IT industry, it is difficult to give even a tentative answer. And, finally, in the food industry the issue does not yet arise because the alliance has only existed since 2004 and remains intact, at least in the most important subsector - fruit and vegetable processing.

In spite of this uncertainty, what is beyond doubt is that CIPI has been an effective transitional arrangement, initiating investment and growth. It remains to be seen whether and in what circumstances it can also help to sustain this growth.

\section{Transitional arrangements}

The notion of transitional arrangements 28 is useful for analysing the Egyptian case material and perhaps also for research on state-business relations in general. As suggested in the introductory section, the search for best practice (best in all places and at all times) makes it difficult to recognise ways forward for a particular stage and to understand sequence and dynamics. The empirical research supports this view. Rules-based governance is widely considered best practice for raising investment and generating growth but the Egyptian communication industry suggests that relationship-based governance was significant in attracting the big early investments. These investors were then major contributors to the working groups that drafted the new telecommunication law and laid down the rules for the sector. Similarly, the food investors - due to their close relationships with policymakers contributed to the horizontal improvements in business regulations. Since these investors were feeding into a wider policy process, their specific contribution is hard to document. Nevertheless, the question raised in the introductory chapter of whether investors follow or lead regulatory reform seems to have some validity. Of course, involving business in the drafting of rules and laws is not without dangers but it seems better to acknowledge that the way forward is potentially messy than wait for neutral rule-makers to bring about a step change in investment and growth.

\section{The roots of CIPI}

CIPI is often rooted in informal relationships. In the case of the old sectors, these roots lay in coming from the same city or extended family. In the case of the new sectors, these roots lay in a common professional background - career paths had crossed in universities and work assignments in the public and private sectors. However, the Damietta experience shows that such relationships are not a precondition for the development of common interests. What the common social or professional background does is make it easier to come together and explore the potential for common interests. Of course, there must be situations where 
common history has the opposite effect and where old tensions make it difficult to explore joint futures, but these did not surface in the interviews.

In the new sectors, the bond between the key public and private players did not just come from a common past. We also noticed the pride that came from commanding expertise in a new and difficult technical field, the pleasure that came from applying things learnt in the US or Europe in their native Egypt, and the belief that the new technology provided an opportunity for creating a new industry in a country which seemed trapped in history and in the political conflicts of the Middle East. These motives, often detectable only through the way respondents spoke about their experiences, should not be ignored but they are hard to verify.

Of course, there was also the realisation that there was money to be made in the private ventures and that new careers would open up in the public sector. Without the belief in significant business opportunities and career opportunities none of the socio-cultural factors would have come into play. But in trying to understand why these growth alliances came together - in the new and old sectors - it would not be helpful to reduce everything to pecuniary motives. Such a reductionist conclusion would prevent us from detecting the glue that helped keep CIPI together. Some of the top policymakers could have made more money in the private sector; in fact some were successful businesspeople before working in government for a period.

\section{Necessary conditions}

On the basis of the formal interviews and informal conversations, we cannot disentangle and give weights to the financial and non-financial contributors to the creation of CIPI. We can however conclude that:

- Common social roots facilitate the coming together of public and private actors but are not a necessary condition.

- Common professional background facilitates the process of developing a common understanding of the problems to be solved but is not a necessary condition.

- Common interest and common understanding of the challenges are necessary conditions for an effective public-private growth alliance.

\section{Implications for policy and future research}

We suggested in the introductory section that there is too much focus, both in the literature and in real world advice to developing countries' governments, on the need for a rules-based enabling environment in order to attract investment, and not enough attention on the process of getting there. The key question for policymakers is therefore how to initiate investment in practice and unleash a new dynamic. The research presented here cannot give definitive answers but it indicates a way of triggering a process that accelerates private investment and which is both politically and economically viable. 


\section{Short term and long term}

This research is not in any way trying to discredit the importance of improving the investment climates in general. This is a worthwhile long-term goal, but policymakers must be clear that institutional reform tends to be more difficult and take more time than the consultants acknowledge. And even when it succeeds it does not always lead to a surge of private investment. This is the context in which this research was carried out and this is why we experimented with the approach first outlined in Moore and Schmitz (2008).

While CIPI is no substitute for a better formal enabling environment in the longer term, this research does show how informal relationships based on common interests can provide investors with the necessary reassurance to kick-start investment in the short to medium term. It is however important to note that certain features of the political and economic context in Egypt were significant in helping to ensure that exclusive benefits were targeted on sectors with the potential for productive investment, and that some of the more negative effects of 'crony' relationships were avoided. Ministers had incentives to deliver on a range of public goods, not just narrow patronage benefits, and were subject to media scrutiny. Informal relationships between politicians/policymakers and private investors are likely to play out quite differently in more difficult governance contexts, although they may still offer the best way forward.

\section{Organisational capacity}

For this approach to work, one needs more than a few committed individuals on the public and private sides. Both sides need organisational capacity. On the public side, it is no accident that the impressive public-private alliance for establishing a new CIT industry was not just spearheaded by a Minister with a vision. This Minister had been able to set up a new Ministry for which he could recruit a small but very capable staff, free from the recruitment restrictions and salary scales prevailing in the civil service. It is no accident that the public-private alliance for the food industry came into life with a new Minister of Trade and Industry who was an industrialist and who appointed very capable people to key positions. And on the private sector side, there was an effective food chamber and council, with leaders who had a vision for the sector and a clear idea of where Egypt could fit into the international division of labour. The significance of this factor became clear when we compared the food industry with another sector which had high profit potential but little, if any, organisational capacity. The sector in question is the marble and granite industry, not studied explicitly for this project but known to us from other work. This organisational capacity of the private sector seems an important point which is rarely given sufficient attention. Failure to adopt policies and the failure of policies adopted tend to be attributed to the public sector. This research highlights the need to give equal attention to private sector failure. ${ }^{29}$

29 Considering the organisational strength/weakness of the private sector is important for another reason. From the public policymakers' point of view there is a paradox. Old sectors tend to be well organised but do not always deserve public support. New sectors tend to be less well organised, because enterprises are so young or merely in the process of getting established, but may deserve public support (Meyer-Stamer 2004). 


\section{Broad-based organisation of the private sector}

The organisation of the private sector influences not only whether policymakers have a credible counterpart in the private sector, it also influences the outcome of joint action between the two sides. Broad-based organisations are more likely than small exclusive clubs to spread gains. Figure 12.1 captures this connection between the nature of private sector organisation and the likely effects of CIPIinduced measures. Note that it does not present conclusive results. The findings are tentative and need further comparative enquiry. Such research would be of great interest to politicians and policymakers, particularly in countries where parliament and/or the press scrutinise the effects of close relationships between policymakers and business people.

\section{Figure 12.1 Organisation of the private sector and its effects}

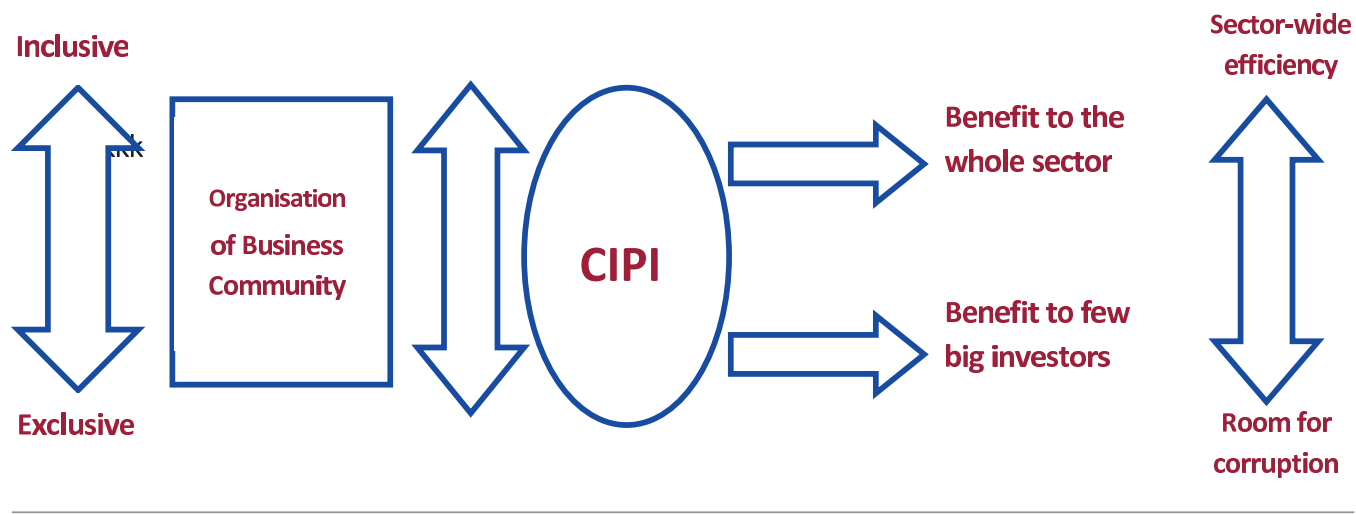

\section{Institutionalising state-business relations}

The research has shown that informal relationships are not necessarily bad and corruptive as often assumed in the literature. It has shown how such relationships evolved and it has contrasted paths and patterns in old sectors (traditional informal ties based on family and locality) and new sectors (modern informal ties based on common university, professional and business backgrounds). These informal roots were a source of strength in the analysed cases, but leave policymaking with two problems: these relationships are difficult to recreate in other sectors and their accountability is difficult to organise. The big policy question is therefore whether and how such relationships can be institutionalised in an effective way. This question cannot be answered with the information collected, because institutionalisation was limited.

However, the sectoral experiences brought out the importance of distinguishing between temporary and permanent institutionalisation. In the early stage of establishing the CIT sector, working groups were established to deal with particular challenges. These proved very effective. Once their tasks were accomplished, these working groups were dissolved. The participants were handpicked by the Minister from the informal networks but the meetings were not secret or behind closed doors. Other ministries later imitated the same working group system because it was seen as successful for aligning interests, developing a common understanding of problems and getting the relevant stakeholders 
involved in working out ways forward. Specifying the factors that determine the success or failure of such temporary public-private taskforces would be a useful exercise. Note that this is not about taskforces in general. It is about taskforces that bring together those players who really matter and that concentrate on accelerating investment and fostering competitiveness.

When it comes to permanent institutionalisation, the Egyptian experiences remain very limited and our research did not focus on specifying the conditions for institutional effectiveness. Issues that would need to be considered in future research include: source of funding; political independence; formal appointments; informal leadership; location in state apparatus (in particular, relationships with the Cabinet); how proposals find their way into public action; frequency of meetings; transparency; and accountability.

\section{National public-private councils}

Institutionalisation at the sectoral level is important but has its limitations: the issues of sectoral priorities and interdependence are not addressed. This does not mean that no decisions are made. On the contrary, decisions on these issues are made all the time but usually through informal arrangements and/or by default. This is a key problem for policymakers concerned with investment and growth and concerned with building a better state.

There are no easy solutions, but in recent years there have been interesting experiments from which lessons can be learnt. The most interesting national-level experiments are competitiveness councils which have sprung up in several parts of the world. Competitiveness councils are institutional mechanisms for improving policymaking in the policy fields concerned with raising a country's investment, growth and competitiveness. The councils seek to achieve this by bringing together key representatives of the public and private sectors, seeking common understanding of the problems that need to be addressed, and making joint proposals for action.

The scope of issues addressed by such councils and the way they are designed varies between countries. Ireland, for example, is thought to be a successful example in terms of improving the policy process and outcomes. Egypt also has a competitiveness council but it is thought to be ineffective in both respects. Identifying specific positive and negative lessons (on the issues set out above) would be of considerable interest not just for Egypt but also for other developing countries.

\section{Financial crisis and economic downturn}

The insights from this research might have some relevance for understanding how governments are trying to get out of the recent financial crisis and curb the global economic downturn. While the full effects of the financial crisis on the real economy are not yet clear, it is clear that belief in the 'West is Best' ideology has lost all credibility. The leading Western countries can no longer claim superior knowledge or ability in creating an enabling environment for investment and growth. Nor can they claim to know how to climb out of the crisis. Martin Jacques might be overstating the case when he concludes that 'the business and political 
elite are flying blind' (The New Statesman, 12 February 2009), but measures adopted so far have merely laid bare further layers of malfunctioning national systems and the downside of global interconnectedness.

Seen through the lens adopted in this research on investment and growth in developing countries, there are two features that demand attention. First, there is a lot of talk about the need to reform the legal and regulatory framework at the national and global levels. Second, top policymakers and business leaders from specific sectors get together to make deals that are in the common interest overriding previous rules and conventions. The parallels to our analysis of the investment climate are striking: first, there is agreement that major improvement in rules-based governance is essential in the long run; second, relationship-based governance offers a quicker way forward.

Recent responses to the financial crisis underline that common interests and common understanding of the problems to be solved are the basis for quick action, while concerns with accountability are put on hold. The leaders of big companies seek government support for their private rescue plans, the political leaders seek the glory of avoiding massive job losses and rescuing a sector threatened by closure. The vast majority of enterprises look on in bewilderment, aghast that the big companies can make new deals while they themselves have to live by the old rules. But even they recognise that such relationship-based governance might help to stop a downward and trigger an upward dynamic.

\section{Normal times and turning points}

The state interventions prompted by the recent global financial crisis and economic downturn certainly suggest that state-business relations need more attention, not just in developing countries but also in the more advanced Western and Asian countries. Fundamental questions need to be re-examined, for example:

- How much progress have North American and West European countries made in moving towards rules-based governance? To what extent does reality live up to the model that developing countries are asked to emulate?

- Given that East Asian countries have a superior recent record of investment and growth, to what extent have they moved away from relationship-based governance? How effective have they been in institutionalising such relationships?

These are big questions far beyond the scope of our research report. We raise them here and now for two reasons. First, research and advice for the developing world is heavily influenced by what is seen to work in the developed world. Second, the global financial crisis and economic downturn suggest that we need to distinguish between two very different situations - normal times and times when extraordinary challenges arise. Extraordinary times are when major crises need to be dealt with or huge opportunities arise. These are the turning points in an economy or sector. Judgement of what kind of governance is effective and desirable will probably differ depending on whether we are considering normal times or turning points. 
Research making this distinction will at times struggle to specify where the normal ends and the extraordinary begins but it is likely that a more realistic picture emerges of how state and business interact. There is likely to be a clearer recognition that public-private alliances can play an effective role at turning points and that informal relationships can provide effective transitional arrangements.

Our research suggests that what matters most is that there is a common interest and common understanding of the challenge. Once this is recognised, research can get down to the central task of specifying the conditions that determine whether a growth alliance has the desired outcome. 


\section{Appendix}

Table Al Policy changes of relevance to investment in the period 19741997

\begin{tabular}{cl}
\hline Phase & \multicolumn{1}{c}{ Main features } \\
\hline $\begin{array}{c}\text { Pre-1974 } \\
(1952-1974)\end{array}$ & $\begin{array}{l}\text { While not explicitly discouraging private investment (national and } \\
\text { foreign), the nationalisation of existing private facilities and huge } \\
\text { investments by the government (more than } 80 \% \text { of total investment } \\
\text { particularly in industry) created a general atmosphere of ambiguity } \\
\text { and lack of trust in the government that discouraged all investments. }\end{array}$ \\
\hline
\end{tabular}

1974-1977 Investment law \#43/1974 - amended by law \#32/1977 - was a point of transformation in the investment climate and in the Egyptian economy as a whole. It marked the beginning of the move away from socialism. The law provided several advantages to investors such as tax exemptions for five to seven years and imports without the need for a licence, among others. But the most important advantage was the guarantee that projects under this law could not be nationalised or confiscated except due to a serious legal felony and only within the framework of international agreements. It also encouraged joint ventures with enterprises that were at least 51\% Egyptian-owned. Free zones were created with additional advantages and the General Authority for Investment (GAFI) was established to assess projects and be in charge of all investment procedures.

1979 Law \#59/1979 focused on encouraging the establishment of new cities with the purpose of encouraging new projects and a more even distribution of the population. The law offered investment projects located in new cities (Sixth of October and Tenth of Ramadan, among other cities) a number of advantages, the most important of which was a tax holiday of ten years. The law did not distinguish between industrial and commercial projects.

\begin{tabular}{|c|c|}
\hline 1981 & $\begin{array}{l}\text { Law \#159/1981, or the companies' law, was introduced to organise } \\
\text { the establishment of new companies in all activities. }\end{array}$ \\
\hline 1989 & $\begin{array}{l}\text { Law \#230/1989 for local investments and free zones was introduced } \\
\text { to put local and foreign investors on an equal footing and attempt to } \\
\text { simplify procedures for launching a project. It also specified a number } \\
\text { of priority areas for investment such as land reclamation, tourism and } \\
\text { housing. Industry was also one of the areas but with no specific } \\
\text { focus. }\end{array}$ \\
\hline
\end{tabular}
A comprehensive economic reform and structural adjustment program (ERSAP) was implemented in Egypt commencing in 1991 under the supervision of the World Bank and the IMF. With seven components (public sector reform, fiscal and monetary reform, investment reform, exterior policies, pricing policies, and social policies), it aimed at regaining Egypt's macroeconomic stability, correcting structural imbalances and regaining Egypt's credibility. It was a point of transformation for the Egyptian economy. Improvements in budget deficit, inflation, foreign debt and the debt service ratio were observed as a result. 
Table A2 Recent policies and strategies for improving the investment and business climates in Egypt, 1997-2006

Policy Main features

Fiscal policy

Trade and investment policies

Legal, regulatory and business environment
1) New Tax Law \#91/2005 involving substantial reduction in tax rates, unification of tax rates, cancellation of surcharges and all previous tax exemptions. The law also aims to simplify procedures and regain trust between taxpayers and tax authorities.

2) Removal of sales tax from capital goods in 2006 - a disincentive to the purchase of all equipment.

1) Decree \#770/2005 Issuing the Executive Regulations to Implement Import and Export Law \#118/1975 - a new Executive Regulation for the implementation of Import and Export law \#118/1975. While based on the same articles that were passed 30 years ago, it attempts to accommodate recent factors and Egypt's commitments to the World Trade Organization (WTO). The new regulations are to be implemented in coordination with 18 other Presidential Decrees, Prime Ministerial Decrees, Ministerial Decrees and Laws issued at various times.

2) Customs changes (2004):

Cuts in customs duties, from $14 \%$ to $9 \%$.

Simplification of customs procedures.

- Consolidation of dutiable items from 13,000 to 6,000 .

Cutting the number of tariff bands from 27 to 6 .

3) Free zones and export promotion law \#155/2002 - the main component of which being an export subsidy fund to encourage exports of different products.

4) Trade Agreements 1998-2005 - Egypt signed three regional trading agreements (COMESA 1998; GAFTA 1998; and AGHADEER Protocol 2004) in addition to eight bilateral trade agreements (the most important being the one with the EU (2001) and the most recent being the one with Turkey (2005)); all in addition to QIZ Protocol (December 2004).

5) Investment Laws 1997-2005 - The investment guarantees and incentives law \#8/1997 amended by laws \#196/2000 and \#13/2004, and the special economic zones law \#83/2002. Law \#8 involved a number of tax holidays later cancelled by new tax law. A new Presidential Decree \#30/2005 gives the Prime Minister authority to make exceptions if projects are strategic for Egypt.

1) Intellectual Property Rights Law (IPR) - \#82/ 2002 - Always pushed for by donors as being key to attracting investment.

2) Labor Law \#12/2003, amended by Law \#90/2005 - Issued in replacement of the old law that has been operational from the $1960 \mathrm{~s}$.

3) Competition Law \#3/2005 and Executive Regulations 2005 - More than a decade in the making, Egypt's first competition law (anti-trust law) was finally passed in 2005. It aims at ensuring that all commercial activities are undertaken without impairing free competition in the market.

4) Consumer protection law 2006 - Focus on establishing a Consumer Protection Agency and specifying its responsibilities and organisation. This Consumer Protection Agency will be responsible for receiving complaints and investigating cases of consumer rights violation. 
Table A3 Hypothesised CIPI phases

\begin{tabular}{|c|c|c|c|}
\hline Phases & Description & Features & Key influencing factors ${ }^{30}$ \\
\hline $\begin{array}{l}\text { One } \\
\text { Initial } \\
\text { relation }\end{array}$ & $\begin{array}{l}\text { Introductory } \\
\text { protocol meetings } \\
\text { between all } \\
\text { investors and new } \\
\text { policymakers }\end{array}$ & $\begin{array}{l}\text { Investors testing the water on the } \\
\text { orientation and direction of the } \\
\text { new policymakers in office, to start } \\
\text { lobbying for their needs }\end{array}$ & $\begin{array}{l}\text { Previous relations with policymakers such as } \\
\text { common education, family relations, business } \\
\text { acquaintance, social acquaintance, all leading } \\
\text { to mutual trust between two groups }\end{array}$ \\
\hline
\end{tabular}

Key investors capable of leading

the sector identified

\begin{tabular}{lll}
$\begin{array}{l}\text { Two } \\
\text { Common } \\
\text { interest- } \\
\text { building } \\
\text { stage }\end{array}$ & $\begin{array}{l}\text { Policymakers and } \\
\text { key investors } \\
\text { discuss issues of } \\
\text { interest to the } \\
\text { sector in question } \\
\text { and the problems } \\
\text { faced by } \\
\text { investors }\end{array}$ & $\begin{array}{l}\text { Serious detailed discussions } \\
\text { about constraints upon investment } \\
\text { in sector in a typically informal and } \\
\text { confidential setting and involving } \\
\text { policymakers }\end{array}$ \\
& & $\begin{array}{l}\text { Preparatory work preceding policy } \\
\text { formulation done }\end{array}$ \\
\hline $\begin{array}{l}\text { Three } \\
\text { Common } \\
\text { interest- } \\
\text { maturity } \\
\text { stage }\end{array}$ & $\begin{array}{l}\text { Observed } \\
\text { changes in } \\
\text { policies and } \\
\text { procedures } \\
\text { specific to the } \\
\text { sector in question } \\
\text { but also in } \\
\text { relation to all } \\
\text { types of } \\
\text { investment }\end{array}$ & $\begin{array}{l}\text { Policy formulation steps out from } \\
\text { behind closed doors to actual } \\
\text { public announcement and } \\
\text { traditional process of adoption }\end{array}$ \\
\hline
\end{tabular}

Leadership characteristics of key investors combined with strategic thinking and vision and deep understanding of sector needs

Policymakers with clear understanding of the needs of the business community, particularly in relation to specific sectors

Policymakers already knowing each other and trying to find a way forward that recognises the interests of both sides

Leadership characteristics of key investors combined with strategic thinking, vision and deep understanding of sector needs

The characteristics of the policymakers and their ability to push for changes beyond the bureaucracy

Constraints to the sector are not only specific to the sector but also of a more general nature (tax reform, customs, etc.)

\begin{tabular}{ll}
\hline Four & New local \\
The & investment \\
tipping & attracted to the \\
point & sector
\end{tabular}

The key investors increase their investments followed by others within the same sector

The characteristics of the market setting, international conditions of relevance to the sector, 31 the nature of the sector

The level of organisation of the business community

Inclusive or exclusive arrangements

Local investors' affiliation with foreign partners

\begin{tabular}{lll}
\hline Five & Positive response & $\begin{array}{l}\text { Observing boost in local } \\
\text { investment, FDI starts to gain } \\
\text { The }\end{array}$ by FDI in sector \\
mectoral & & $\begin{array}{l}\text { monfidence in investment in } \\
\text { the sector }\end{array}$ \\
knock-on & &
\end{tabular}

Six Investment in

The inter- other sectors

sectoral shows some

knock-on increase as well

effects
Confidence in the investment climate is contagious even if no actual changes take place
The market structure of the sector in question (monopoly, oligopoly, monopolistic competition or perfect competition)

International conditions of relevance to the sector

The nature of the sector: similarity to or linkages with booming sector

Constraints to investment are of a more general than specific nature

30 Each phase is dealt with separately so, when relevant, some factors are repeated.

31 For example, all other factors being equal, booming demand for a product in the international market is a favourable condition that speeds up the tipping point because larger investments to satisfy the increasing export demand have a high profit potential. 


\begin{tabular}{|c|c|c|c|}
\hline Phases & Description & Features & Key influencing factors \\
\hline \multirow{17}{*}{$\begin{array}{l}\text { Seven } \\
\text { Beyond } \\
\text { the peak } \\
\text { of CIPI } \\
\text { (alternative } \\
\text { scenarios) }\end{array}$} & $\begin{array}{l}\text { Path (A) - } \\
\text { positive } \\
\text { scenario }\end{array}$ & $\begin{array}{l}\text { Success of sector in attracting } \\
\text { investment, expanding exports } \\
\text { and creating jobs }\end{array}$ & $\begin{array}{l}\text { Performance indicators of the sector enjoying } \\
\text { benefits of CIPI in terms of investments, } \\
\text { exports and job creation (macro objectives) }\end{array}$ \\
\hline & \multirow{8}{*}{$\begin{array}{l}\text { Continued } \\
\text { positive } \\
\text { collaboration } \\
\text { between the key } \\
\text { investors and the } \\
\text { policymakers for } \\
\text { the benefit of the } \\
\text { sector }\end{array}$} & $\begin{array}{l}\text { CIPI positively perceived by } \\
\text { community and media }\end{array}$ & \multirow{2}{*}{$\begin{array}{l}\text { The market structure of the sector in question } \\
\text { (monopoly, oligopoly, monopolistic competition } \\
\text { or perfect competition) }\end{array}$} \\
\hline & & CIPI evolves into more & \\
\hline & & $\begin{array}{l}\text { involvement of key investors in } \\
\text { policy formulation }\end{array}$ & \multirow{3}{*}{$\begin{array}{l}\text { The perception of the community and } \\
\text { specifically the media of CIPI (positive or } \\
\text { negative) } \\
\text { The personal characteristics of policymakers }\end{array}$} \\
\hline & & \multirow{3}{*}{$\begin{array}{l}\text { Relation between key investors } \\
\text { and policymakers made more } \\
\text { explicit and more formal }\end{array}$} & \\
\hline & & & \\
\hline & & & \multirow{2}{*}{$\begin{array}{l}\text { The personal characteristics of the key } \\
\text { investors }\end{array}$} \\
\hline & & \multirow{2}{*}{$\begin{array}{l}\text { Role of key investors expanding to } \\
\text { other areas, within the same } \\
\text { sector, as well as extending } \\
\text { beyond the sector to general } \\
\text { policy formulation }\end{array}$} & \\
\hline & & & $\begin{array}{l}\text { International conditions of relevance to the } \\
\text { sector }\end{array}$ \\
\hline & $\begin{array}{l}\text { Path }(B)- \\
\text { negative } \\
\text { scenario }\end{array}$ & $\begin{array}{l}\text { Failure of sector in attracting } \\
\text { investment, expanding exports } \\
\text { and creating jobs }\end{array}$ & $\begin{array}{l}\text { Performance indicators of the sector enjoying } \\
\text { benefits of CIPI in terms of investments, } \\
\text { exports and job creation (macro objectives) }\end{array}$ \\
\hline & \multirow{5}{*}{$\begin{array}{l}\text { Collapse of CIPI } \\
\text { and possibility of } \\
\text { conflicts between } \\
\text { policymakers and } \\
\text { the key investors }\end{array}$} & $\begin{array}{l}\text { CIPI negatively perceived by } \\
\text { community and media }\end{array}$ & \multirow[t]{2}{*}{$\begin{array}{l}\text { The market structure of the sector in question } \\
\text { (monopoly, oligopoly, monopolistic competition } \\
\text { or perfect competition) }\end{array}$} \\
\hline & & \multirow{2}{*}{$\begin{array}{l}\text { Policymakers feel threatened by } \\
\text { their collaboration with key } \\
\text { investors }\end{array}$} & \\
\hline & & & \multirow{2}{*}{$\begin{array}{l}\text { The perception of the community and } \\
\text { specifically the media of CIPI (positive or } \\
\text { negative) }\end{array}$} \\
\hline & & \multirow{2}{*}{$\begin{array}{l}\text { At least a cooling of the } \\
\text { relationship }\end{array}$} & \\
\hline & & & The personal characteristics of policymakers \\
\hline & & \multirow{2}{*}{$\begin{array}{l}\text { Potential conflicts between the two } \\
\text { groups as policymakers take } \\
\text { policy actions unfavourable to the } \\
\text { sector in order to boost their } \\
\text { image }\end{array}$} & $\begin{array}{l}\text { The personal characteristics of the key } \\
\text { investors }\end{array}$ \\
\hline & & & The adequacy of the international conditions \\
\hline
\end{tabular}




\section{Table A4 Actions triggered by CIPI - proxy governance benefits to the food sector}

\begin{tabular}{|c|c|c|c|c|}
\hline $\begin{array}{l}\text { Area of } \\
\text { intervention }\end{array}$ & Specific action & $\begin{array}{l}\text { Benefit to specific groups } \\
\text { within the food sector }\end{array}$ & $\begin{array}{c}\text { Benefit to the food sector } \\
\text { as a whole }\end{array}$ & $\begin{array}{l}\text { Benefit to any other } \\
\text { additional sector }\end{array}$ \\
\hline $\begin{array}{l}\text { Protection } \\
\text { of specific } \\
\text { property } \\
\text { rights }\end{array}$ & $\begin{array}{l}\text { Completely change the system } \\
\text { for reclaimed land allocation from } \\
\text { the current small slots allocation } \\
\text { to fresh graduates to large slots } \\
\text { cultivated by big investors in fruit } \\
\text { and vegetable processing }\end{array}$ & $\begin{array}{l}\text { Action triggered by big } \\
\text { investors in fruit and } \\
\text { vegetable processing to } \\
\text { address the needs of their } \\
\text { lines of production }\end{array}$ & $\begin{array}{l}\text { Beyond fruit and vegetable } \\
\text { processing, oil industries, } \\
\text { dairy products, bakery and } \\
\text { confectionery also stand to } \\
\text { benefit. For example, wheat } \\
\text { is currently planted in the } \\
\text { desert (flour production). } \\
\text { Similarly, animal husbandry } \\
\text { (milk production) typically } \\
\text { joins agricultural cultivation } \\
\text { in the desert. Animal fodder } \\
\text { is also planted in the desert } \\
\text { now. }\end{array}$ & $\begin{array}{l}\text { Act seen by experts } \\
\text { as a step forward for } \\
\text { the agricultural sector. } \\
\text { It allows the adoption } \\
\text { of a new model (large- } \\
\text { scale plantations for } \\
\text { industrial purposes) } \\
\text { as an alternative to } \\
\text { the traditional model } \\
\text { of small farmers/ } \\
\text { small plantations in } \\
\text { the delta area }\end{array}$ \\
\hline
\end{tabular}

\begin{tabular}{|c|c|c|c|c|}
\hline $\begin{array}{l}\text { Specific } \\
\text { policy } \\
\text { changes of } \\
\text { technical } \\
\text { relevance to } \\
\text { the sector }\end{array}$ & $\begin{array}{l}\text { - Harmonisation of local } \\
\text { standards for } 2000 \text { food items } \\
\text { with international standards } \\
\text { - Changes in board of directors } \\
\text { of Egyptian Accreditation } \\
\text { Council's Food Division, by } \\
\text { introducing the active food } \\
\text { chamber and dissolving the } \\
\text { inactive representation of an } \\
\text { old public agency } \\
\text { - Creation of an Agricultural } \\
\text { Modernization Council that } \\
\text { consists of big investors from } \\
\text { agriculture and fruit and } \\
\text { vegetable processing to } \\
\text { introduce changes in the } \\
\text { agricultural system that can be } \\
\text { pushed beyond the typical } \\
\text { bureaucratic structure of the } \\
\text { Ministry of Agriculture } \\
\text { - Appointing big investors from } \\
\text { fruit and vegetable processing to } \\
\text { Ministry of Agriculture } \\
\text { committees in the critical areas } \\
\text { of setting the criteria for new } \\
\text { varieties of seeds, along with } \\
\text { others able to approve different } \\
\text { types of pesticides for Egypt } 32\end{array}$ & $\begin{array}{l}\text { - Changes triggered by big } \\
\text { investors in food industries/ } \\
\text { leadership of Food } \\
\text { Chamber in the Federation } \\
\text { of Egyptian industries } \\
\text { - Clearly triggered by big } \\
\text { investors to promote } \\
\text { changes of direct interest to } \\
\text { their business } \\
\text { - Triggered by big investors } \\
\text { and direct outcome of CIPI } \\
\text { in its narrow sense. } \\
\text { Removes obstacles faced } \\
\text { by investors planting in } \\
\text { reclaimed land for export } \\
\text { and/or fruit and vegetable } \\
\text { processing directed to } \\
\text { exports }\end{array}$ & $\begin{array}{l}\text { - Benefit to the sector is } \\
\text { well established as } \\
\text { harmonisation of } \\
\text { standards is a huge } \\
\text { barrier between } \\
\text { producing for the local } \\
\text { market and producing } \\
\text { for exports } \\
\text { - Fruit and vegetable } \\
\text { processing as a whole } \\
\text { will benefit but only if the } \\
\text { sector is well organised } \\
\text { - The benefit to the sector } \\
\text { as a whole is established } \\
\text { for the long run because } \\
\text { it improves the backward } \\
\text { linkages of fruit and } \\
\text { vegetable processing with } \\
\text { agriculture }\end{array}$ & $\begin{array}{l}\text { - Advances in agro } \\
\text { processing trigger } \\
\text { improvements in } \\
\text { products and } \\
\text { process of } \\
\text { agricultural sector } \\
\text { - Direct benefit to } \\
\text { big investors in } \\
\text { agriculture }\end{array}$ \\
\hline $\begin{array}{l}\text { Removal or } \\
\text { at least } \\
\text { reduction of } \\
\text { uncertainties } \\
\text { in relation } \\
\text { to } \\
\text { transaction } \\
\text { costs }\end{array}$ & $\begin{array}{l}\text { - Creation of an informal ad hoc } \\
\text { mechanism for solving big } \\
\text { company problems one by one } \\
\text { (company registration, customs } \\
\text { clearance problems, training } \\
\text { needs) } \\
\text { - Simplification of industrial control } \\
\text { system faced by producers } \\
\text { - Establish an institute to handle } \\
\text { all issues related to land } \\
\text { allocation for industrial use, } \\
\text { including infrastructure } \\
\text { preparation } \\
\text { - Support Food Chamber claims } \\
\text { for a unified regulatory system } \\
\text { and one single food authority }\end{array}$ & $\begin{array}{l}\text { - Direct gain only to individual } \\
\text { investors with access to the } \\
\text { policymaker, specifically the } \\
\text { big players. The action } \\
\text { triggered by Minister of } \\
\text { Trade and Industry to } \\
\text { facilitate operations of the } \\
\text { biginvestors - and gain } \\
\text { their trust } \\
\text { - Triggered by big players in } \\
\text { the sector } \\
\text { - Triggered by big players and } \\
\text { solves a big obstacle to } \\
\text { investment } \\
\text { - Triggered by big investors/ } \\
\text { leadership of Chamber and } \\
\text { of benefit to their } \\
\text { businesses but more so to } \\
\text { the whole }\end{array}$ & $\begin{array}{l}\text { - Other enterprises within } \\
\text { the food sector face the } \\
\text { same problems but have } \\
\text { no access to the } \\
\text { policymaker for solution } \\
\text { - Clear benefit to the whole } \\
\text { food sector for this } \\
\text { specific act and the ones } \\
\text { below }\end{array}$ & $\begin{array}{l}\text { - Big players in other } \\
\text { sectors besides } \\
\text { food received the } \\
\text { same treatment } \\
\text { - Clear benefit to all } \\
\text { industry }\end{array}$ \\
\hline
\end{tabular}

32 These two committees are particularly critical for both agriculture and industry. Agricultural authorities see it as their responsibility to decide what to allow and what not to allow while industry sees internationally accepted restrictions on new varieties of products and also certain types of pesticides as obstructions to its expansion as fruit and vegetable processing requires high agricultural flexibility if it is to expand. 


\begin{tabular}{|c|c|c|c|c|}
\hline $\begin{array}{l}\text { Area of } \\
\text { intervention }\end{array}$ & Specific action & $\begin{array}{l}\text { Benefit to specific } \\
\text { groups within the food } \\
\text { sector }\end{array}$ & $\begin{array}{l}\text { Benefit to the food } \\
\text { sector as a whole }\end{array}$ & $\begin{array}{l}\text { Benefit to any } \\
\text { other additional } \\
\text { sector }\end{array}$ \\
\hline $\begin{array}{l}\text { Reduction } \\
\text { of public } \\
\text { duties }\end{array}$ & $\begin{array}{l}\text { - Reduction of customs on all } \\
\text { imported inputs } \\
\text { - Removal of tariffs on capital } \\
\text { goods } \\
\text { - Food industries have been } \\
\text { exempted from } \\
\text { energy subsidy cancellation }\end{array}$ & $\begin{array}{l}\text { - Big players were involved in } \\
\text { preparation of changes } \\
\text { - Strong pressure by big } \\
\text { players is behind the } \\
\text { exemption of food }\end{array}$ & $\begin{array}{l}\text { - Clear benefit to the entire } \\
\text { industry } \\
\text { - Benefit to the sector as a } \\
\text { whole }\end{array}$ & $\begin{array}{l}\text { - Reduction of } \\
\text { customs took place } \\
\text { on all imported } \\
\text { inputs and thus } \\
\text { benefited all } \\
\text { industrial sectors } \\
\text { - Exemption also for } \\
\text { textiles and } \\
\text { garment industries }\end{array}$ \\
\hline $\begin{array}{l}\text { Provision of } \\
\text { support } \\
\text { services } \\
\text { and infra- } \\
\text { structure }\end{array}$ & $\begin{array}{l}\text { - Facilitating process of service } \\
\text { delivery to enterprises and } \\
\text { raising the ceiling of technical } \\
\text { assistance from } 100,000 \text { euros } \\
\text { to } 500,000 \text { euros, depending } \\
\text { on the size of the enterprise } \\
\text { - Provision of training of workers } \\
\text { through ITC }\end{array}$ & $\begin{array}{l}\text { - Benefits to specific } \\
\text { companies from IMC, clear } \\
\text { bias toward large } \\
\text { companies } \\
\text { - Important badly needed } \\
\text { service triggered by the } \\
\text { needs of big investors } \\
\text { and provided in full to them }\end{array}$ & $\begin{array}{l}\text { - Small companies } \\
\text { theoretically have access } \\
\text { to the technical support of } \\
\text { the IMC but in reality it is } \\
\text { at a much lower priority } \\
\text { level at the institution. } \\
\text { Small enterprises } \\
\text { complain about limited } \\
\text { access } \\
\text { - Of long-term benefit to } \\
\text { sector but only in a } \\
\text { limited way because } \\
\text { access is mostly } \\
\text { limited to big players not } \\
\text { the entire sector }\end{array}$ & $\begin{array}{l}\text { - Again benefit to big } \\
\text { enterprises from } \\
\text { different sectors }\end{array}$ \\
\hline $\begin{array}{l}\text { Adoption of } \\
\text { a clear } \\
\text { long-term } \\
\text { vision for a } \\
\text { particular } \\
\text { sector }\end{array}$ & $\begin{array}{l}\text { - Minimise shock effects by } \\
\text { announcing changes of } \\
\text { significance to investors over } \\
\text { the next five years and } \\
\text { discussing these changes with } \\
\text { industrialists in advance (e.g. } \\
\text { removal of energy subsidy and } \\
\text { announcement of energy prices } \\
\text { to be paid by industrialists for } \\
\text { next five years) } \\
\text { - Support Food Chamber efforts } \\
\text { to reduce the size of the } \\
\text { informal sector which is known } \\
\text { to be a danger to the future of } \\
\text { the industry } \\
\text { - Revision of trade agreement } \\
\text { with EU to create more } \\
\text { opportunities for Egypt } \\
\text { - Improving collection and } \\
\text { precision of import and export } \\
\text { data collected by GOEIC } \\
\text { (General Organization for } \\
\text { Export and Import Control) } \\
\text { - Change of symbolic commodity } \\
\text { councils into effective export } \\
\text { councils that do all preparatory } \\
\text { work for policy changes }\end{array}$ & $\begin{array}{l}\text { - Had a very positive effect } \\
\text { on big investors and foreign } \\
\text { investors in achieving trust } \\
\text { in the system } \\
\text { - Action triggered by the big } \\
\text { investors/leadership of } \\
\text { Chamber, whose } \\
\text { businesses are negatively } \\
\text { affected by the informal } \\
\text { sector } \\
\text { - Action triggered by big } \\
\text { exporters to the EU to plan } \\
\text { ahead for the needs of } \\
\text { this huge market } \\
\text { - Triggered by Food Chamber } \\
\text { and Food Export Council } \\
\text { and contributes to the } \\
\text { solution of a chronic } \\
\text { problem in Egypt } \\
\text { - An initiative of Minister of } \\
\text { Trade and Industry but CIPI } \\
\text { is very much at heart of the } \\
\text { choice of members }\end{array}$ & $\begin{array}{l}\text { - Small players in the } \\
\text { sector are not part of the } \\
\text { process but benefit from } \\
\text { the outcome as future } \\
\text { uncertainties are reduced } \\
\text { - Very high benefit to the } \\
\text { sector as a whole } \\
\text { - Of benefit to both } \\
\text { agriculture and fruit and } \\
\text { vegetable processing } \\
\text { exports } \\
\text { - Of considerable benefit to } \\
\text { the sector as a whole, } \\
\text { particularly new investors } \\
\text { and exporters } \\
\text { - Excellent for both the } \\
\text { present and future of the } \\
\text { sector. One of their } \\
\text { objectives is to reach a } \\
\text { long-term vision and } \\
\text { strategy for the sector to } \\
\text { follow. The Minister of } \\
\text { Trade and Industry } \\
\text { adopts the strategy and } \\
\text { supports its } \\
\text { implementation }\end{array}$ & $\begin{array}{l}\text { - Change of symbolic } \\
\text { commodity councils } \\
\text { into effective export } \\
\text { councils that do all } \\
\text { preparatory work } \\
\text { for policy changes } \\
\text { - The informal sector } \\
\text { is a problem for all } \\
\text { industry in different } \\
\text { domains, though it } \\
\text { is most noticeable } \\
\text { in the food } \\
\text { industries } \\
\text { - Same measure } \\
\text { adopted for all } \\
\text { sectors but the } \\
\text { most active export } \\
\text { council is the food } \\
\text { one }\end{array}$ \\
\hline
\end{tabular}




\begin{tabular}{|c|c|c|c|}
\hline $\begin{array}{l}\text { Communication } \\
\text { subsectors }\end{array}$ & Components & Main characteristics & $\begin{array}{l}\text { Nature and size of the } \\
\text { business community }\end{array}$ \\
\hline $\begin{array}{l}\text { Communication } \\
\text { infrastructure }\end{array}$ & $\begin{array}{l}\text { - Fixed phone } \\
\text { lines } \\
\text { - Mobile } \\
\text { companies } \\
\text { - Internet (main } \\
\text { licence- } \\
\text { holders) }\end{array}$ & $\begin{array}{l}\text { - Large companies, huge } \\
\text { investments in } \\
\text { infrastructure } \\
\text { - High profit potential as } \\
\text { mobiles and internet are } \\
\text { becoming essential } \\
\text { everywhere (size of the } \\
\text { Egyptian market already } \\
40 \text { million subscribers) } \\
\text { and return is guaranteed } \\
\text { - High technical expertise } \\
\text { is pre-condition for } \\
\text { entering the three } \\
\text { domains }\end{array}$ & $\begin{array}{l}\text { - Three multinational } \\
\text { mobile companies } \\
\text { (MobiNil, Vodafone and } \\
\text { Itisalat - the first two } \\
\text { have local partners and } \\
\text { third is all foreign) } \\
\text { - One fixed phone line } \\
\text { owned by Telecom } \\
\text { Egypt ( } 80 \% \text { public } \\
\text { company and } 20 \% \\
\text { private) } \\
\text { - Tender of second line } \\
\text { planned } \\
\text { - Internet (class A, four } \\
\text { companies; class B, ten } \\
\text { companies) }\end{array}$ \\
\hline & Internet cafés & $\begin{array}{l}\text { - Small companies } \\
\text { delivering service to } \\
\text { public } \\
\text { - High profitability } \\
\text { especially after decrease } \\
\text { in price of computers } \\
\text { - No prerequisite } \\
\text { technical knowledge }\end{array}$ & $\begin{array}{l}\text { - Very large number of } \\
\text { local private companies } \\
\text { (class C) }\end{array}$ \\
\hline $\begin{array}{l}\text { Diversified } \\
\text { applications on } \\
\text { mobile and } \\
\text { fixed line } \\
\text { systems }\end{array}$ & $\begin{array}{l}\text { Entertainment } \\
\text { Ringtones } \\
\text { Banking } \\
\text { Advertisements } \\
\text { Prepaid phone } \\
\text { cards }\end{array}$ & $\begin{array}{l}\text { - Small investments } \\
\text { - High profit potential } \\
\text { because of high demand } \\
\text { by already huge } \\
\text { population of mobile } \\
\text { subscribers } \\
\text { - Minimum technical pre- } \\
\text { qualifications are } \\
\text { required for entry }\end{array}$ & $\begin{array}{l}\text { - A large number of } \\
\text { private investments; } \\
\text { Egyptian and regional }\end{array}$ \\
\hline
\end{tabular}


Figure Al Telecommunication licences in Egypt

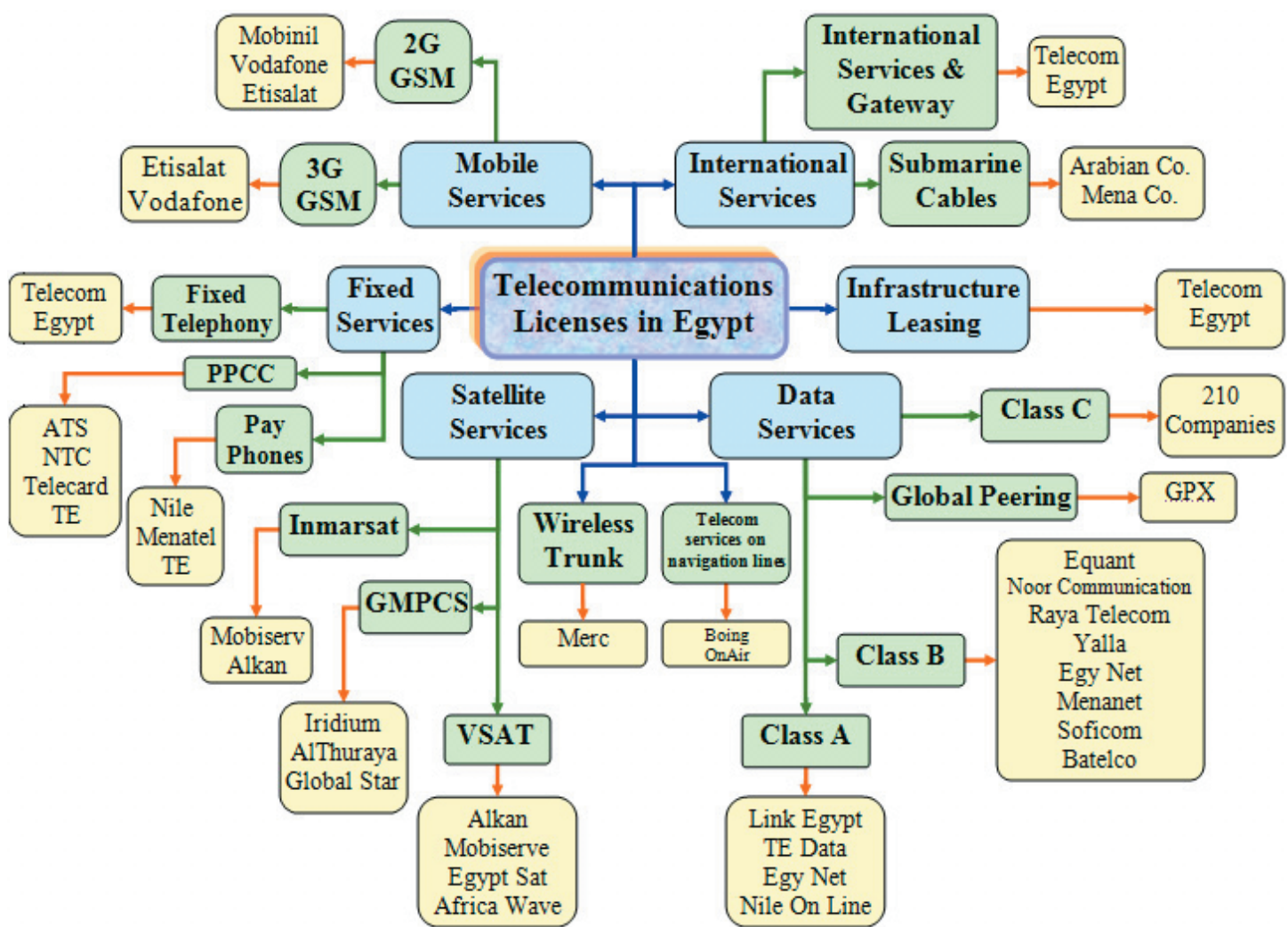

Source: Ministry of Communications and Information Technology (MCIT) and the National Telecommunications Regulatory Authority (NTRA) 


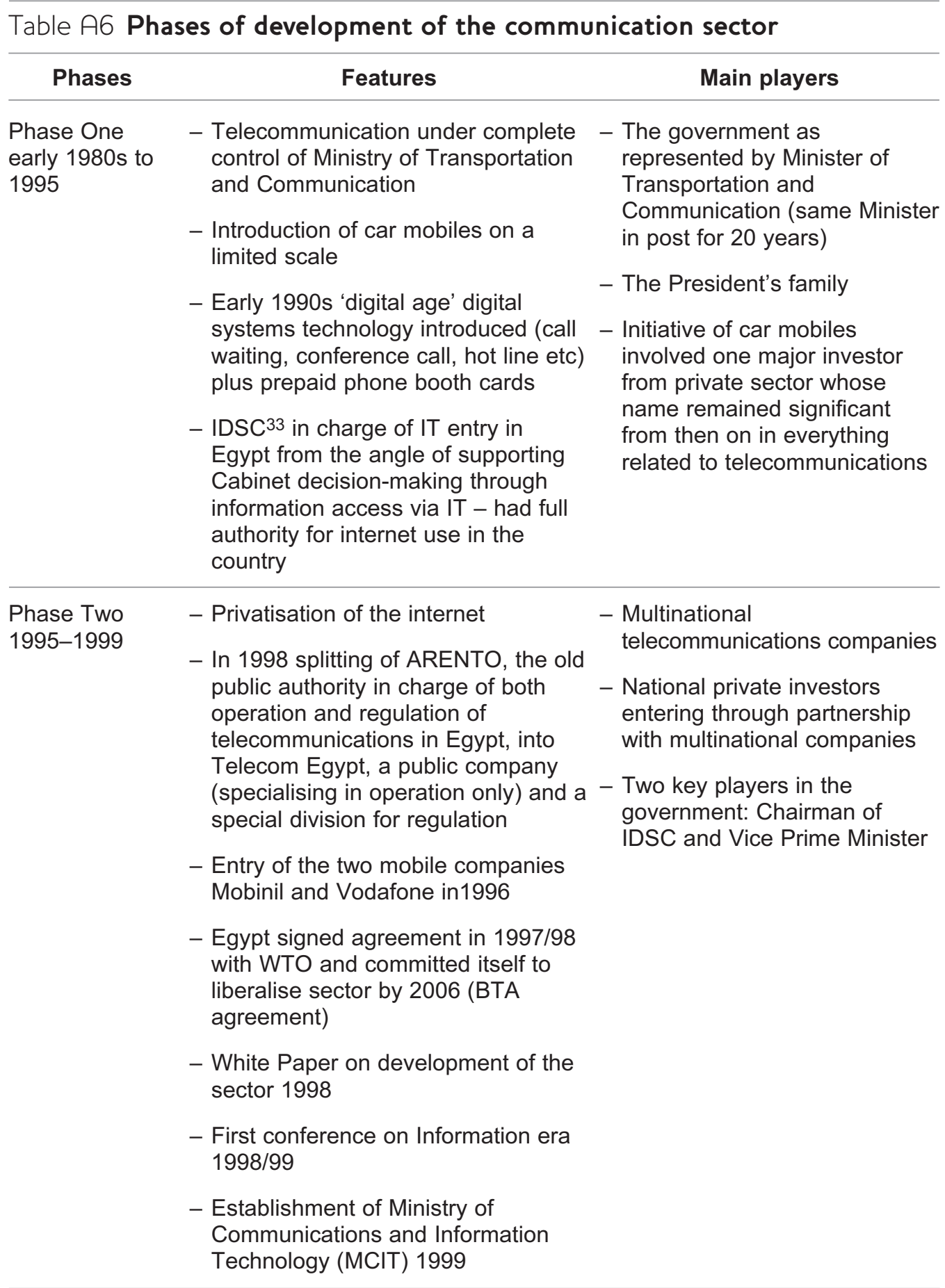

33 In 1985, the Cabinet of Egypt established the Information and Decision Support Center (IDSC) whose mission was and is to provide information and decision support services to the Cabinet for socioeconomic development. A key player in IDSC is the Chairman from 1985-1999, Dr Hisham ElSherif, who led the introduction of internet services in Egypt and promoted Egypt's entry into the information age. 


\begin{tabular}{|c|c|c|}
\hline Phases & Features & Main players \\
\hline $\begin{array}{l}\text { Phase Three } \\
\text { 1999-2004 }\end{array}$ & $\begin{array}{l}\text { - Ahmed Nazif is first Minister of MCIT } \\
\text { - The telecommunications law (\# } 10 \text { in } \\
\text { 2003) } \\
\text { - Establishment of the regulatory body } \\
\text { for telecommunications NTRA in } \\
2003 \\
\text { - Partial privatisation of Telecom } \\
\text { Egypt. 20\% of shares sold to private } \\
\text { sector and exchanged in stock } \\
\text { market. } 80 \% \text { of Telecom Egypt } \\
\text { remains public } \\
\text { - Establishment of the Smart Village } \\
\text { (to include both C and IT institutions } \\
\text { and investors) }\end{array}$ & $\begin{array}{l}\text { - Continuation of role of } \\
\text { multinational companies and } \\
\text { Egyptian partners } \\
\text { - MCIT, the Minister plays a } \\
\text { critical role } \\
\text { - NTRA } \\
\text { - Telecom Egypt }\end{array}$ \\
\hline $\begin{array}{l}\text { Phase Four } \\
2004 \text { to date }\end{array}$ & $\begin{array}{l}\text { - A new Minister for MCIT is in charge } \\
\text { (Tarek Kamel) } \\
\text { - Old Minister of MCIT promoted to } \\
\text { PM status } \\
\text { - Entry of a third player in mobile } \\
\text { phone industry } \\
\text { - Introduction of a second fixed line in } \\
\text { progress }\end{array}$ & $\begin{array}{l}\text { - MCIT and the new Minister } \\
\text { - Telecom Egypt } \\
\text { - NTRA } \\
\text { - Nazif (as Prime Minister) } \\
\text { - New and old multinational } \\
\text { companies and their Egyptian } \\
\text { partners }\end{array}$ \\
\hline
\end{tabular}


Table A7 Structure of the IT sector

\begin{tabular}{|c|c|c|c|}
\hline $\begin{array}{l}\text { Information } \\
\text { Technology } \\
\text { subsectors }\end{array}$ & Components & Main characteristics & $\begin{array}{l}\text { Nature and size of the } \\
\text { business community }\end{array}$ \\
\hline
\end{tabular}

Hardware

All equipment related to CIT, - Completely imported from mainly all kinds of computers, abroad either fully printers and phone sets and assembled or in parts other equipment
- Local assembly of computer parts that is perceived to be profitable in the local market

- Limited technical expertise is needed for entry in the assembly line
Software development
- This is the part of IT that is described as the real IT industry

- It focuses on using Oracle and Microsoft tools to develop software solutions to be applied on a large scale or doing the programming for the multinational companies themselves

- Examples of areas of application include: conversion of old IBM applications to modern IT technology; preparation of generic programs for specific functions such as automatic archiving, Arabic software or development tools for multinationals. And also specialised Enterprise Resource Planning for the needs of particular manufacturing sectors
- Software development is very limited in Egypt (India lead there)

- A constraining prerequisite is very high programming skills and large companies with (1000 programmers as in the case of India)
Systems integration (hardware and software services custommade to the needs of a specific project or specific application - for example mapping the country, transportation for railways etc.

Also specific systems Enterprise Resource Planning (ERP)

CIT applications in stock market, banking, security, postal service, security, business management

\author{
distributors of imported \\ hardware from famous \\ worldwide suppliers (such \\ as IBM, BP, etc.) \\ companies that assemble \\ parts
}
- Market is fragmented
- Only 3 to 4 big players (300-400 programmers, large by Egypt's standards but still small by international standards)
- The rest are small companies ranging from 1 to 100 programmers




\begin{tabular}{|c|c|c|c|}
\hline $\begin{array}{l}\text { Information } \\
\text { Technology } \\
\text { subsectors }\end{array}$ & Components & Main characteristics & $\begin{array}{l}\text { Nature and size of the } \\
\text { business community }\end{array}$ \\
\hline $\begin{array}{l}\text { IT-enabled } \\
\text { services }\end{array}$ & $\begin{array}{l}\text { Call centres } \\
\text { Outsourcing } \\
\text { Business process } \\
\text { interpretation (doctors' } \\
\text { prescription, surgery } \\
\text { processes) - big domain in } \\
\text { India }\end{array}$ & $\begin{array}{l}\text { - Egypt has an advantage in } \\
\text { call centres because India is } \\
\text { becoming expensive in that } \\
\text { area and Egyptians have the } \\
\text { advantage of a neutral } \\
\text { accent - high potential for IT } \\
\text { exports } \\
\text { - The widespread use of call } \\
\text { centres in the domestic } \\
\text { market helps prepare the } \\
\text { ground for call centres } \\
\text { aimed at the international } \\
\text { market. } \\
\text { - Call centres create an } \\
\text { employment opportunity for } \\
\text { fresh graduates plus the } \\
\text { asset of learning eight } \\
\text { languages to a fluent level } \\
\text { - Outsourcing of business } \\
\text { process is still far from being } \\
\text { developed; scope for } \\
\text { Arabising the contents of } \\
\text { many applications }\end{array}$ & $\begin{array}{l}\text { - Mostly local companies with } \\
\text { a limited number of foreign } \\
\text { players } \\
\text { - A small number of } \\
\text { companies involved in } \\
\text { export (outsourcing) and } \\
\text { technical support for } \\
\text { Microsoft and other } \\
\text { multinationals (biggest } \\
\text { Exceed with } 4000 \\
\text { employees) } \\
\text { - There is a large group of } \\
\text { much smaller call centres } \\
\text { operating in the domestic } \\
\text { market }\end{array}$ \\
\hline
\end{tabular}


Table A8 Phases of development of the IT sector

\begin{tabular}{|c|c|c|}
\hline Phases & Features & Main players \\
\hline $\begin{array}{l}\text { Phase One } \\
\text { early } 1980 \text { s to } \\
1995\end{array}$ & $\begin{array}{l}\text { - Some scattered initial investments in } \\
\text { IT } \\
\text { - IT definition and extent not clear } \\
\text { - Big focus on hardware in the 1990s } \\
\text { (selling desktop computers to a } \\
\text { limited segment of the public) } \\
\text { - Software sales to Egyptian } \\
\text { community by multinationals with } \\
\text { heavy counterfeits by all, including } \\
\text { government entities }\end{array}$ & $\begin{array}{l}\text { - A very small group of private } \\
\text { investors }\end{array}$ \\
\hline $\begin{array}{l}\text { Phase Two } \\
\text { 1995-1999 }\end{array}$ & $\begin{array}{l}\text { - Continuation of same scattered } \\
\text { activities as in Phase One } \\
\text { - First conference on Information era } \\
\text { 1998/99 } \\
\text { - Establishment of Ministry of } \\
\text { Communications and Information } \\
\text { Technology (MCIT) } 1999\end{array}$ & $\begin{array}{l}\text { - Same group of key private } \\
\text { players }\end{array}$ \\
\hline $\begin{array}{l}\text { Phase Three } \\
\text { 1999-2004 }\end{array}$ & $\begin{array}{l}\text { - Initiatives by MCIT headed by Nazif } \\
\text { to promote IT } \\
\text { - Decision like a PC for every } \\
\text { Egyptian, making PC available at } \\
\text { very low, extremely affordable prices } \\
\text { - Free internet for all } \\
\text { - No tariff on CIT equipment (in } 2004 \\
\text { went down from 15\% to 5\%) } \\
\text { - Prepared for establishment of ITIDA } \\
\text { - E-government initiative starting } \\
\text { under MCIT } \\
\text { - Training institute to prepare IT } \\
\text { experts } \\
\text { - Plans for increasing IT exports (plan } \\
\text { for } \$ 1.2 \text { billion by } 2010 \text { ) }\end{array}$ & $\begin{array}{l}\text { - Multinationals particularly } \\
\text { Microsoft } \\
\text { - Key private sector players in } \\
\text { Phases One and Two } \\
\text { - A very small number of new } \\
\text { players with diversified } \\
\text { interests in IT } \\
\text { - Hundreds of small companies } \\
\text { involved in hardware only }\end{array}$ \\
\hline $\begin{array}{l}\text { Phase Four } \\
2004 \text { to date }\end{array}$ & $\begin{array}{l}\text { - ITIDA operational with the objective } \\
\text { of promoting IT and developing it } \\
\text { - E-government initiative separated } \\
\text { under its own ministry, Ministry of } \\
\text { State of Administrative Development } \\
\text { (MSAD) } \\
\text { - New focus on export of IT } \\
\text { (particularly call centres) }\end{array}$ & $\begin{array}{l}\text { - New ministry, MSAD } \\
\text { - ITIDA } \\
\text { - ETEISAL } \\
\text { - Chamber of CIT } \\
\text { - Same group of private sector } \\
\text { players } \\
\text { - Hundreds of small companies } \\
\text { involved in hardware and } \\
\text { support systems and software }\end{array}$ \\
\hline
\end{tabular}


Table A9 The institutional framework directly relevant to CIT

\begin{tabular}{ll}
\hline Institution & \multicolumn{1}{c}{ Mandate } \\
\hline $\begin{array}{l}\text { The Ministry of } \\
\text { Communications and } \\
\text { Information }\end{array}$ & $\begin{array}{l}\text { Strengthen economic and social } \\
\text { development through the provision and } \\
\text { development of communications and } \\
\text { Technology }\end{array}$ \\
$\begin{array}{l}\text { information systems to serve the national } \\
\text { issues that are connected with the reform } \\
\text { and growth of the Egyptian economy and } \\
\text { \#379, 1999 }\end{array}$ & $\begin{array}{l}\text { with raising the standard of living of citizens } \\
\text { and families. Also prepare Egyptian society } \\
\text { to accept and follow up the enormous influx } \\
\text { of developed information and knowledge } \\
\text { and benefit therefrom }\end{array}$
\end{tabular}

1. Supervise the operation of the authorities and companies affiliated to the Ministry to guarantee their operation on economic bases.

2. Update the administration systems in all authorities and companies attached to the Ministry by employing the modern administration programs used by successful firms worldwide.

3. Establish and develop the institutes and training centres to prepare a generation of technical and administrative manpower capable of assimilating modern technologies.

4. Develop savings funds with the aim of developing national savings.

5. Prepare futuristic plans to keep pace with the growth in local and worldwide demand for communications, information and postal services.

6. Prepare the programme to attract world industries in the fields of communications, information and postal services in order to encourage their presence in Egypt alongside deepening local industrialisation.

7. Conclude and maintain international agreements related to communications, information and postal services, following up their implementation and observing the rights and obligations set forth therein.

The National

Telecommunications

Regulatory Authority (NTRA)

Law \#10, 2003
Regulate the telecommunications sector, improve its services and expand the usage thereof.

NTRA operates in a manner that keeps pace with state of the art technologies, satisfies all user needs at the most reasonable prices and encourages national and international investments in telecommunications within a framework of open competition
1. Draw up the telecommunications plans and programmes.

2. Prepare and publish the telecommunications services statistics.

3. Set the general policies and regulations for operation of the telecommunications services.

4. Set the standards and regulations for the noneconomical telecommunications services.

5. Set customer protection rules.

6. Provide state-of-the-art services with the best prices.

7. Ensure the quality of telecommunications services.

8. Manage customer complaints

9. Regulate the licence issuance procedures.

10. Set the National Numbering Plan.

11. Regulate the equipment type approval processes.

1. Issue and renew the licences required for the certification service providers (CSPs) in the field of e-signature services and electronic transactions.

2. Address complaints and assist in resolving legal conflicts related to the use of e-signatures and electronic transactions.

3. Offer technical counselling in disputes related to esignatures and electronic transactions.

4. Function as the registration centre for original computer software produced by organisations or individual publishers and producers to protect intellectual property and other rights.

5. Pave the way for the diffusion of the e-government and e-business services in Egypt and also to support an export-oriented IT industry in Egypt. 
Table A10 Critique of law \#10 for 2003

Phases Features

General 1) The fact that the telecommunications law does not yet have an executive regulation is heavily comments criticised. Many of the provisions of the law indicate that the guidelines and specific rules necessary for its application will be outlined in an executive regulation. The absence of this therefore leaves application of the law very unclear.

2) This criticism is strengthened by the fact that the law uses general language and little effort has been made to precisely define its terms. This can lead to misinterpretation.

3) Also, the alleged independence of the regulator is questionable. The fact that the regulator and the incumbent fixed-line operator both come under the MCIT umbrella is also a matter for concern.

\section{Critique of Article 4}

specific articles

The law is vague and many of the articles and provisions can be interpreted in several ways, hence allowing for varying standards depending on the situation at hand. For example, a provision that might be used to justify a number of different actions is Article 4(2). It states that the NTRA ${ }^{34}$ shall consider protecting national security and top state interests when encouraging investment. The NTRA could therefore use the 'national security' argument to rebut any protests against its operations or decisions.

Similarly, Article 4(5) states that the NTRA has the obligation to '[monitor] the realization of the technical and economical efficiency programs for different Telecommunication Services'. The law does not, however, indicate what these 'efficiency' standards are. This allows for selective and subjective interpretations.

\section{Article 8}

Article 8(8) allows the Board of Directors of the NTRA to accept grants, donations and subsidies subject to the approval of the military forces. ${ }^{35}$ The law states in Article 8(8) that the rules for such acceptance of grants, donations and subsidies are in accordance with the NTRA's rules and resolutions in this regard. The fact that the law does not state what these rules and resolutions are leaves room for favouritism and strategic positioning depending on the donor.

\section{Article 12}

This article lists the members of the Board of Directors who manage the NTRA. The pool from which the applicants are chosen, as listed in the law, may be subject to some criticism. First, the article shows the extensive involvement of the Minister in the selection process, whereby he can appoint six members to the Board.

Also, the fact that four representatives of the National Security Entities have seats on the Board might seem to tilt its functioning more towards national security than telecommunications.

\section{Article 19}

This article requires all entities and companies working in the telecommunication field to provide the NTRA with reports, statistics or information on all activities except for those relevant to national security.

This duty to disclose should have been accompanied by a duty of confidentiality on the part of NTRA. Also, other exemptions to the duty to disclose, other than those related to national security, should have been permitted if such disclosure would harm the company in question.

\section{Article 24}

According to this article, 'the Board of Directors shall determine the limits which, if exceeded, shall result in the occurrence of monopolistic practices in any of the fields regulated by this Law. The Board of Directors shall set the rules that should be applied to confront such practices'.

This article seems to supplant the competition authority with the Board of the NTRA in terms of determining the monopolistic practices that might result out of the application of this law. It also seems to indicate that the authority of the Board is extended to become a de facto competition regulatory authority in terms of setting the rules that should be applied to monopolistic practices.

34 The National Telecommunication Regulatory Authority.

35 The approval provision is listed in Article 44. 

compliance, by the Board of the NTRA.

This may not be the ideal way to ensure fair competition. It may also mean that this sector is excluded from application of the competition law, which may raise doubts as to whether competition issues will really be raised. Once competition issues are left to the sectoral regulators, it is hard to discern whether action or inaction are a result of bias, strategic action, favouritism, or simply inability to enforce a highly technical market regulatory law.

\section{Article 26}

This article gives the NTRA the right to set the prices of the licenced telecommunications services. This may be considered price-fixing and hence in violation of the competition law.

\section{Article 29}

This article states that 'in the event of any dispute arising between Services Providers with regard to Interconnection agreements between them, such dispute shall be referred to the NTRA in order to issue a decision therein in accordance with the provisions of such agreements'.

The article goes on to set the guidelines for the NTRA in terms of making such a decision. This clause may conflict with private contracts that have arbitration clauses.

\section{Article 34}

This article allows the licensee, if necessary, to use the components of another licensee's telecommunications network or service, upon agreement amongst them and in return for a fair charge. However, the article also mandates that should they fail to agree, the matter shall be brought to the NTRA for arbitration.

This facility-sharing requirement may be deter innovation and might be strategically used by the NTRA to favour certain licensees over others. No detailed guidelines to this facility-sharing requirement are listed. This is usually a competition issue that should have been left to the competition authority to rule on. 
Table Al1 Main objectives of the two official plans for development of CIT industry and the Egyptian information society initiative (EISI)

\begin{tabular}{|c|c|c|}
\hline National CIT plan 1999 & $\begin{array}{l}\text { The Egyptian Information } \\
\text { Society Initiative (EISI) } 2003\end{array}$ & Strategy $2007 / 2010$ \\
\hline $\begin{array}{l}\text { - Create legislative } \\
\text { environment to } \\
\text { encourage local and } \\
\text { foreign investors to } \\
\text { enter the sector } \\
\text { - Create local demand } \\
\text { for CIT sector to } \\
\text { motivate local and } \\
\text { foreign investors to } \\
\text { enter the sector } \\
\text { - Target international } \\
\text { markets by creating a } \\
\text { competitive CIT sector } \\
\text { capable of competing } \\
\text { globally and transform } \\
\text { the sector into an } \\
\text { export-led industry in } \\
\text { order to capture a } \\
\text { greater share of the } \\
\text { global market } \\
\text { - Develop qualified HR } \\
\text { by training } \\
\text { professionals, skilled } \\
\text { labour and university } \\
\text { graduates to develop } \\
\text { and employ state of } \\
\text { the art technology }\end{array}$ & $\begin{array}{l}\text { - Development of a strong } \\
\text { CIT sector as a key to } \\
\text { foster local competitiveness } \\
\text { in the global arena } \\
\text { - Vision of EISI is delivering } \\
\text { custom-made services to } \\
\text { customers with appropriate } \\
\text { efficiency and allowing them } \\
\text { to participate in the } \\
\text { decision-making process } \\
\text { - MCIT's plan geared towards } \\
\text { supporting and empowering } \\
\text { the information society in } \\
\text { Egypt in close coordination } \\
\text { with relevant government } \\
\text { agencies and with the } \\
\text { private sector } \\
\text { - These commitments have } \\
\text { been translated into } \\
\text { developing and expanding } \\
\text { the telecommunications } \\
\text { infrastructure, establishing } \\
\text { hundreds of information } \\
\text { centres, expanding the pool } \\
\text { of IT skilled labour and } \\
\text { creating information systems } \\
\text { and databases among } \\
\text { government and private } \\
\text { entities }\end{array}$ & $\begin{array}{l}\text { - Continue development of state } \\
\text { of the art CIT infrastructure } \\
\text { that provides an enabling } \\
\text { environment for government } \\
\text { and business throughout Egypt } \\
\text { and links it globally } \\
\text { - To create a vibrant and export- } \\
\text { oriented CIT industry } \\
\text { - To leverage public-private } \\
\text { partnerships as an } \\
\text { implementation mechanism } \\
\text { whenever possible } \\
\text { - To enable society to absorb } \\
\text { and benefit from expanding } \\
\text { sources of information } \\
\text { - To create a learning } \\
\text { community whose members } \\
\text { have access to all the } \\
\text { resources and information they } \\
\text { require, regardless of gender } \\
\text { and location, thus allowing all } \\
\text { to achieve their full potential } \\
\text { and play a part in the country's } \\
\text { socioeconomic development } \\
\text { - To support the development of } \\
\text { the skills required by the CIT } \\
\text { industry } \\
\text { - To support research and } \\
\text { innovation in the field of CIT }\end{array}$ \\
\hline
\end{tabular}




\section{References}

Abdel-Latif, A. (2008) The Potential Impact of Recent Industrial Policy Changes in Egypt on the Environment, Working Paper Series 137, Cairo: Egyptian Center for Economic Studies

- (2007) 'A Conceptual Framework for Common Interest Between

Policymakers and Key Investors (CIPI): Research on the Politics of Productive Investment in Egypt', mimeo, Brighton: Centre for the Future State, IDS

Altenburg, T. and von Drachenfels, C. (2006) 'The "New Minimalist Approach" to Private Sector Development: A Critical Assessment', Development Policy Review 24.4: 397-411

Amsden, A. (1989) Asia's Next Giant. South Korea and Late Industrialization, New York: Oxford University Press

Bates, R. (2004) 'On the Politics of Property Rights by Haber, Razo, and Maurer', Journal of Economic Literature 42.2: 494-500

BSAC (2001) Telecommunications in Egypt, Business Studies Series, Cairo: Business Studies and Analysis Center of the American Chamber of Commerce in Egypt

Commander, S. and Tinn, K. (2007) 'An Independent Evaluation of the WB/IFC Doing Business Indicators', mimeo, London Business School and Stockholm School of Economics, presented at workshop 'The Doing Business Agenda and Beyond: Smart Policies for Competitiveness and Social Inclusion', 4 and 5 December, Bonn: German Development Institute

El-Mezlawy, S. (2006) 'Investment Policy in Egypt: Obstacles to Implementation', mimeo, policy paper for MA Governance and Development, Brighton: IDS

ESCWA (2007) National Profile for the Information Society in Egypt, Cairo: United Nations Economic and Social Commission for Western Asia

Evans, P. (1995) Embedded Autonomy. States and Industrial Transformation, Princeton: Princeton University Press

Haber, S.; Razo, A. and Maurer, N. (2003) The Politics of Property Rights: Political Instability, Credible Commitments, and Economic Growth in Mexico, Cambridge: Cambridge University Press: 1876-1929

Handoussa, H.; El Oraby, N.; El Din, D.N.; Abou Shnief, H. and El Din, Z.B. (2003) 'Study on Creating an Enabling Business Environment in Egypt', mimeo, Cairo: Industrial Modernization Center

Hausmann, R.; Rodrik, D. and Velasco, A. (2007) 'Growth Diagnostics', in D. Rodrik, One Economics, Many Recipes: Globalization, Institutions, and Economic Growth, Princeton and Oxford: Princeton University Press

Humphrey, J. and Navas-Aleman, L. (2009) 'Multinational Value Chains, Small and Medium Enterprises and "Pro-Poor Policies": A Review of Donor Practices', mimeo, Brighton: IDS 
Hutchcroft, P.D. (1998) Booty Capitalism: The Politics of Banking in the Philippines, Ithaca and London: Cornell University Press

IEG (2008) Doing Business: An Independent Evaluation: Taking the Measure of the World Bank-IFC Doing Business Indicators, Independent Evaluation Group, Washington DC: World Bank

IMC (2006) Food Export Strategy Study, Cairo: Industrial Modernization Center

- (2005) Strategic Study of the Egyptian Food Processing Sector, Cairo: Industrial Modernization Center

_ (2003) The Structure of the Furniture Industry, Cairo: Industrial Modernization Center

ITIDA (2007) 'IT Industry: National Development Strategy, Targeting Export Growth - Status Review', presentation, Ministry of Communications and Information Technology, Egypt

_ (2006) 'IT Industry: National Development Strategy, Targeting Export Growth', presentation, Ministry of Communications and Information Technology, Egypt

Kelsall, T. and Booth, D. with Cooksey, B. (2009) 'Developmental Patrimonialism? The Management of Clientelist Crises and Business-Politics Relations', mimeo, Africa Power and Politics Programme

Khan, M. (2008) 'Governance and Development: The Perspective of Growthenhancing Governance', in GRIPS Development Forum (ed.), Diversity and Complementarity in Development Aid - East Asian Lessons for African Growth, Tokyo: GRIPS National Graduate Institute for Policy Studies

_ (2005) 'What is a "Good Investment Climate"?', in G. Kochendörfer-Lucius and B. Pleskovic (eds), Investment Climate, Growth, and Poverty, Washington DC: World Bank

Kohli, A. (2005) 'Politics of Economic Growth in India, 1980-2005', mimeo, Princeton: Princeton University

Li, J.S. (2003) 'Relation-Based Versus Rule-Based Governance: An Explanation of the East Asian Miracle and Asian Crisis', Review of International Economics 11.4: $651-73$

Malesky, E. (2008) 'Straight Ahead on Red: How Foreign Direct Investment Empowers Subnational Leaders', Journal of Politics 70.1: 1-23

MCIT (2005a) Egypt's Information Society, Ministry of Communications and Information Technology, Egypt

- (2005b) Egypt's Best Practices in ICT, Ministry of Communications and Information Technology, Egypt

_ (1999-2007) Monthly Indicators, Ministry of Communications and Information Technology, Egypt 
Meyer-Stamer, J. (2004) 'Paradoxes and Ironies of Locational Policies in the New Global Economy', in H. Schmitz (ed.), Local Enterprises in the Global Economy Issues of Governance and Upgrading, Cheltenham: Edward Elgar

Moore, M. and Schmitz, H. (2008) Idealism, Realism and the Investment Climate in Developing Countries, IDS Working Paper 307, Brighton: IDS

Pritchett, L. and Rodrik, D. (2005) 'Growth Accelerations', Journal of Economic Growth 10.4: 303-29

Qian, Y. (2003) 'How Reform Worked in China', in D. Rodrik (ed.), In Search of Prosperity. Analytic Narratives on Economic Growth, Princeton and Oxford: Princeton University Press

Rodrik, D. (2005) 'Growth Strategies', in P. Aghion and S. Durlauf (eds), Handbook of Economic Growth, Amsterdam: Elsevier

Rodrik, D. and Subramanian, A. (2004) From 'Hindu Growth' to Productivity Surge: The Mystery of the Indian Growth Transition, IMF Working Paper WO/04/77, Washington: Harvard University and International Monetary Fund

Sakr, F. (2003) 'Physical Capital and Challenges of Rapid Growth', mimeo, Cairo: Industrial Modernization Center

Schmitz, H. (2005) Value Chain Analysis for Policymakers and Practitioners, Geneva: ILO

Schneider, B.R. (1998) ‘Elusive Synergy: Business-Government Relations and Development', Comparative Politics 31.1: 101-22

Sen, K. and Te Velde, D.W. (2009) 'State-business Relations, Investment Climate Reform, and Economic Growth in sub-Saharan Africa', Journal of Development Studies 45, forthcoming

VNCI (2007) The Vietnam Provincial Competitiveness Index - Measuring Economic Governance for Private Sector Development, VNCI Policy Paper 12, available at www.pcivietnam.org

Winters, J.A. (1996) Power in Motion. Capital and the Indonesian State, Ithaca and London: Cornell University Press

Wood Chamber (2005) 'Furniture Export Strategy', presentation by investors to Minister of Trade and Industry at inauguration of Furnex

Yousfi, H. and Humphrey, J. (2008) The Investment Climate in Egypt: Institutions or Relationships as Conditions for Sustainable Reform?, Working Paper 66, Paris: Agence Française de Développement 